\title{
Slipstream Testing of Particulate Filters at the Wabash River Coal Gasification Repowering Project
}

\section{Final Report}

\author{
June 2003 \\ Work Performed Under \\ D.O.E. Award No. DE-FC26-97FT34158 \\ For: \\ The U.S. Department of Energy \\ National Energy Technology Laboratory \\ Morgantown, West Virginia
}

Prepared by:

Michael J. Hickey

For Further Information Contact:

\author{
Michael J. Hickey \\ Director - Projects \\ ConocoPhillips
}

Wabash River Coal Gasification Repowering Project

444 West Sandford Avenue

West Terre Haute, IN 47885 


\section{ConocơPhillips}

United States Department of Energy

National Energy Technology Laboratory

Mail Stop C05

3610 Collins Ferry Road

Morgantown, $W V 26507$

Copy Number: $32 己$

ATTN: Ted McMahon

July 15, 2004

Dear Mr. McMahon:

Under this cover letter please find one copy of the Slipstream Testing of Particulate Filters at the Wabash River Coal Gasification Repowering Project required under Cooperative Agreement DE-FC21-92MC29310.

Should you have any questions on the information contained herein, please contact me at your earliest convenience.

Regards,

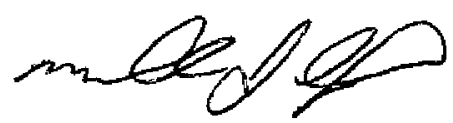

Michael J. Hickey

Director-Projects

ConocoPhillips

Wabash River Energy Ltd.

Distribution: $\quad D O E-2$

Wabash File - I 


\section{LEGAL NOTICE/DISCLAIMER}

This report was prepared by the Wabash River Coal Gasification Repowering Project Joint Venture pursuant to a Cooperative Agreement partially funded by the U.S. Department of Energy, and neither the Wabash River Coal Gasification Repowering Project Joint Venture nor any of its subcontractors nor the U.S. Department of Energy, nor any person acting on behalf of either:

(A). Makes any warranty or representation, express or implied, with respect to the accuracy, completeness, or usefulness of the information contained in this report, or that the use of any information, apparatus, method, or process disclosed in this report may not infringe privately-owned rights; or

(B). Assumes any liabilities with respect to the use of, or for damages resulting from the use of, any information, apparatus, method or process disclosed in this report.

Reference herein to any specific commercial product, process, or service by trade name, trademark, manufacturer, or otherwise, does not necessarily constitute or imply its endorsement, recommendation, or favoring by the U.S. Department of Energy. The views and opinions of authors expressed herein do not necessarily state or reflect those of the U.S. Department of Energy. 
4.1.4 Filter Reliability ....................................................................... 4-2

4.1.5 Corrosion Studies......................................................................... 4-3

4.2 Operating Summary ................................................................................. 4-3

4.2.1 Cold Flow Testing............................................................................ 4-3

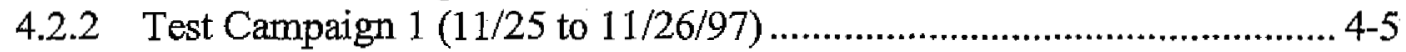

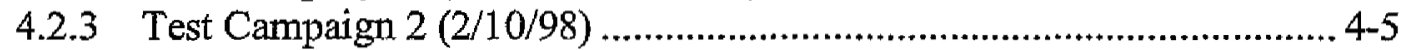

4.2.4 Test Campaign $3(3 / 12$ to $3 / 23 / 98)$.................................................... 4-6

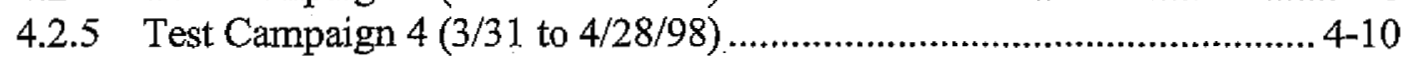

4.2.6 Test Campaign $5(6 / 14$ to $6 / 27 / 98)$.................................................... 4-13

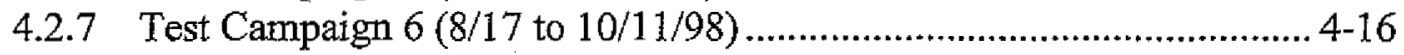

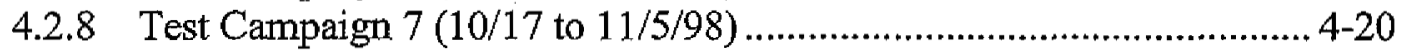

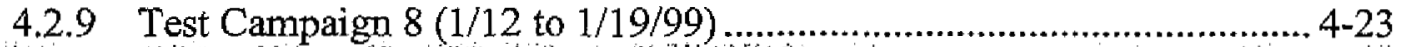

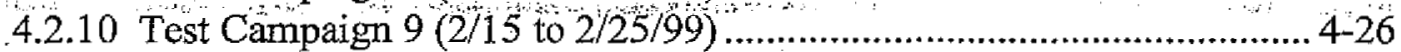

4.2.11 Test Campaign $10(6 / 28$ to $7 / 10 / 99)$.................................................. 4-29

4.2.12 Test Campaign 11 (8/13 to $8 / 14 / 99)$................................................. 4-32

4.2.13 Test Campaign 12 (8/22 to $9 / 3 / 99)$................................................. 4-33

4.2.14 Test Campaign $13(9 / 14$ to $9 / 28 / 99$..................................................... 4.36

4.2.15 Test Campaign 14 (9/8 to 9/13/00) .................................................. 4-39

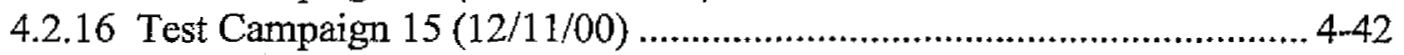

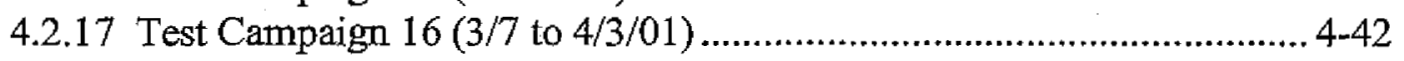

4.2.18 Test Campaign $17(7 / 14$ to $7 / 21 / 01)$................................................... 4-46

4.2.19 Test Campaign 18 (3/10 to $3 / 11 / 03)$................................................. 4-49

5.0 CONCLUSIONS AND TECHNICAL INSIGHTS ................................................. 5-1

$5.1 \quad$ Slipstream Validation................................................................................ $5-1$

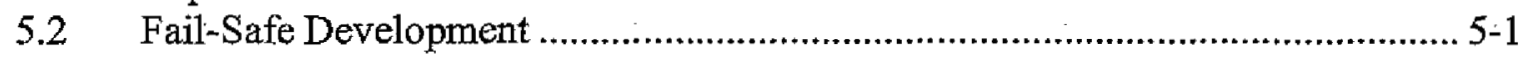

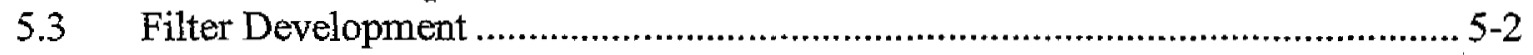

5.3.1 Metallic Filters ............................................................................ $5-2$

5.3.2 Ceramic Filters........................................................................... 5-5

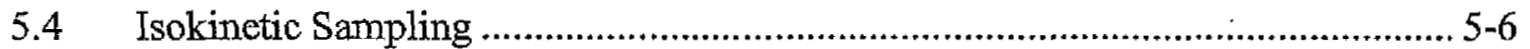

5.5 Filter Hardware Configurations ............................................................... 5-6

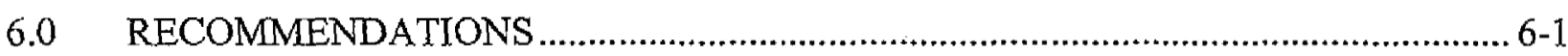

\section{APPENDICES}

Appendix I Original Proposed Slipstream Test Matrix .............................................. A-1

Appendix II Characterization of Field-Exposed Iron Aluminide Hot Gas Filters ..................B-1

Slipstream Testing of Particulate Filters at the Wabash River Coal Gasification Project Final Report
DOE Award No. DE-FC26-97FT34158 June 2003 


\section{Slipstream Testing of Particulate Filters at the Wabash River Coal Gasification Repowering Project Final Report}

\section{LIST OF TABLES}

\begin{tabular}{|c|c|c|}
\hline $\begin{array}{c}\text { Table } \\
\text { Number }\end{array}$ & Description & Page Number \\
\hline
\end{tabular}

Table 2.2.1 Wabash River Plant Availability Summary ..................................................22-3

Table 2.3.1 Wabash River Plant Downtime Summary .........................................................2-4

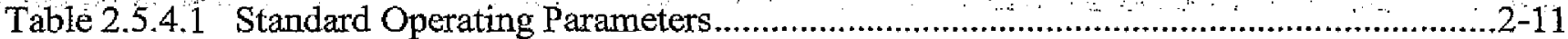

Table 2.5.5.1 Slipstream Test Program.....................................................................................2-12

Table 1-1 Original Proposed Slipstream Test Matrix ....................................................... 


\section{Slipstream Testing of Particulate Filters at the Wabash River Coal Gasification Repowering Project \\ Final Report}

LIST OF FIGURES

\begin{tabular}{|c|c|c|}
\hline Figure & Description & Page Number \\
\hline
\end{tabular}

Figure 3.2.1 Slipstream Process Flow Diagram ........................................................................3-3

Figure 3.3.1 Slipstream Vessel Configuration .............................................................

Figure 4.2.4.1 Test Campaign 3 - Slipstream Evaluation of Metal Fiber Filters and Metal Powder Fail-Safes ..................................................................................................4-8

Figure 4.2.5.1 Test Campaign 4: Evaluation of Metal Powder Filters with Reduced Surface Pores (Coal Operation).

Figure 4.2.6.1 Test Campaign 5: Evaluation of Clay-Bonded Silicon Carbide Candiles with 15 Micron Mean Pore Membrane.

Figure 4.2.7.1 Test Campaign 6 - Evaluation of Clay-Bonded Silicon Carbide Candles with 5 Micron Membrane

Figure 4.2.8.1 Test Campaign 7 - Evaluation of Iron Aluminide Powder Type Filters

Figure 4.2.9.1 Test Campaign 8 - Evaluation of Prototype Metal Fiber Media Candles (New Alloy - Recipe \#1)

Figure 4.2.10.1 Test Campaign 9 - Evaluation of Clay-Bonded Silicon Carbide Candle with a Proto-type Membrane

Figure 4.2.11.1 Test Campaign 10 - Evaluation of Prototype Metal Fiber Candles (New Alloy - Recipe \#2).

Figure 4.2.13.1 Test Campaign 12 - Evaluation of Oxide Composite Filters

Figure 4.2.14.1 Performance Comparison for Metal Fiber Filters (without Conditioning Period) .4-38

Figure 4.2.15.1 Test Campaign 14 - Evaluation of Metal Powder Filters During Petroleum Coke Operation.

Figure 4.2.17.1 Test Campaign 16 - Cleaning Method Evaluation for Metal Fiber Candles (New Alloy)... $4-45$

Figure 4.2.18.1 Test Campaign 17 - Evaluation of Oxide Composite Filters (2 Types) 4-48

Slipstream Testing of Particulate Filters at the Wabash River Coal Gasification Project Final Report
DOE Award No. DE-FC26-97FT34158

June 2003 iv 


\section{Acronyms and Abbreviations}

WRCGRP Wabash River Coal Gasification Repowering Project

DOE United States Department of Energy

CCT Clean Coal Technology

CAAA Clean Air Act Amendinents

E-Gas ${ }^{\mathrm{TM}} \quad$ Formerly Destec's Coal Gasification Technology

WREL Wabash River Energy Ltd. (formerly Destec)

HGF Hot Gas Filter

HP High Pressure

CFCC Continuous Fiber Ceramic Composites

PSI Public Service Indiana

SEM/EDAX Scanning Electron Microscopy/Energy Dispersive X-Ray

$\mathrm{SiC} \quad$ Silicon Carbide

psig Pounds per Square Inch Gauge

N2 Nitrogen

LLB Lurgi Lentjes Babcock

LGTI Louisiana Gasification Technologies Inc.

$\mathrm{H}_{2} \mathrm{~S} \quad$ Hydrogen Sulfide

$\cos \quad$ Carbonyl Sulfide 
DCS

PSV

O\&M

HFV

OEM

JV
Digital Control System

Pressure Safety Valve

Operating \& Maintenance

Figher Heating Value

Original Equipment Manufacturer

Joint Venture
Slipstream Testing of Particulate Filters at the Wabash River Coal Gasification Project Final Report
DOE Award No. DE-FC26-97FT34158 June 2003 


\subsection{EXECUTIVE SUMMARY}

\subsection{Background}

The Wabash River Coal Gasification Repowering Project (WRCGRP or "Project") is currently the largest single-train gasification facility in the United States, as well as the cleanest coal fired plant of any kind in the world. Its design allows for lower emissions than other high sulfur coal fired power plants and a resultant heat rate improvement of approximately $20 \%$ over the previous plant configuration. The Wabash River gasification facility was developed, designed, constructed, started-up and is currently operated by what are now Wabash River Energy Ltd. (WREL) personnel. Wabash River Energy Ltd. is a wholly owned subsidiary of Global Energy Inc. The Project successfully operated through a Demonstration Period from November of 1995 through December of 1999.

The original Project participants, Destec Energy, Inc. (which was later acquired by Dynegy Power Corporation (Dynegy)) of Houston, Texas, and PSI Energy, Inc. (PSI), of Plainfield, Indiana, formed a Joint Venture (JV) to participate in the United States Department of Energy's (DOE) Clean Coal Technology (CCT) program to demonstrate coal gasification repowering of an existing generating unit impacted by the Clean Air Act Amendments (CAAA). The participants jointly developed, separately designed, constructed, own, and are now operating an integrated coal gasification combined-cycle power plant, using Destec's coal gasification technology (now known as E-Gas ${ }^{T M}$ Technology) to repower the oldest of the six units at PSI's Wabash River Generating Station in West Terre Haute, Indiana. In 1999, Global Energy acquired the Project and the gasification technology from Dynegy. The gasification process is integrated with a new General Electric 7FA combustion turbine generator and a heat recovery steam generator in the repowering of a 1950's-vintage Westinghouse steam turbine generator using some pre-existing coal handling facilities, interconnections and other auxiliaries. The Project processes locally mined Indiana high sulfur coal or petroleum coke to produce 262 net megawatts of electricity. In doing so, the Project is also demonstrating some novel technology while advancing the commercialization of integrated coal gasification combined cycle technology. 
A full scale Hot/Dry Particulate Removal system is one of several technology improvements being demonstrated at the Wabash River plant. However, the original as-installed OEM filter system had a number of reliability problems that negatively affected plant availability. Early in the startup period it became clear that continued testing and development work would be required to improve the reliability of the hot gas filter system. Initial testing had shown that it was not economically feasible to perform this work in the commercial filters. It jeopardized plant availability and did not always yield meaningful data. For these reasons it was decided to implement a multi-element slipstream unit that could provide reliable data without risking plant production.

In 1996, WREL (formerly Destec) decided to engineer and implement a slipstream unit capable of performing the development work necessary to enhance the reliability and lower O\&M costs for the Wabash hot gas filter (HGF) system. In 1997, the U. S. Dept. of Energy provided funding to help support the design, construction and operation of the slipstream system. The unit was successfully commissioned and began operation in November of 1997.

\subsection{Slipstream Project Description}

In early 1996, the Hot Gas Filter (HGF) Slipstream project was initiated with the generation of its process design package. The detailed design and material procurement phases progressed into the second quarter of 1997. Field construction for the project lasted from April through August of 1997. Several months of commissioning and startup activities followed and the system came on line in November 1997.

The HGF slipstream receives particulate laden gas (640-780 F/350-410 psig) from a tie-point located between the high-pressure steam generator and the commercial HGF. The slipstream filter ( $\mathrm{V}-159)$ is capable of testing 7 full size candle elements in a single cluster or it can be configured for testing multi-tiered arrangements. Char is periodically removed from the primary filters by pulsing a high pressure (HP) syngas into the "clean" side of the element. The HP syngas (280-400F/750-900 psig) is supplied by the commercial blowback system and is stored in an accumulator vessel (D-158). Fast acting valves are used to simulate blowback conditions in

\begin{tabular}{ll}
\hline Slipstream Testing of Particulate Fitters at the Wabash River Coal Gasification Project & DOE Award No. DE-FC26-97FT34158 \\
Final-Report & June 2003
\end{tabular}




\section{EXECUTIVE SUMMARY}

the full-scale unit ( $250-350 \mathrm{msec})$. During the blowback cycle, the dislodged char cake falls to the bottom of V-159 and flows into a solids collection and char transfer drum (D-159). Level detectors are used to monitor char accumulation in this vessel. Char is recycled back into the commercial process by using HP syngas in the transfer vessel. Particulate free syngas flows out of V-159 and into a backup filter system that prevents solids from entering the commercial process. The particulate free syngas is recycled back into the process downstream of the commercial HGF.

A Mod5 digital control system, developed by the Dow Chemical Co., provides the automated control and operator interface with the slipstream unit. The control logic for pulse cleaning can be triggered on a manual input, a time increment, or a selected filter differential pressure. A time increment was the typical mode of operation for this controller. This mode of control was typically used to initiate the char transfer sequence as well.

\subsection{Slipstream Test Objectives}

The Wabash HGF slipstream test program was developed to meet a specific list of objectives focusing on ways to improve operation of the commercial HGF in support of plant production goals. They are summarized as follows:

1. Provide blinding rate and corrosion data to support the development of a filter that exceeds 10,000 hours of operation.

2. Evaluate filter types (various pore sizes, materials, constructions) and supporting hardware configurations that will provide a system capable of operating at $100 \%$ reliability.

3. Develop filters, supporting hardware and filter system designs that extend HGF maintenance requirements beyond 6 months.

4. Develop a reliable and low cost backup or fail-safe filter system for the HGF process.

Slipstream Testing of Particulate Filters at the Wabash River Coal Gasification Project Final Report
DOE Award No. DE-FC26-97FT341.58

June 2003

ES-3 


\section{EXECUTIVE SUMMARY}

\subsection{Results}

The Wabash slipstream HGF (Slipstream) began operation in November of 1997 and to date, it has been used to conduct eighteen (18) different test campaigns. The system has accumulated over 4128 hours of syngas operation when feeding Indiana high sulfur coal or petroleum coke to the gasifier. Nineteen (19) different types of filters have been evaluated so far.

Filter blinding trends have been established for twelve (12) variations of metal and ceramic candle filters. Using this data along with plant HGF corrosion studies, a predicted operating life has been determined for five (5) different types of filters. A number of metallic filters developed using the Slipstream are now operating in the commercial process. They are a major reason why the system has performed $100 \%$ reliably over the last three and a half years.

Four types of filter hardware configurations were evaluated in the slipstream system. They consist of new types of filter to tubesheet connecting hardware, fail-safe mounting devices and filter bottom restraint systems. The new configurations were evaluated both for reliability in the process and maintenance labor savings. Two types of metallic filter hardware were evaluated in the slipstream unit. One design is now successfully being used in the commercial HGF. The new configuration has proven to be highly reliable and has significantly reduced the maintenance time required to replace a set of candles. Another hardware configuration used for ceramic filters has been proven as a highly reliable system in both the slipstream and commercial processes.

The particulate laden gas entering the commercial HGF was isokinetically sampled using the slipstream system for three (3) different types of gasifier feedstock. One was taken with the plant on Indiana high sulfur coal and the other two consisted of different petroleum coke derived samples. The sample data was used to validate plant process models and for char characterization. Samples have also been used in cold flow evaluations of new equipment.

Slipstream Testing of Particulate Filters at the Wabash River Coal Gasification Project Final Report
DOE Award No. DE-FC26-97FT34158

June 2003 


\section{EXECUTIVE SUMMARY}

The slipstream system was used as an initial screening tool when evaluating various metal alloys and ceramic materials for corrosion in the process. Typical evaluations could oniy provide 250 to 500 hours of data. Due to the difficulty in predicting media corrosion trends, significant runtime is required (in excess of $5000 \mathrm{hrs}$ ) to obtain meaningful data. Since it can be structured with essentially no risk to commercial production, these types of studies are better suited for the plant HGF system. This provides optimal media exposure times. Consequently, all long-term corrosion evaluations were conducted in the commercial filter.

A major objective in the slipstream test program was to evaluate a fail-safe device to potentially replace the existing commercial backup filter system. The backup filter was used to contain any solids that might break through the primary HGF. It had proven both unreliable and required significant maintenance expenditures to keep it operational. A major shortcoming of this system was its inability to sustain plant operation when one or more primary filter failures occurred. A fail-safe system offers a number of distinct advantages over the existing backup filter. It has the ability to keep the plant on line even if multiple candles fail and is significantly less costly to install and maintain. There were two major concerns with sustained long-term operation of these fail-safes in the commercial system. Both dealt with fail-safe blinding over time due to either primary filter inefficiencies or from condensation of trace elements in the media. During the study, the increase in overall fail-safe resistance was found to be negligible. The study helped to prove that concerns with fail-safe blinding were unfounded for the Wabash process. Post-test inspections revealed failures in several fail-safe devices. The supplier evaluation found that a manufacturing defect was the root cause for failure. A number of improvements were implemented in both the fail-safe manufacturing process and quality control program to correct this problem. Subsequent testing and operation of the fail-safe device demonstrated that the problems had successfully been eliminated. As a result of these studies, the commercial backup filter was replaced with this type of fail-safe system. The system has proven to be highly effective at preventing solids breakthrough into downstream equipment and is the single most important contributor to the $100 \%$ reliability of the commercial HGF over the past three and a half years. 


\section{EXECUTTVE SUMMARY}

\subsection{Conclusions and Technical Insights}

The most significant conclusions and technical insights gained from the slipstream studies are listed below.

1. The slipstream unit is a valuable tool for predicting filter behavior in the commercial process. Data from studies involving both metallic sintered powder and sintered fiber elements closely followed the commercial HGF trends while operating with similar types of filters. There was also general agreement in data trends for clay-bonded silicon carbide filters. The similarities in filter behavior between the two systems has shown the slipstream is a valuable tool to evaluate filters being considered for the Wabash $\mathrm{HGF}$ process.

2. A fail-safe system is a better altemative to serve as a backup for the primary HGF. It provides much higher HGF reliability and is significantly less costly to operate than a backup filtration system. The fail-safe device selected for the Wabash HGF has proven to effectively prevent solids breakthrough into downstream equipment, and to date, has demonstrated $100 \%$ reliability in the process.

3. For metallic candles, those constructed with fiber type media consistently demonstrated the lowest rates of blinding in the Wabash HGF slipstream process. They are much more robust than ceramic candles and are able to withstand a high degree of rough handling during the maintenance process. Metal fiber media has an extremely low corrosion tolerance, but by using newly developed alloys they are capable of providing sufficient life in the process.

4. In general, there were two types of ceramic filters evaluated in this program. They were variations of clay-bonded silicon carbide and oxide composites (CFCC-continuous fiber ceramic composites). Over the course of these studies, the clay-bonded silicon carbide filters had perfect reliability in the process. In contrast, all but one oxide composite filter failed during operation in the slipstream system. The oxide composite filters were found 
to have inadequate strength to withstand the rigorous blowback requirements for the Wabash process.

5. For clay-bonded silicon carbide candles, better blinding rates were achieved as the membrane mean pore size was reduced. Optimum blinding rates were generated with the 5 micron mean pore membranes. These blinding rates were comparable to those found in the best metal fiber candles.

6. The HGF slipstream is a useful tool to evaluate new filter hardware configurations for fixing filters to the clean gas plenum and restraining bottom candle movement. In this program, new and unique designs were tested in an actual HGF environment with no risk to plant availability. The hardware was successfully evaluated for both reliability and maintenance requirements

7. In addition to filter evaluations, a slipstream HGF is useful for isokinetically sampling a gas stream containing a high concentration of particulate matter. The slipstream proved invaluable for sampling the solids laden syngas just upstream of the commercial HGF for a number of different types of gasifier feedstock. This data is helpful to validate plant process models for various types of gasifier feed. Characterization of collected char samples will be useful for future plant designs. The char is also used for cold flow studies to evaluate alternate filter and filter/cyclone systems. 


\subsection{INTRODUCTION}

\subsection{Overview of the Wabash River Gasification Facility}

The Wabash River Coal Gasification Repowering Project (WRCGRP or "Project") is currently the largest single-train gasification facility in the United States, as well as the cleanest coal fired plant of any kind in the world. Its design allows for lower emissions than other high sulfur coal fired power plants and a resultant heat rate improvement of approximately $20 \%$ over the previous plant configuration. The Wabash River gasification facility was developed, designed, constructed, commissioned, and is currently operated by what are now Wabash River Energy Ltd. (WREL) personnel. Wabash River Energy Ltd. is a wholly owned subsidiary of Global Energy Inc. The Project successfully operated through a Demonstration Period from Noveraber of 1995 through December of 1999.

The original Project participants, Destec Energy, Inc. (which was later acquired by Dynegy Power Corporation (Dynegy)) of.Houston, Texas, and PSI Energy, Inc. (PSI), of Plainfield, Indiana, formed a Joint Venture (JV) to participate in the United States Department of Energy's (DOE) Clean Coal Technology (CCT) program to demonstrate coal gasification repowering of an existing generating unit impacted by the Clean Air Act Amendments (CAAA). The participants jointly developed, separately designed, constructed, own, and are now operating an integrated coal gasification combined-cycle power plant, using Destec's coal gasification technology (now known as E-Gas ${ }^{\mathrm{TM}}$ Technology) to repower the oldest of the six units at PSI's Wabash River Generating Station in West Terre Haute, Indiana. In 1999, Global Energy acquired the Project and the gasification technology from Dynegy. The gasification process is integrated with a new General Electric 7FA combustion turbine generator and a heat recovery steam generator in the repowering of a 1950's-vintage Westinghouse steam turbine generator using some pre-existing coal handling facilities, interconnections and other auxiliaries. The Project processes locally mined Indiana high sulfur coal or petroleum coke to produce 262 net megawatts of electricity.

The Project has demonstrated the ability to run at full load capability while meeting the 


\section{INTRODUCTION}

environmental requirements for sulfur and $\mathrm{NO}_{\mathbf{x}}$ emissions. Cinergy, PSI's parent company, dispatches power from the Project, with a demonstrated heat rate of under $9,000 \mathrm{Btu} / \mathrm{kWh}$ (HIV), second only to their hydroelectric facilities on the basis of environmental emissions and efficiency.

In late 1998, PSI Energy reached agreement to purchase the gasification services contract from Dynegy subject to regulatory approval. Regulatory approval was granted in September of 1999 and the sale was completed in October of 1999. This agreement allowed PSI to purchase the remaining term of the 25-year contract, which had become "out-of-market" in comparison to today's alternate sources for power. WREL explored alternatives for continued operation of Wabash River in a more "market-based" mode. In June of 2000, Global Energy Inc. announced that WREL had entered into a competitive market contract with PSI for the sale of syngas. Syngas, sold under this market-based three year agreement, is priced to allow the power it produces to compare favorably year-round to PSI's alternate sources for on-peak and off-peak power.

This recent development, coupled with efforts to improve the commercial viability of the Wabash River Coal Gasification Repowering Project, has sharpened the focus to make the technology competitive in today's market. The hot gas filter (HGF) slipstream test program has been instrumental in supporting this effort.

\subsection{Wabash River Gasification Facility Operating History}

Construction for the WRCGR Project commenced in September 1993 and was completed by July 1995. After a three month period of commissioning, startup, and performance testing activities, commercial operation began in late November 1995.

Table 2.2.1 summarizes annual gasifier and overall plant availability statistics from the beginning of the commercial operating period through the end of 2002 . The data shows that 1996 was an extremely challenging year for the facility. Although gasifier availability was at $87 \%$, the plant operated only $27 \%$ of the year. Low plant availability was caused by problems in 


\section{INTRODUCTION}

syngas path related processes, gasifier support systems, and in the combined cycle power generation facility. One of the most significant contributors to plant downtime in 1996 was low availability in the hot gas particulate removal system. A number of fast track projects were implemented that improved plant availability in 1997 to 57\%. Additional improvements in 1997 and 1998 had increased plant availability close to $70 \%$. By 2000 plant availability had increased to near $80 \%$. The high availability demonstrated since then is a direct result of intensive development work undertaken in both the Slipstream and HGF systems.

Table 2.2.1: Wabash River Plant Availability Summary

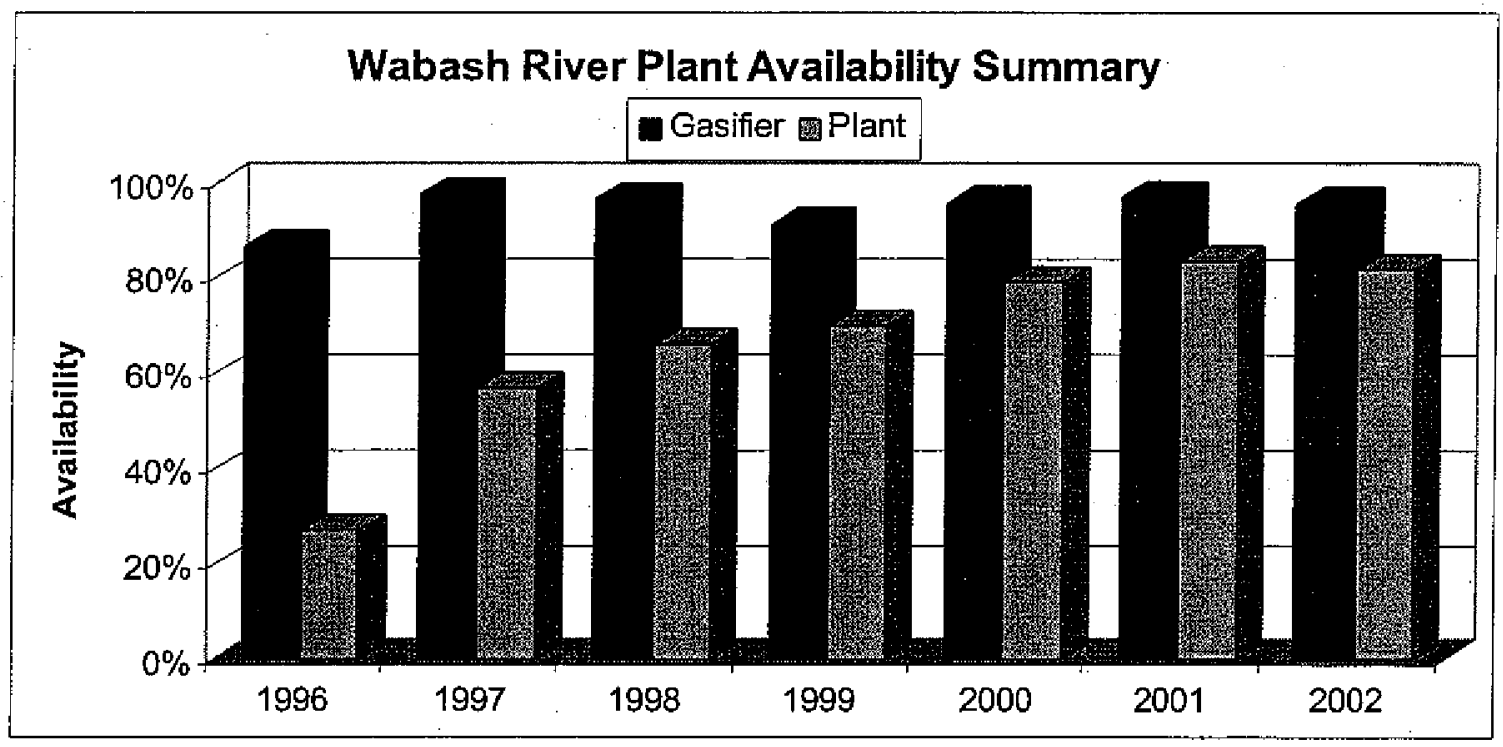

\subsection{Hot Gas Filter Startup and Operating History}

Table 2.3.1 illustrates the percentage of total downtime hours attributable to the hot gas filter (HGF) system as well plant outage hours caused by other gasification plant processes and the combined cycle power generation facility. In 1996 difficulties in the HGF made up over $39 \%$ of the total plant downtime. As HGF improvements were implemented, its operation improved in 1997 with the total attributable downtime being reduced to around $17 \%$. Additional improvements in 1997 and1998 further reduced HGF downtime to below $6 \%$ of the total. Using improvements developed in both the slipstream and commercial processes the HGF has demonstrated consistent operation with $100 \%$ reliability since 2000 . 
Table 2.3.1: Wabash River Plant Downtime Summary

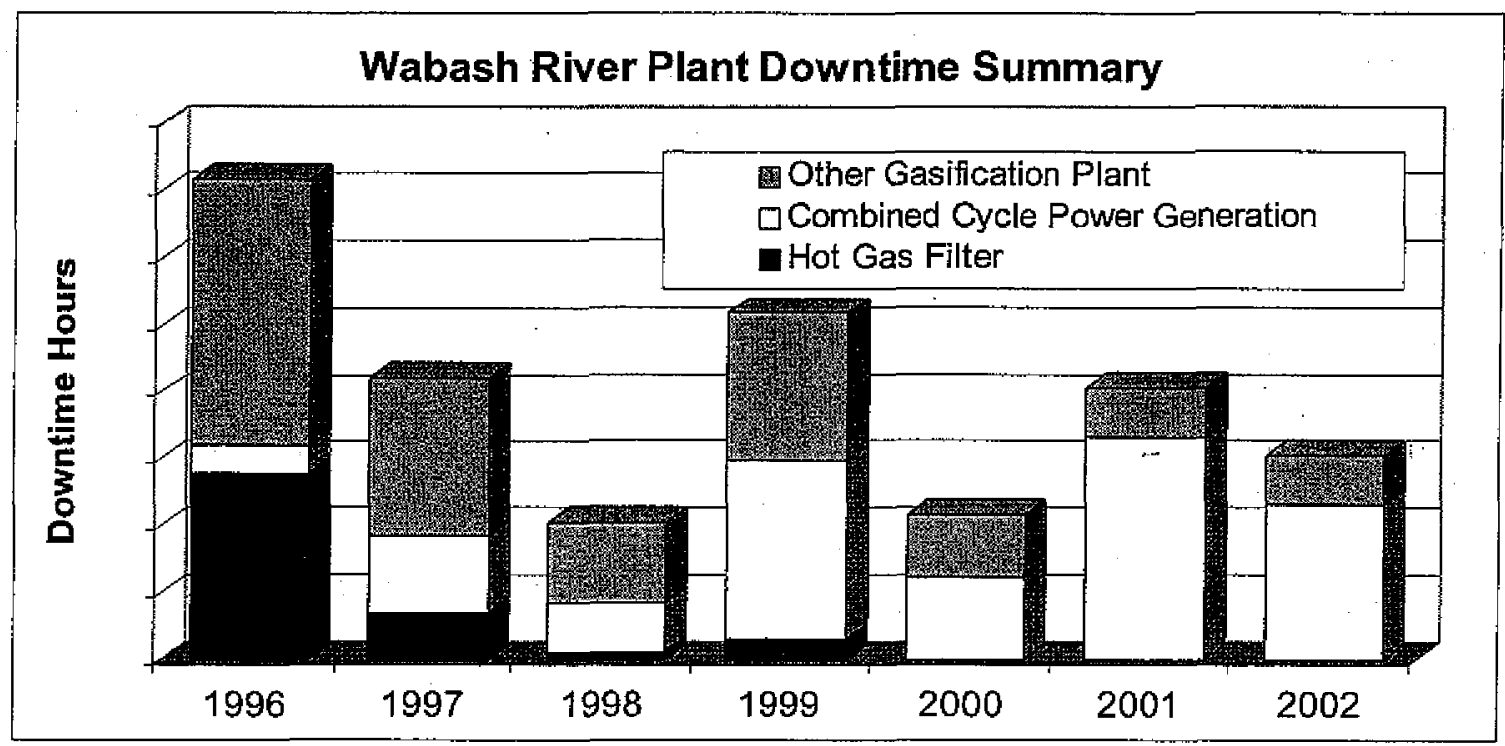

During the 1995 - 1996 startup and commercial operating period, a number of reliability problems in the hot gas filter system were quickly identified and corrected. During the initial plant startup char was found breaking through the commercial HGF. The leakage was a result of gasket problems in both the element fixing hardware and filter modular tubesheet flange connections. The problems were easily resolved by changing gasket materials and by implementing a number of changes in the modular tubesheet flange design. As operating time increased, more challenges developed as ceramic candles failed and solids bridging began to occur.

In the original HGF design low reverse flow pressure was measured inside the candle filter during the blowback event. This inadequacy was found to be the root cause for solids bridging that occurred in the candle filters. Several components witbin the system were re-sized to correct this problem.

Another source of candle bridging and breakage resulted from mixing filters of various flow resistances (or permeability) within the primary vessels. Post-operating inspection data showed that installing a new cluster of fitters in a vessel full of conditioned (or used) candles typically led to bridging and resultant ceramic candle breakage within that cluster. Breakage also 


\section{INTRODUCTION}

occurred in the new filters due to the extremely high instantaneous face velocity that resulted immediately after the backpulse event. Filter conditioning periods (at low production rates) during plant startup and changes in vessel candle loading practices were used to mitigate this problem.

The initial candie elements used in the Wabash hot gas filter was a ceramic clay-bonded SiC type. Failures of candle filters in 1996 caused at least 5 major plant outages. Candle breakage tesulted from a number of sources such as bridging, improper handling, and filter fixing hardware problems. As a result, the system was retrofitted with metal candles late in 1996.

Another problem in the HGF was caused by flow imbalances in the vessel internal gas/solids distribution system. The distribution system was designed to direct the incoming dirty gas evenly over the upper section of the candle filters. High filter impingement velocities from gas exiting the internal gas distributor caused erosion on the candle surface and resulted in blinding (loss of permeability) the filters at these locations. Filter permeability was totally lost in the areas of high velocity gas impingement. High erosion rates on some distributor parts also yielded low component life and required frequent vessel internal repairs. Several improvements were implemented to this system to significantly improve its performance and reduce filter impingement velocities.

During the 1995-1996 operating period, many improvements were implemented to address the above-mentioned challenges and they significantly increased the reliability of the Wabash HGF system. However, additional improvements would be required to enable the system to meet specific performance goals. This required further development work in a number of areas. Accelerated filter blinding continued to be a concern since it limited filter life and necessitated frequent filter replacement or cleaning (off-line). Consequently, this was a key focus in the filter development program. Filter corrosion was also a concern when operating metal candles with high sulfur coal and petroleum coke feedstock. Additional improvements were required for the internal gas distribution system to further increase component life as well as minimizing filter surface gas impingement velocities. It soon became obvious that many of these improvements could best be developed utilizing a slipstream system. 


\section{INTRODUCTION}

\subsection{Slipstream Program Objectives}

To position the E-Gas process as a competitive and marketable technology the Wabash plant had to achieve specific operating and maintenance goals. Given the hot gas filter is an essential part of the gasification process, it must be a highly reliable system. Early on, specific performance goals were established for the Wabash HGF. The goals were no attributable lost plant availability, a 10,000 hour minimum filter life and a 7500 hour HGF maintenance frequency.

The original hot gas filter selected for the Wabash facility was designed by the OEM to provide $100 \%$ reliability between : scheduled maintenance outages. However this was not the case. During the plant startup period, it became evident that significant testing and development work would be required to achieve this reliability. It was also evident that much of the development work could not be performed in the commercial process since it would jeopardize plant availability and could not always be structured to provide meaningful data. Full scale testing would require significant maintenance expenditures as well. Consequently, a decision was made to implement a multi-element slipstream unit that could provide reliable data without risking plant availability.

Utilization of a slipstream test unit is better suited to test unproven filter types and system modifications without risking availability of the commercial process. It also provides more accurate blinding studies since the filters being tested have similar permeability. Previous blinding studies conducted in the full size vessels required installing new test elements in with different and/or conditioned (previously used) filters. Consequently, the data often yielded somewhat questionable results. The slipstream unit also provides crucial data for new HGF systems to be used at future gasification facilities. Data such as particulate loading, char characterization, and backpulse requirements for various types of feedstocks are essential to design alternate types of filter systems. By utilizing the slipstream system, process conditions can be altered to determine how they affect filter performance. Conducting these studies on a smaller scale is a much more cost effective approach. 


\section{INTRODUCTION}

\subsection{Slipstream Test Program}

\subsubsection{Test Objectives}

The primary objective in this program was to evaluate various types of candle filters in the E-gas gasification process to identify those that provide optimum performance and reliability. The objectives set forth in this test program were established to improve the reliability of the Wabash River coal gasification facility and reduce its operating costs. Supporting objectives are as follows:

1. Establish a list of acceptable materials for filter element fabrication by demonstrating the effectiveness of porous metal and ceramic filter elements in the E-gas process.

2. Determine the optimum filter element (pore size, material, construction) for use in the E-gas gasification process.

3. Gain insight on the mechanisms that cause accelerated hot gas filter blinding and determine what parameters can be changed in the commercial vessels to improve filter system availability.

4. Determine the optimum backpulse system operating parameters to efficiently clean hot gas filter elements.

5. Gain insight on the mechanisms that cause char bridging within filter clusters and implement noted operating parameter improvements in the commercial vessels.

6. Gain insight on the mechanisms that cause ceramic element breakage and identify corrective design modifications.

7. Measure the syngas stream solids loading into and out of the hot gas filter system so material balances can be performed. Also perform characterization studies on char derived from coal 
and petroleum coke feedstocks.

8. Evaluate alternate filtration systems that will adequately backup the Wabash primary filters and reduce current O\&M costs. This system should protect downstream equipment from damage caused by solids breaking through the primary filter. It should also allow the plant to remain on-line if breakthrough occurs in the primary filter system.

9. Establish design criteria for constructing future hot gas particulate filter systems. 


\section{INTRODUCTION}

\subsubsection{Basis for Test Selection and Prioritization}

- The Wabash River coal gasification facility was designed to run high sulfur coal feedstock. The facility also operates on petroleum coke, which has a much higher sulfur content (increase from $2 \%$ to $5 \%$ ). This increase could accelerate corrosion rates in porous metal filters while operating in the process.

- Recent studies indicate that vapor phase condensation of trace metals on candle filters and in the residual (non-transient) char layer is causing an accelerated rate of blinding: Plant data: has shown these blinding rates will change for different types of filters. In addition to alternate filter types, studies may be performed to determine if certain process changes can improve blinding rates.

- Membrane type ceramic candles of various pore size have been tested in the Wabash commercial hot gas filter system. Pre- and post- test filter resistance data indicates that a reduction in membrane pore size may lower filter blinding rates.

- Utilization of major equipment currently in operation at the Wabash gasification facility must be considered in achieving the Test Program objectives.

- The original backup or secondary char filtration system in the Wabash gasification process has experienced significant numbers of failures since plant startup. The failures result in low secondary filter system availability as well as high O\&M expenditures. This places a high priority on improving or replacing this system.

- Operating experience in the Wabash HGF has provided some insight into the formation of candle element bridging. Post-operating inspections have shown that mixing filters of various resistance (for example: new and old) results in bridging of the lower resistance candles. Also, flow imbalances between the two HGF vessels can contribute to element bridging. Since utilizing these learning experiences, element bridging has not been a significant problem in the commercial vessels and for this reason it will be a low priority 


\section{Slipstream Testing of Particulate Filters at the Wabash River Coal Gasification Repowering Project Final Report}

\section{TABLE OF CONTENTS}

\begin{tabular}{|c|c|}
\hline Contents & Page Number \\
\hline
\end{tabular}

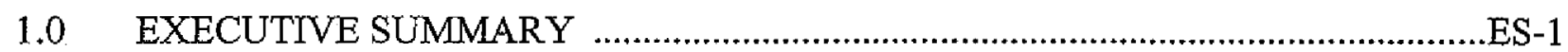

$1.1 \quad$ Background .............................................................................................

1.2 Slipstream Project Description .....................................................................ES-2

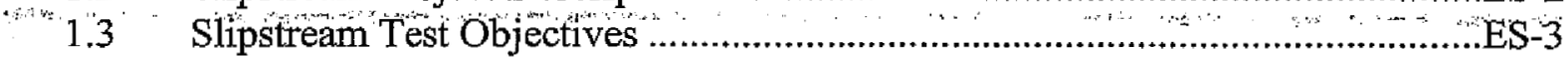

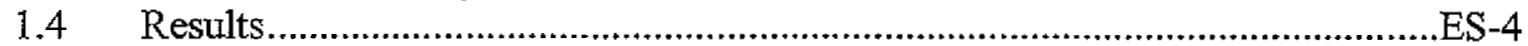

1.5 Conclusions and Technical Insights...........................................................ES-6

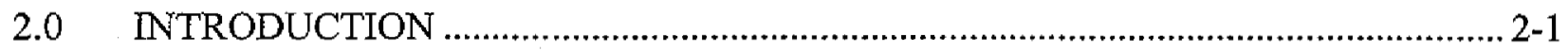

2.1 Overview of the Wabash River Gasification Facility …….................................. 2-1

2.2 Wabash River Gasification Facility Operating History ....................................... 2-2

2.3 Hot Gas Filter Startup and Operating History ................................................. 2-3

$2.4 \quad$ Slipstream Program Objectives......................................................................... 2-6

2.5 Slipstream Test Program............................................................................ 2-7

2.5.1 Test Objectives.............................................................................. 2-7

2.5.2 Basis for Test Selection and Prioritization.............................................. 2-9

2.5.3 Test Evaluation Methods .................................................................. 2-10

2.5.4 Standard Operating Parameters.......................................................... 2-11

2.5.5 Test Matrix..................................................................................... 2-11

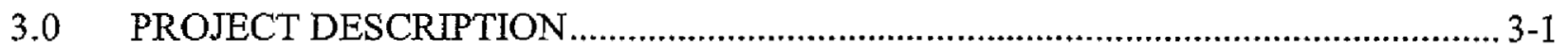

3.1 Project Overview ………..................................................................... 3-1

3.2 Process Overview....................................................................................... 3-2

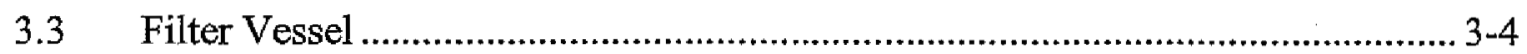

3.4 Blowback System.......................................................................................

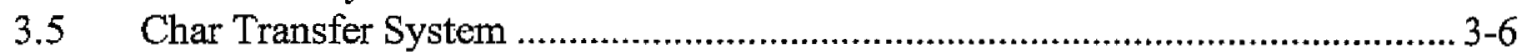

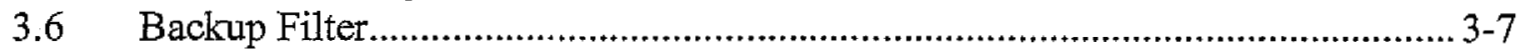

3.7 Controls and Data Acquisition........................................................................ 3-7

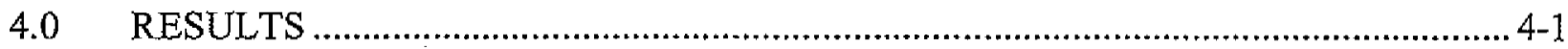

4.1 Test Methodology .................................................................................. 4-1

4.1.1 Filter Blinding Life Predictions ............................................................. 4-1

4.1.2 Filter Efficiency ........................................................................... 4-2

4.1.3 Isokinetic Gas Sampling ................................................................... 4-2 


\section{INTRODUCTION}

objective for the test matrix.

- Minimum blowback pressure and reverse pulse time have been studied to some degree in the commercial hot gas filter unit. This study has provided a set of guidelines that has proven useful in operating the HGF system. For this reason, backpulse optimization studies will be considered a low priority objective for the test matrix.

-... Studies to evaluate alloy corrosion rates have been ongoing since metal filter testing was initiated in the commercial vessels (early 1996). Due to the long test periods required to obtain meaningful data, these studies will continue to be performed in the commercial vessels.

\subsubsection{Test Evaluation Methods}

The following methods were used to evaluate filters tested in the Wabash slipstream system. For more detail refer to Section 4.1 .

1. Plant data acquisition systems were used to collect operating data for the slipstream unit. The data was used to calculate blinding rates for comparison with various filters and/or process changes. Blinding rates were also compared to plant data for various types of filters previously operated in the Wabash HGF.

2. Scanning electron microscopy/energy dispersive $x$-ray (SEM/EDAX) was used to perform micro structural analysis of filter residual dust cake layers and to study particle/vapor phase deposition within the filter substrate.

3. Characterization of residual dust cake layers and substrate deposition using EDS mapping.

4. Material strength/ductility evaluations using $\mathrm{C}$-ring/O-ring compressive and/or tensile testing methods. Also hoop stress tests were used to determine strength changes in sintered metal type filters. 
5. Pre and post-test evaluation of filter permeability was made using a single element air flow test unit.

6. Metallurgical examination using both light and scanning electron microscopy (SEM).

\subsubsection{Standard Operating Parameters}

Listed in Table 2.5.4:1 are the standard operating parameters for the Wabash HGF slipstream system.

Table 2.5.4.1 Slipstream Operating Parameters

\begin{tabular}{|l|c|}
\hline Filter Vessel Temperature & $640-780 \mathrm{~F}$ \\
\hline Filter Vessel Pressure & $350-410 \mathrm{psig}$ \\
\hline Filter Inlet Mass Flow & $2476 \mathrm{lb} / \mathrm{hr}$ \\
\hline Filter Face Velocity & $2.5 \mathrm{fpm}$ \\
\hline Char Solids Loading & $46.8-49.4 \mathrm{lb} / \mathrm{hr}$ \\
\hline Blowback Gas Pressure & $775-880 \mathrm{psig}$ \\
\hline Blowback Gas Temperature & $280-390 \mathrm{~F}$ \\
\hline Blowback Duration & $250-350 \mathrm{msec}$. \\
\hline Blowback Cycle Time & $84 \mathrm{sec}$. (total) \\
\hline Char Bulk Density & $13.7 \mathrm{lb} / \mathrm{ft}^{3}$ (coal) \\
\hline Char Permeability & $0.45 \mathrm{nPm}$ (coal) \\
\hline Char Mean Particle Size & $20-25 \mu$ (coal) \\
\hline
\end{tabular}

\subsubsection{Test Matrix}

The original test matrix proposed for the slipstream study is located in Table I-lin Appendix 1. A summary of the actual testing performed is provided in Table 2.4.5.1 below. A significant portion of the test program was developed to meet specific plant HGF development needs. The original test matrix was developed in late 1996. It was based on projected plant and technology development needs that were evident at that time. As HGF system reliability increased development priorities changed. Consequently, a number of tests proposed in the original matrix were not performed. Other tests were substituted to improve reliability and reduce the maintenance tequired for the commercial facility. 
Table 2.5.5.1 Slipstream Test Program

\begin{tabular}{|c|c|c|c|c|c|}
\hline $\begin{array}{l}\text { Test } \\
\text { No. }\end{array}$ & Test Description & $\begin{array}{l}\text { Filter } \\
\text { Type }\end{array}$ & $\begin{array}{c}\text { Duration } \\
\text { (hours) }\end{array}$ & $\begin{array}{c}\text { Operating } \\
\text { Parameters }\end{array}$ & $\begin{array}{c}\text { Objectives } \\
\text { (Section 2.5.1) }\end{array}$ \\
\hline 1 & $\begin{array}{c}\text { Isokinetic Sampling of } \\
\text { a Petroleum Coke } \\
\text { Derived Syngas }\end{array}$ & $\begin{array}{l}\text { Metal } \\
\text { Fiber }\end{array}$ & 30 & $\begin{array}{c}\text { See Table } \\
2.5 .4 .1\end{array}$ & 7,9 \\
\hline 2 & $\begin{array}{l}\text { Isokinetic Sampling of } \\
\text { a Coal Derived Syngas }\end{array}$ & $\begin{array}{l}\text { Metal } \\
\text { Fiber }\end{array}$ & 15 & $\begin{array}{l}\text { See Table } \\
2.4 .4 .1\end{array}$ & 7,9 \\
\hline$\overline{3}$ & $\begin{array}{l}\text { Filter and Fail-Safe } \\
\text { Evaluation }\end{array}$ & $\begin{array}{l}\text { Metal } \\
\text { Fiber }\end{array}$ & 263 & $\therefore \quad \begin{array}{c}\text { See Table } \\
2.4: 4.1\end{array}$ & $1,2,8$ \\
\hline 4 & Filter Evaluation & $\begin{array}{c}\text { Metal } \\
\text { Powder }\end{array}$ & $5 \overline{564}$ & $\begin{array}{c}\text { See Table } \\
2.4 .4 .1 \\
\end{array}$ & $1,2,3$ \\
\hline 5 & Filter Evaluation & $\begin{array}{l}\text { Ceramic } \\
\mathrm{SiC}\end{array}$ & 239 & $\begin{array}{c}\text { See Table } \\
2.4 .4 .1\end{array}$ & $1,2,3$ \\
\hline 6 & $\begin{array}{c}\text { Filter and Fixing } \\
\text { Hardware Evaluation }\end{array}$ & $\begin{array}{l}\text { Ceramic } \\
\mathrm{SiC}\end{array}$ & 375 & $\begin{array}{c}\text { See Table } \\
2.4 .4 .1\end{array}$ & $1,2,3,6,9$ \\
\hline$\overline{7}$ & Filter Evaluation & $\begin{array}{l}\text { Iron } \\
\text { Aluminide } \\
\text { Powder }\end{array}$ & 423 & $\begin{array}{c}\text { See Table } \\
2.4 .4 .1\end{array}$ & $1,2,3$ \\
\hline 8 & Filter Evaluation & $\begin{array}{l}\text { Metal } \\
\text { Fiber }\end{array}$ & 158 & $\begin{array}{l}\text { See Table } \\
2.4 .4 .1\end{array}$ & $1,2,3,9$ \\
\hline 9 & Filter Evaluation & $\begin{array}{l}\text { Ceramic } \\
\mathrm{SiC}\end{array}$ & 235 & $\begin{array}{c}\text { See Table } \\
2.4 .4 .1\end{array}$ & $1,2,3$ \\
\hline 10 & Filter Evaluation & $\begin{array}{l}\text { Metal } \\
\text { Fiber }\end{array}$ & 257 & $\begin{array}{c}\text { See Table } \\
2.4 .4 .1\end{array}$ & $1,2,3,9$ \\
\hline 11 & Filter Evaluation & $\begin{array}{c}\text { Oxide } \\
\text { Composite }\end{array}$ & 29 & $\begin{array}{c}\text { See Table } \\
2.4 .4 .1 \\
\end{array}$ & $1,2,6$ \\
\hline 12 & Filter Evaluation & $\begin{array}{c}\text { Oxide } \\
\text { Composite }\end{array}$ & 290 & $\begin{array}{c}\text { See Table } \\
2.4 .4 .1\end{array}$ & $1,2,6$ \\
\hline 13 & Filter Evaluation & $\begin{array}{l}\text { Metal } \\
\text { Fiber }\end{array}$ & 300 & $\begin{array}{c}\text { See Table } \\
2.4 .4 .1 \\
\end{array}$ & $1,2,3,9$ \\
\hline 14 & Filter Evaluation & $\begin{array}{c}\text { Metal } \\
\text { Powder }\end{array}$ & 114 & $\begin{array}{c}\text { See Table } \\
2.4 .4 .1\end{array}$ & $1,2,3$ \\
\hline 15 & $\begin{array}{c}\text { Isokinetic Sampling of } \\
\text { a Petroleum Coke } \\
\text { Derived Syngas }\end{array}$ & $\begin{array}{l}\text { Metal } \\
\text { Fiber }\end{array}$ & $1 \overline{2}$ & $\begin{array}{c}\text { See Table } \\
2.4 .4 .1\end{array}$ & 7,9 \\
\hline 16 & Filter Evaluation & $\begin{array}{l}\text { Metal } \\
\text { Fiber }\end{array}$ & 620 & $\begin{array}{c}\text { See Table } \\
2.4 .4 .1\end{array}$ & $1,2,3,9$ \\
\hline 17 & Filter Evaluation & $\begin{array}{l}\text { Oxide } \\
\text { Composite }\end{array}$ & 188 & $\begin{array}{c}\text { See Table } \\
2.4 .4 .1\end{array}$ & $1,2,6$ \\
\hline 18 & $\begin{array}{l}\text { Isokinetic Sampling of } \\
\text { a Petroleum Coke } \\
\text { Derived Syngas }\end{array}$ & $\begin{array}{l}\text { Metal } \\
\text { Fiber }\end{array}$ & 12 & $\begin{array}{c}\text { See Table } \\
2.4 .4 .1\end{array}$ & 7,9 \\
\hline
\end{tabular}




\subsection{PROJECT DESCRIPTION}

\subsection{Project Overview}

In 1996, WREL decided to implement a slipstream unit to support the development work necessary for improving the reliability of the Wabash HGF system. In 1997, the U. S. Dept. of Energy provided funding to help support the design, construction and operation of a multielement HGF slipstream unit at the Wabash facility.

When designing the Slipstream system, specific criteria was established to ensure it would provide relevant data. Another important aspect was to ensure the flexibility to test alternate filter types and various system configurations. To develop this, a comprehensive list was generated detailing various improvements that could be studied in the slipstream unit. The list includes specific studies required to increase Wabash HGF reliability and those used to support development work for future gasification facilities. The design criteria used for the Slipstream system is as follows:

- Design into the system the capability to test various filter types (candles, honeycomb, etc.), lengths, hardware configurations, and system arrangements such as multi-tiered designs.

- The slipstream system should be designed to test multiple filters in a similar cluster type arrangement as is used in the commercial scale vessels.

- The slipstream system should fully simulate process conditions in the commercial scale vessels such as gas composition, gas pressure, gas temperature, solids loading, filter face velocities, backpulse conditions, and char recycle capabilities.

- The system must be capable of performing re-entrainment studies so that alternate configurations for internal gas distribution can be studied.

- The slipstream system must be capable of testing various types of secondary or backup filtration systems.

- Flexibility must be built into the system so that blowback optimization studies can be performed. 
The WREL (formerly Destec) engineering group generated a process design package for the slipstream project in early 1996. The Dow Chemical Engineering and Construction group in Houston, Texas performed the detailed design engineering. This effort was kicked off in lateMay of 1996 and was completed by the middle of the 3rd quarter of that same year. Material procurement was initiated for the project during the late phases of detailed design and was completed by mid-second quarter of 1997. Procurement was slightly delayed due to the project getting placed on hold for the winter months and as a result of shifting manpower requirements to complete other higher priority plant projects. Field construction kicked off in late April of 1997 and was completed by August of that same year. Several months of commissioning and startup activities followed and the system came on line in November 1997.

\subsection{Process Overview}

This section provides an overview of the Wabash Slipstream process. Figure 3.2.1 illustrates the process described in this section.

Slipstream Testing of Particulate Filters at the Wabash River Coal Gasification Project Final Report
DOE Award No. DE-FC26-97FT34158

June 2003 


\section{PROJECT DESCRIPTION}

\section{Figure 3.2.1 Slipstream Process Flow Diagram}

WABASH HOT GAS FILTER SLIPSTREAM SYSTEM

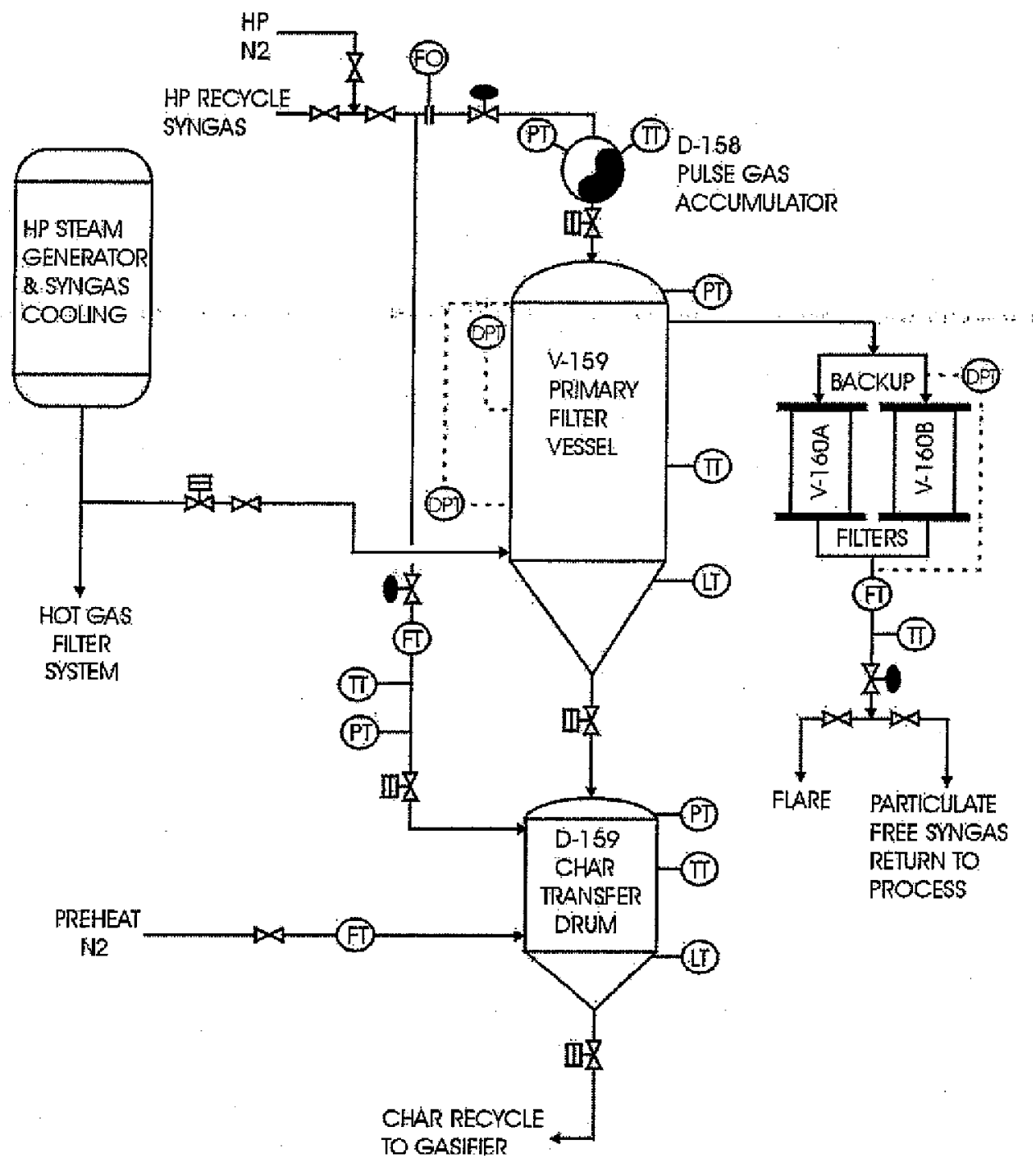

The slipstream HGF, located at the Wabash River Gasification facility, is configured to operate utilizing the same process syngas as is fed to the commercial particulate removal system. As in the commercial process, the incoming "dirty" gas enters the primary filter vessel, V-159, at 650 $800 \mathrm{~F}$ and $360-420$ psig. Particulates entrained in the gas stream consist of ash carryover from the gasifier first stage process and partially reacted coal particles from its second stage process. The particulate matter, high in carbon, is classified as char. The "dirty" syngas is removed from the process just upstream of the commercial HGF through an isokinetically designed nozzle. The slipstream of gas then enters V-159 through an internal gas distribution system that directs 


\section{PROJECT DESCRIPTION}

the flow downward over the outer surface of the candles. Particulates are removed from the gas as it flows through the filters into the clean gas plenum. The particulate free syngas leaves $\mathrm{V}$ 159 where it flows through a secondary or backup filtration system (V-160 A/B) and is recycled back into the commercial process. The solids that collect on the primary filters are periodically removed by using a high-pressure recycled syngas to momentarily reverse gas flow through the element. High-speed automated valves configured over a nozzle and venturi arrangement are used to regulate the blowback flow. The high-pressure recycled syngas is the same as that used to blowback the commercial hot gas filters. This gas is stored in D-158, the blowback gas accumulator. The char cake is dislodged from the filter and falls to the lower section of V-159. It then flows downward into D-159, the char collection and transfer drum. The char is collected in D-159 for a specified period of time after which it is transferred back into the commercial process using high-pressure recycled syngas. Process ties into the plant nitrogen and flare systems enable the Slipstream unit to be purged and preheated up to process temperatures.

\subsection{Filter Vessel}

Figure 3.3.1 shows the general vessel layout for the slipstream system. Sections $3.3-3.5$ provide a detailed description of the vessels unsed in the Slipstream system.

Slipstream Testing of Particulate Filters at the Wabash River Coal Gasification Project Final Report
DOE Award No. DE-FC26-97FT34158

June 2003 


\section{Figure 3.3.1 Slipstream Vessel Configuration}

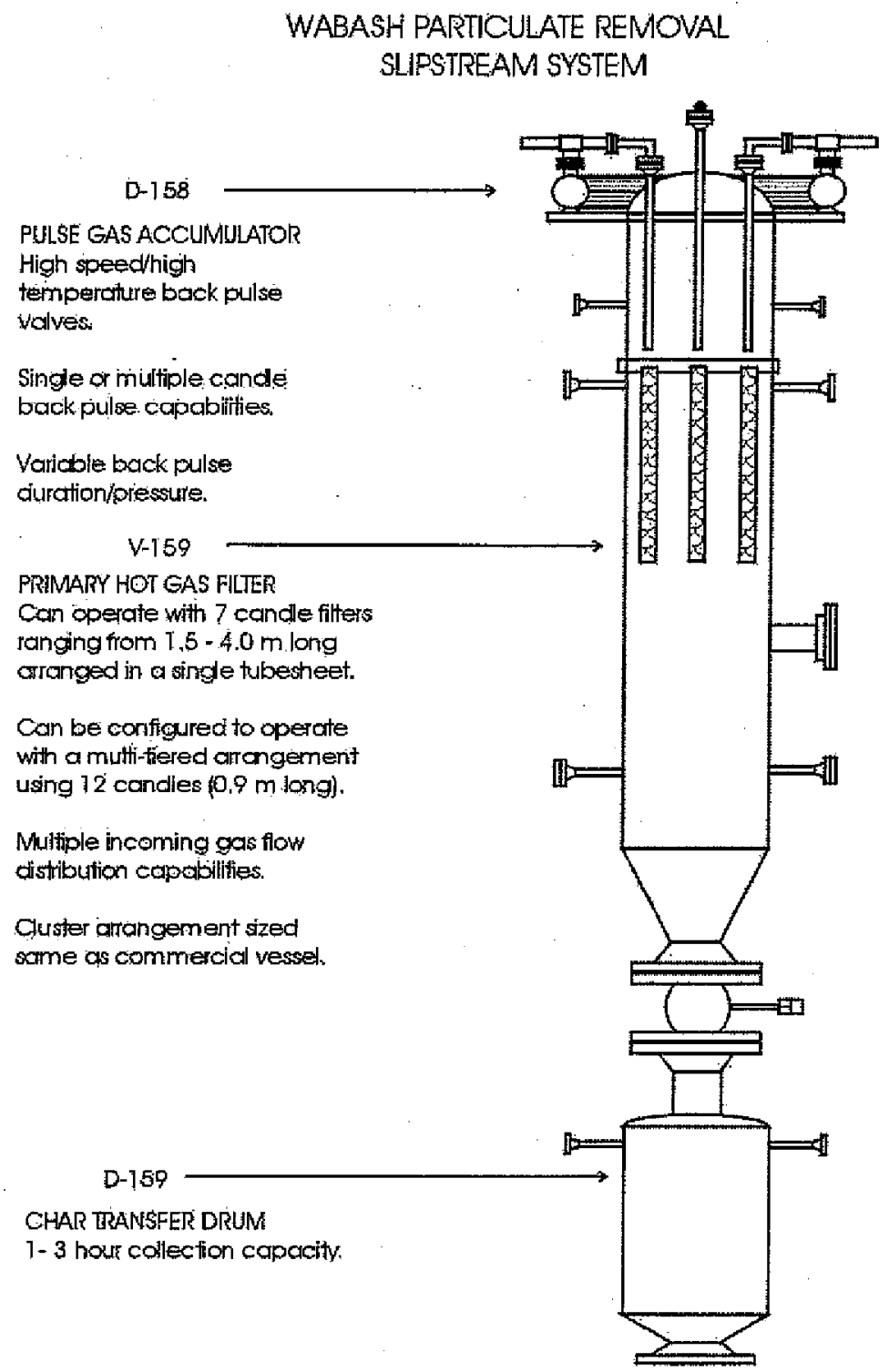

The primary filter, V-159, consists of an 18 inch diameter 15 foot long pressure vessel designed to operate at commercial filter conditions (see Table 2.5.4.1). The standard configuration uses a single tubesheet to separate the clean gas plenum from the incoming dirty process gas (see Figure 3.3.1). The tubesheet is designed to contain up to seven candle filters ranging from $1.5-$ 4.0 meters long. The filters are arranged to maintain the same spacing as is used in the commercial vessels. During the test program, a number of methods were evaluated for holding the filter in the tubesheet. An internal gas distribution system is used to prevent direct 


\section{PROJECT DESCRIPTION}

impingement of the incoming gas on the candle filters. The incoming gas exits the distribution system near the top of the candles and flows in a downward direction across the candles. Nuclear level devices are used to detect any char bridging that may occur at the bottom of the vessel. Flexibility is incorporated into the vessel design so it can also be configured to operate with a multi-tiered arrangement such as the Lurgi Lentjes Babcock (LLB) Energietechnik GmbH design. A high temperature heat trace and insulation system is used to maintain the vessel at process operating temperatures. This system is also useful for preheating the vessel above the syngas moisture dewpoint prior to placing the unit on-line.

\subsection{Blowback System}

The blowback system utilizes high pressure (HP) syngas to periodically remove the solids that are collected on the primary filter elements. It consists of a pulse gas accumulator, D-158, seven (7) high speed/high temperature automated valves, and a nozzle and venturi system to regulate gas flow into the filters. The gas accumulator is made up of a "U" shaped arrangement of 12 inch diameter stainless steel piping. It's designed to operate at commercial blowback system conditions (see Table 2.4.4.1). A high temperature heat trace and insulation system is used to maintain the accumulator at process operating temperature. Seven (7) high-speed valves are used to provide a short burst of gas into the clean side of each filter. The valves are capable of going fully open to fully closed in just over $100 \mathrm{msec}$. The blowback duration is adjusted by the time increment of the electrical input into the valve solenoid. Flexibility is incorporated within the control system to blowback each filter individually or together as a cluster. The control logic for blowback cleaning can be triggered on a manual input, a time increment, or a selected filter differential pressure. The time increment mode was typically used for this controller. Various pulse tube and venturi arrangements are used to facilitate fail-safe testing.

\subsection{Char Transfer System}

The char transfer system is used to recycle solids collected in the slipstream unit back into the commercial process. The recycle system selected for the slipstream has proven to be highly reliable for this process. The char collection drum, D-159, is an 18 inch diameter, $\sim 6.5$ foot long pressure vessel designed to operate at process conditions. High pressure syngas is supplied

Slipstream Testing of Particulate Filters at the Wabash River Coal Gasification Project Final Report
DOE Award No. DE-FC26-97FT34158

Jume 2003 


\section{PROJECT DESCRIPTION}

to the drum to periodically recycle char back to the process. A high temperature heat trace and insulation system is used to maintain the transfer drum at process operating temperatures. Nuclear level devices are included on the vessel to monitor char accumulation in the drum. The char transfer sequence can be triggered using the solids level indication or on a timed increment. A timed increment was the typical mode used to trigger the char transfer process.

\subsection{Backup Filter}

Backup filters were included in the slipstream system to prevent solids from entering the commercial process in the clean syngas recycle stream. The backup filters, V-160A/B, utilize a large porous honeycomb type membrane coated ceramic filter. Each filter is contained within a high pressure housing. Both filters are not configured for on-line regeneration.

\subsection{Controls and Data Acquisition}

A Mod5 digital control system, developed by the Dow Chemical Co., provides automated control and operator interface with the slipstream unit. Its primary features include redundant computers and $\mathrm{L} / \mathrm{O}$ cards to enhance reliability and reduce control system induced interruptions in operation. The programming language used for this control system is similar to Fortran. Program control code was generated for the slipstream using in-house expertise. The control schemes are readily accessible by the operations staff and many of them have the capability to modify the code as needed. Data acquisition is also accomplished using the Mod5 system. Thitd party software programs are used to graphically display slipstream data for analysis.

Slipstream Testing of Particulate Filters at the Wabash River Coal Gasification Project Final Report
DOE Award No. DE-FC26-97FT34158

June 2003

3-7 


\section{RESULTS}

\subsection{RESULTS}

\subsection{Test Methodology}

The methods described below were used for stipstream evaluations to help predict filter performance in the commercial process.

\subsubsection{Filter Blinding Life Predictions}

Blinding rate is best defined as an increase in the resistance to flow through a filter as a function of operating time. Increasing resistance is caused by a number of variables. Small particles migrate into the filter substrate causing an obstruction in the available flow area. In addition to this, small particles have an affinity to form bonds (electrostatic or other) with other particles and to the filter media. This formation creates a conditioned or residual char layer that remains on candle surface even during the blowback event. Given that smaller particles form stronger attracting bonds they tend to make up a significant portion of the residual layer. This reduces surface porosity and further impedes gas flow through the filter. In the Wabash process, a number of trace elements in the process gas stream contact the candle filters while still in a molten or vapor form. Many of these elements ( $\mathrm{As}, \mathrm{Ge}, \mathrm{Sb}$, etc) are collected in the nontransient layer and negatively affect its permeability. The end result is seen as a slow steady rise in $\mathrm{HGF}$ resistance over time. Eventually, the resistance is sufficient to render the blowback system incapable of delivering a reverse flow through the candles. When this occurs the candles can no longer be regenerated with the system on line. This limit is well understood for the Wabash HGF vessels and is used to predict filter life. Using this limit and a reliable data trend that depicts resistance as a function of time, a filter blinding life can be projected for the Wabash process.

The first $50-100$ hours of operation for a new filter is typically a period during which a residual char layer forms on the outer surface of the candle. It's called a residual layer because it remains attached to the candle during the blowback event. This is commonly referred to as the "conditioning period" and is typically characterized by a rapid increase in filter baseline differential pressure. Once the filter is conditioned, the rise in baseline differential pressure becomes much more linear with a noticeable decrease in the upward slope of the data. As a

Slipstream Testing of Particulate Filters at the Wabash River Coal Gasification Project Final Report
DOE Award No. DE-FC26-97FT34158

June 2003 
result, the conditioning period is typically neglected when determining filter life. This allows a linear fit of the data to be used for calculating blinding life. The method has proven highly effective at predicting filter life in both the slipstream and commercial processes.

\subsubsection{Filter Efficiency}

Filter efficiency is best measured by extracting an isokinetic sample out of the "clean" gas stream near the outlet of the primary filter vessel. The solids collected in this sample can be used to calculate the particulate loading in the gas stream: This measurement is normally collected using some sort of isokinetic sample system. Unfortunately, the Wabash facility does not have a device such as this. Consequently, a true filtration efficiency could not be quantified for any of the candles involved in this test program. However, since a secondary filter is used to backup the primary filter, a qualitative evaluation was possible. These were made using blinding data in the backup filters. This would typically indicate a gross problem with filter leakage. For the purposes of these studies, it provides sufficient data to validate acceptable filter efficiencies for the Wabash process.

\subsubsection{Isokinetic Gas Sampling}

Since the syngas fed to the Slipstream is removed from the process through an isokinetically designed nozzle, it can be used to sample the particulate laden gas just upstream of the commercial HGF. Sample time periods varied depending on the quantity of char needed for analysis. The sample quantity is also used to calculate the solids loading in the syngas entering the commercial HGF. This data is useful for validation of plant process models.

\subsubsection{Filter Reliability}

Both filters and filter hardware configurations were evaluated for reliability in the process using the Slipstream system. Typical evaluation periods were planned for $250-500$ hours of operation. Backup filter ( -160$)$ blinding rates and detailed post-test inspections are used to evaluate reliability.

Slipstream Testing of Particulate Filters at the Wabash River Coal Gasification Project Final Report
DOE Award No. DE-FC26-97FT34158

June 2003 


\subsubsection{Corrosion Studies}

For the most part, corrosion evaluations are conducted in the commercial HGF. The reason for this is that it provides the maximum amount of process exposure time. However, on several occasions the Slipstream was used to provide an initial evaluation of newly developed alloys. It typically was used when a new media alloy became available and the commercial unit was in service and scheduled to remain on line for an extended period of time. Given the limited run times for each campaign, the corrosion data was not sufficient to predict filter life. This data was : used to determine if further evaluation in the commercial process was warranted.

\subsection{Operating Summary}

The Wabash HGF slipstream (Slipstream) began operation in November of 1997 and to date, it has been used to conduct eighteen (18) different test campaigns. The system has accumulated over 4128 hours of syngas operation when feeding Indiana high sulfur coal or petroleum coke to the gasifier. Nineteen (19) different types of filters have been evaluated so far.

The matrix of tests conducted in the Slipstream was structured to address the most pressing filter development needs for the facility. Most test campaigns were scheduled to last from $250-500$ hours in duration. On several occasions, the system was used to obtain an isokinetic char sample with the plant operating on various types of gasifier feedstock (coal and petroleum coke). An outline describing each operating campaign is provided in Table 2.4.5.1. The results from each test campaign are described in the following sub-sections.

\subsubsection{Cold Flow Testing}

In 1995, a cold flow particulate removal system was constructed at the Dow Chemical Inc. Michigan Division to help support development work for the Wabash facility. The cold flow unit provided critical design and operating data for the Wabash hot gas filter system. The system operated on ambient air and coal char collected from Destec's Louisiana Gasification Technologies Inc. (LGTI) facility. The filter vessel used a tubesheet to contain up to seven candle elements that were fixed in a cluster arrangement. The tubesheet separated the dirty

Slipstream Testing of Particulate Filters at the Wabash River Coal Gasification Project Final Report
DOE Award No. DE-FC26-97FT34158

June 2003

4-3 


\section{RESULTS}

incoming gas from the clean gas plenum. A pneumatic conveying process was used to recycle the char in a closed loop system.

Early studies in the cold flow unit focused on various aspects of filter bridging and solids reintrainment so that a set of startup guidelines and key operating parameters could be developed for the Wabash HGF.

By early 1996 , cold flow studies centered on many of the problems causing low reliability in the HGF process. At this time, ceramic candle failures were one of the most significant contributors to lost availability at the Wabash plant. For this reason, an aggressive effort was launched to develop a reliable metal filter as a potential solution to this problem. As in most evaluations, two of the major points of concern were candle blinding and corrosion. Corrosion studies were initiated for media alloy candidates in the commercial HGF process. The cold flow unit was used as an initial screening process to establish blinding trends for alternate types of both metal and ceramic candle filters. The mode of blinding in the cold flow unit was basically caused by particle penetration into filter pores and to some extent, by the development of a residual layer of char on the candle surface. However, this did not include the effects of other constituents within the process syngas and therefore could not provide definitive rates of candle blinding. Although it could not accurately predict filter life, the cold flow filter did provide an overall trend for candle blinding behavior. The data generated in these studies was especially useful for comparing various types of filters and selecting those that would provide the best performance in the commercial process. The cold flow studies were extremely useful in developing the test matrix for the Wabash HGF slipstream.

Slipstream Testing of Particulate Filters at the Wabash River Coal Gasification Project Final Report
DOE Award No. DE-FC26-97FT34158

June 2003

$4-4$ 


\section{RESULTS}

\subsubsection{Test Campaign $1(11 / 25$ to $11 / 26 / 97)$}

The first Slipstream test was structured with two purposes in mind. First it provided a shakedown of the newly installed system. There were a number of operational issues and instrument problems identified during this operating period. However, the main purpose of this study was to isokinetically sample the solids laden gas upstream of the commercial filter system. The char sample was collected while a petroleum coke gasifier feedstock was being tested at the facility. After transferring the gasifier feed to $100 \%$ petroleum coke, the slipstream unit was placed on line: After acbieving stable operation, several char samples were eollected: The data: obtained was used to validate solids loading to the commercial filters in the facility's process model (Heat \& Material Balance). Characterization of the char was also performed with the sample collected in the study.

\subsubsection{Test Campaign $2(2 / 10 / 98)$}

The second operating period for the Slipstream was similar to the first campaign. In this test the gas stream was again isokinetically sampled to determine solids loading to the commercial filters. This study differed in that the gasifier feed was now Indiana bituminous coal. As in the first test, the data was used to validate process models. The sample also provided characterization data for coal-derived char.

Slipstream Testing of Particulate Filters at the Wabash River Coal Gasification Project Final Report
DOE Award No. DE-FC26-97FT34158

June 2003 


\subsubsection{Test Campaign $3(3 / 12$ to $3 / 23 / 98)$}

Test Campaign 3 was the first evaluation of a new candle filter in the Slipstream unit. The study was structured to help meet the objectives stated for Test No. 2 in the original test matrix plan (see Table I-1 in Appendix I).

In this test, seven (7) 1.5-meter long metal fiber media candles were evaluated in the slipstream unit. The study's primary focus was to establish a blinding rate to be used for predicting filter life in the commercial process: The medra alloy was being developed as a viable candidate to provide optimum filter life when considering both cortosion and blinding as primary life limiting factors. At the same time, this type of candle was undergoing corrosion evaluation in the commercial process and so far it had produced favorable results. However, a reliable blinding trend could not be obtained due to the mixture of filter types being operated in the commercial HGF. An equally important part of this study was the evaluation of a fail-safe device constructed of sintered powder media. Of particular interest was whether the fail-safe would blind from solids passing through the primary filters. At that time, it was unclear if these candies would filter coal char with a high degree of efficiency. Another issue concerned fail-safe media blinding caused by trace elements condensing as the process gas passed through the device. This was especially concerning given the cooler temperatures of the blowback gas. Additional data was required to determine if there would be enough energy in the blowback gas to adequately clean the candle after taking a pressure drop across the fail-safe device. Finally, the last objective to be studied was the overall contribution to filter system resistance caused by the failsafe devices.

The test was scheduled for 250 hours of syngas operation. The actual run time for the campaign period was 263 hours. A number of instrument and equipment problems were identified and corrected during the operating period. This was not surprising given that it was the first sustained run for the Slipstream unit. Some key operating data was lost at the onset of the campaign due to the instrument problems. However, enough data was generated to adequately satisfy the objectives set forth for the study.

Slipstream Testing of Particulate Filters at the Wabash River Coal Gasification Project Final Report
DOE Award No. DE-FC26-97FT34158

June 2003.

$4-6$ 


\section{RESULTS}

A primary objective in this study was to generate a blinding trend for the candle filters. Using this trend, a filter blinding life was predicted for the commercial process. Figure 4.2.4.1 shows the increase in filter differential pressure as a function of time for the operating period. Using the methodology described in Section 4.4.1, the data collected in this study predicts a filter blinding life of 7780 hours. Both this result and those generated in the HGF corrosion studies helped qualify this filter as a viable candidate for the commercial process. This predicted life was significantly higher than the life of the candles that were currently operating in the commercial process. As a result, a full set of these filters was installed in the Wabash HGF in early 1998. After operating for over 1800 hours in the commercial HGF, the blinding trend was comparable to that predicted by the Slipstream unit. This helped to establish confidence that the slipstream unit is a reliable tool for predicting blinding behavior in the commercial process.

The second objective in the study was to evaluate a fail-safe device as a potential replacement for the Wabash backup filter system. The original backup system utilized in-line honeycomb type filters that could be regenerated on line. The backup filter had proven unreliable and required significant maintenance expenditures to keep it operational. A major drawback to this system was with its inability to keep the plant on-line when one or more primary filter failures occurred. Numerous failures had occurred in the backup filters due to its rigorous blowback cleaning requirements. Since they could not sustain plant operation with primary filter leakage, they were only useful to detect char breakthrough, and to prevent it from contaminating downstream equipment. The fail-safe system evaluated in this study offers several distinct advantages over the existing backup filter. It has the ability to keep the plant on line even if multiple candles fail and is significantly less costly to install and maintain. Prior to this study, there were two major concerns with sustained long-term operation of these fail-safes in the commercial system. The first concern was that the fail-safe would blind over time due to inefficiencies in the primary filter. Given that the primary filters were not $100 \%$ efficient, one question to be answered was whether the small amount of char that did get through the primary filter would end up blinding the fail-safe media to the point that the filter could no longer be effectively backpulsed. The second concern was a potential increase in fail-safe resistance due to a buildup of trace elements in the media. Specifically, the concern was that vapor phase trace elements in the syngas might condense in the fail-safe media after being cooled by the backpulse gas. Previous studies had

Slipstream Testing of Particulate Fitters at the Wabash River Coal Gasification Project Final Report
DOE Award No. DE-FC26-97FT34158

June 2003

4-7 


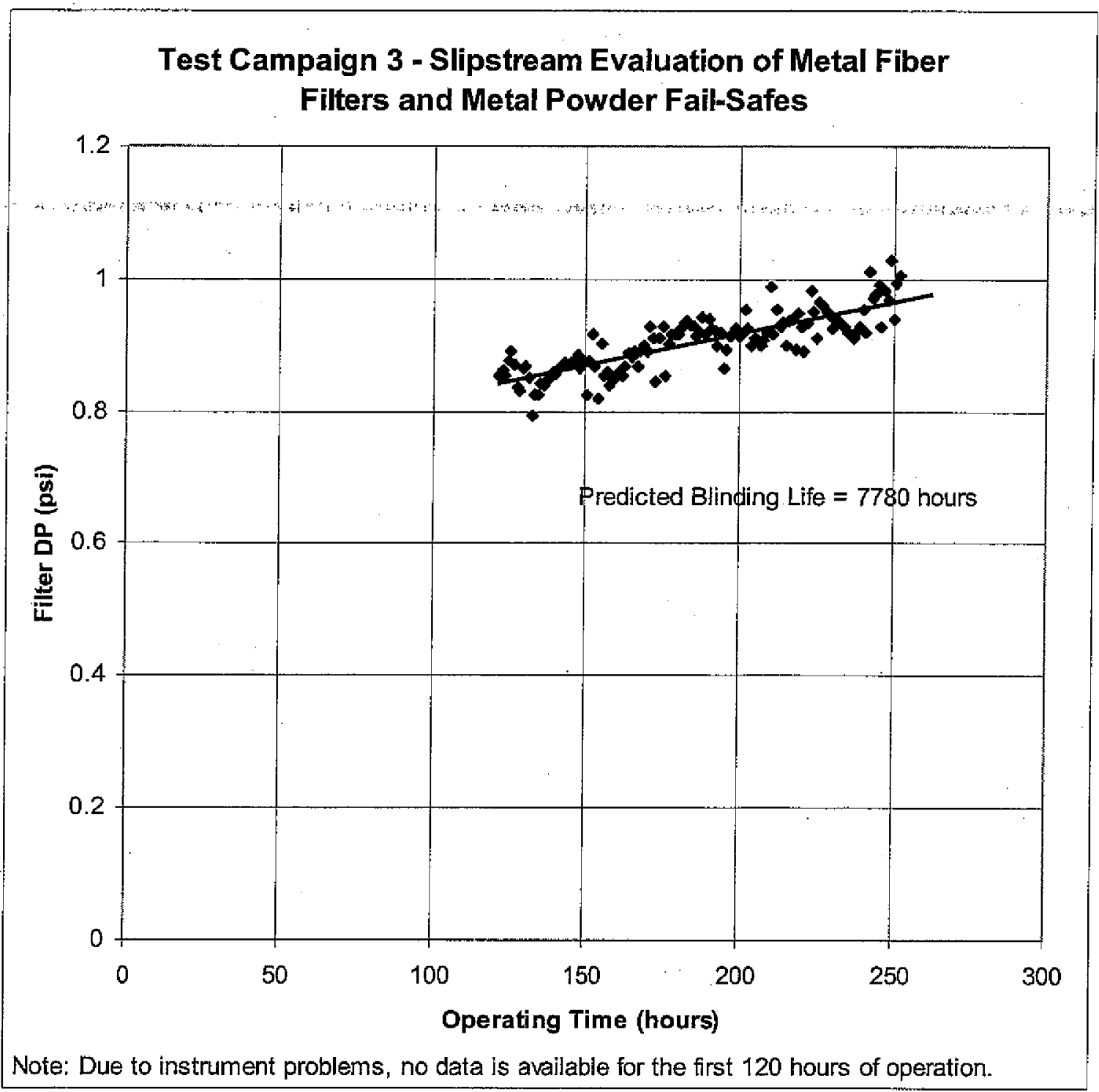

Figure 4.2.4.1: Test Campaign 3 - Slipstream Evaluation of Metal Fiber Filters and Metal Powder Fail-Safes 


\section{RESULTS}

shown that condensation of certain trace elements such as arsenic, germanium, lead and antimony were found both in the filter substrate and in the residual char layer on the candle surface. Given that many of the same trace elements were found in downstream equipment it was assumed that a certain percentage of them were passing through the filters. This raised the concern that trace metals might also condense in the fail-safe media each time it was cooled by the backpulse gas. To evaluate this, air flow vs. pressure drop measurements were made for each fail-safe device before and after the campaign. From this data a pre- and post-test resistance was calculated for each fail-safe. The results showed that only a slight increase in resistance had developed across the fail-safes during the campaign. The increase was negligible when compared to the overall resistance through the filters. The study helped prove that both suspected modes of fail-safe blinding would not occur to any significant degree in the Wabash process.

Post-test inspections revealed two failures in the seven fail-safe devices. The failed devices were returned to the vendor for root cause evaluation. Both failures were found to be caused by a manufacturing defect. To address this, a number of improvements were implemented in both the fail-safe manufacturing process and quality control program. Subsequent testing and long-term operation of the fail-safe device has demonstrated that these problems were successfully eliminated.

Another key part of this study was to determine if the fail-safes would negatively affect blowback cleaning of the primary filters. Calculations predicted that the pressure drop across the fail-safe was negligible and that it would not affect the blowback cleaning. Unfortunately the filter cavity pressure could not be measured during operation due to a problem in the data collection for this system. However, post-test observations showed no evidence of solids bridging between the filters and a "normal" residual char layer on the candles. The on-line pressure drop across the candles was extremely low and well within the expected range. The results showed the fail-safe pressure drop to be negligible and provided sufficient evidence that the blowback gas effectively cleaned the primary filters. 
As a result of this study, the commercial backup filter system was replaced with this type of failsafe device. This change was a major contributor to the increasing plant availability in 1998 . The fail-safe system plays a key role in maintaining 100\% HGF reliability at the Wabash plant.

\subsubsection{Test Campaign $4(3 / 31$ to $4 / 28 / 98)$}

The fourth Slipstream test was structured to support the objectives stated for Test No. 3 in the original test matrix plan (see Table I-1 in Appendix I).

In this test seven (7) 1.5-meter long candles constructed of metal powder media were evaluated. This filter offer a number attributes that make them an excellent candidate for the Wabash HGF system. The filter is quite robust as it offers an extremely high media strength. In addition to this the powder bonds are much larger than the fiber diameter used in metal fiber media. This renders the filter much more capable of withstanding moderate amounts of corrosion. The type of candle used in this study had already accumulated run time in the commercial process. However, a number of improvements were incorporated into the construction of these candles. First, a media with slightly larger mean pore size was used. The filters were also modified using a special manufacturing technique that reduced the media pore size along the outer surface of the candle. In theory, this would help enhance the candle's surface filtration characteristics by restricting small particle migration into the filter substrate. By using a larger internal pore size the media pressure drop is reduced. This should result in higher blowback energy at the candle surface and yield a more effective cleaning.

The test was planned for 250 hours of syngas operation. The actual test lasted over 564 hours in duration. As in the previous test campaign, there were a number of instrument problems that came up and had to be addressed during the run. One of these problems resulted in an excessively high gas flow through the system for a brief period of time. However, the post-test inspection revealed that no char bridging had occurred between the filters as a result of this excursion.

Stipstream Testing of Particulate Filters at the Wabash River Coal Gasification Project Final Report
DOE Award No. DE-FC26-97FT34158.

June 2003 4-10 


\section{RESULTS}

The primary focus in this campaign was to study the blinding behavior of these new filters. The data could then be compared to blinding rates previously established for similar candles operating in the commercial process. Figure 4.2.5.1 shows the differential pressure across the filters as a function of time for the operating period. With the exception of a few instrument induced flow excursions, the system was maintained at a fairly constant gas flow rate with a filter face velocity set point of $2.5 \mathrm{fpm}$. Neglecting the first 50 hours of operation, the overall predicted life is approximately 1900 hours. However, if it is assumed that the candles were being conditioned for the first 300 hours of operation, a much better blinding curve is projected for the Slipstream filter. A fit of the data generated after the first 300 hours of operation yields a blinding life of around 3600 hours. This predicts a significant improvement in filter life but it still falls short of supporting the minimum time required for the process.

Test results also demonstrate that the robust construction of powder filters make it a reliable candle element. Long-term testing has also shown it to have a low rate of corrosion in the process.

A secondary objective in the study was to qualitatively evaluate the filtration efficiency of the candles. The qualitative method for evaluating filter efficiency is to study secondary filter resistance over the operating period. The V-160 resistance data shows a slight upward trend and suggests that there may have been a small amount of char getting through the filters. The data only provides a qualitative means of measurement. Isokinetic sampling would be required to quantitatively measure the inefficiency of these candles. However, this leakage would likely be in the acceptable range and should not pose a problem in the process.

Given that the blinding rate is relatively high, no further evaluations were made for this type of filter.

SHipstream Testing of Particulate Filters at the Wabash River Coal Gasification Project Final Report
DOE Award No. DE-FC26-97FT34158

June 2003

4-11 


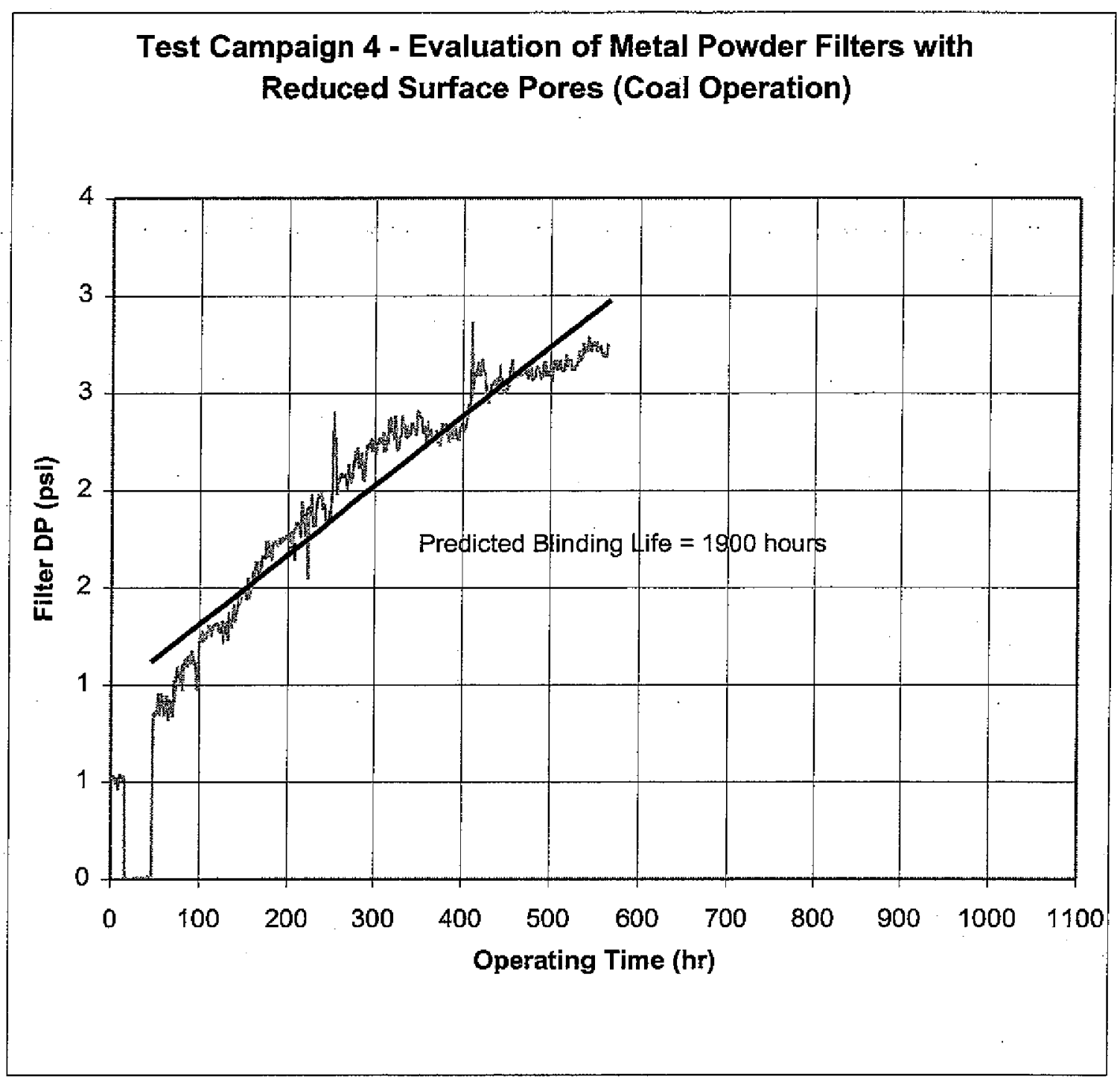

Figure 4.2.5.1: Test Campaign 4: Evaluation of Metal Powder Filters with Reduced Surface Pores (Coal Operation) 


\subsubsection{Test Campaign 5 (6/14 to $6 / 27 / 98)$}

The fifth Slipstream test was structured to support objectives stated for Test No. 8 in the original test matrix plan (see Table I-1 in Appendix I).

In this test, seven (7) 1.5-meter long clay-bonded silicon carbide candles were operated in the Slipstream to study blinding behavior and evaluate their reliability. The test was planned for 250 hours of operation. The actual time on syngas was just over 239 hours. It was concluded early due to a major plant outage.

The evaluation's primary goal was to confirm that these candles could be used as a competitive alternative to the original ceramic filters used at the facility. WREL has an ongoing interest in developing a reliable ceramic filter as a low cost alternative to metal candles. Ceramic filters have several distinct advantages. They demonstrate excellent corrosion resistance in the process and are typically about half the cost of a metal candle. A major concern with this filter is its susceptibility to cracking (low fracture toughness) both during maintenance handling and operation. Cold flow studies involving clay-bonded silicon carbide candles had indicated that a reduction in membrane pore size could provide a much lower rate of blinding. The candles involved in this study were similar to the OEM ceramic filter in that they both utilized a 15 micron mean pore size membrane. This evaluation was the first part in a series of studies aimed at validating the theory of smaller pore size providing better blinding rates in clay-bonded silicon carbide filters. It was the first step in working with this particular supplier to develop a reduced pore size membrane. In this study the supplier's standard membrane was evaluated.

Figure 4.2.6.1 shows the blinding trend established over the operating period. As expected, the blinding life for this candle was quite low. The trend yields a predicted blinding life of just over 1150 hrs. The Slipstream data shows that these filters closely follow the blinding behavior of a similar type of candle (OEM) that operated in the commercial HGF. The general agreement in both Slipstream and commercial HGF blinding trends confirms the Slipstream as a useful tool for predicting filter life in the commercial process.

Slipstream Testing of Particulate Filters at the Wabash River Coal Gasification Project Final Report
DOE Award No. DE-FC26-97FT34158

June 2003

4-13 
Assuming that the filters were being conditioned over the first $150 \mathrm{hrs}$ of the test, the blinding life is slightly improved. However, the predicted life still remains well below the minimum acceptable filter life for the WREL HGF. The blinding data shows that these candles are incapable of providing an acceptable period of sustained operation. For this reason they would not be a candidate for the WREL commercial HGF.

SEM analysis of a previously operated 15 -micron mean pore membrane filter showed a complete penetration of char through the membrane layer. Similar analysis of 10 -micron mean pore membranes showed only slight char penetration into the first or second pore layer of the membrane. The ingress of char into the larger pore membrane is a major contributor to the high rate of blinding in these filters. The blinding behavior demonstrated by this candle is more characteristic of a depth type filter. Consequently, the supplier was asked to reduce the membrane mean pore size to enhance the filter blinding characteristics. This evaluation of this new membrane was conducted in Test Campaign 9.

There was no evidence of solids breaking through the candles during the post-test inspection. There was no appreciable increase in V-160 backup filter resistance for the campaign. The overall filter efficiency appears to be within the acceptable range for the commercial process.

During the post-test inspection solids bridging was found in one area of the filter cluster that extended over half the length of the candles. There was no indication of damage to the filters as a result of this. The bridging likely started around 58 hours into the campaign as shown by the steep increase in filter differential pressure. This coincides with a plant trip at which time the Slipstream was taken off-line. The bridging probably occurred as it was taken off-line or when it was placed back in service. If this were the case, the filters operated for $180 \mathrm{hrs}$ with some degree of solids bridged between them. Given that there were no failures in this campaign, the results would indicate these filters have sufficient strength to withstand some of the forces generated by solids bridging. This data suggests that the filter would provide an acceptable level of robustness in the process given a filter restraint system is used. 


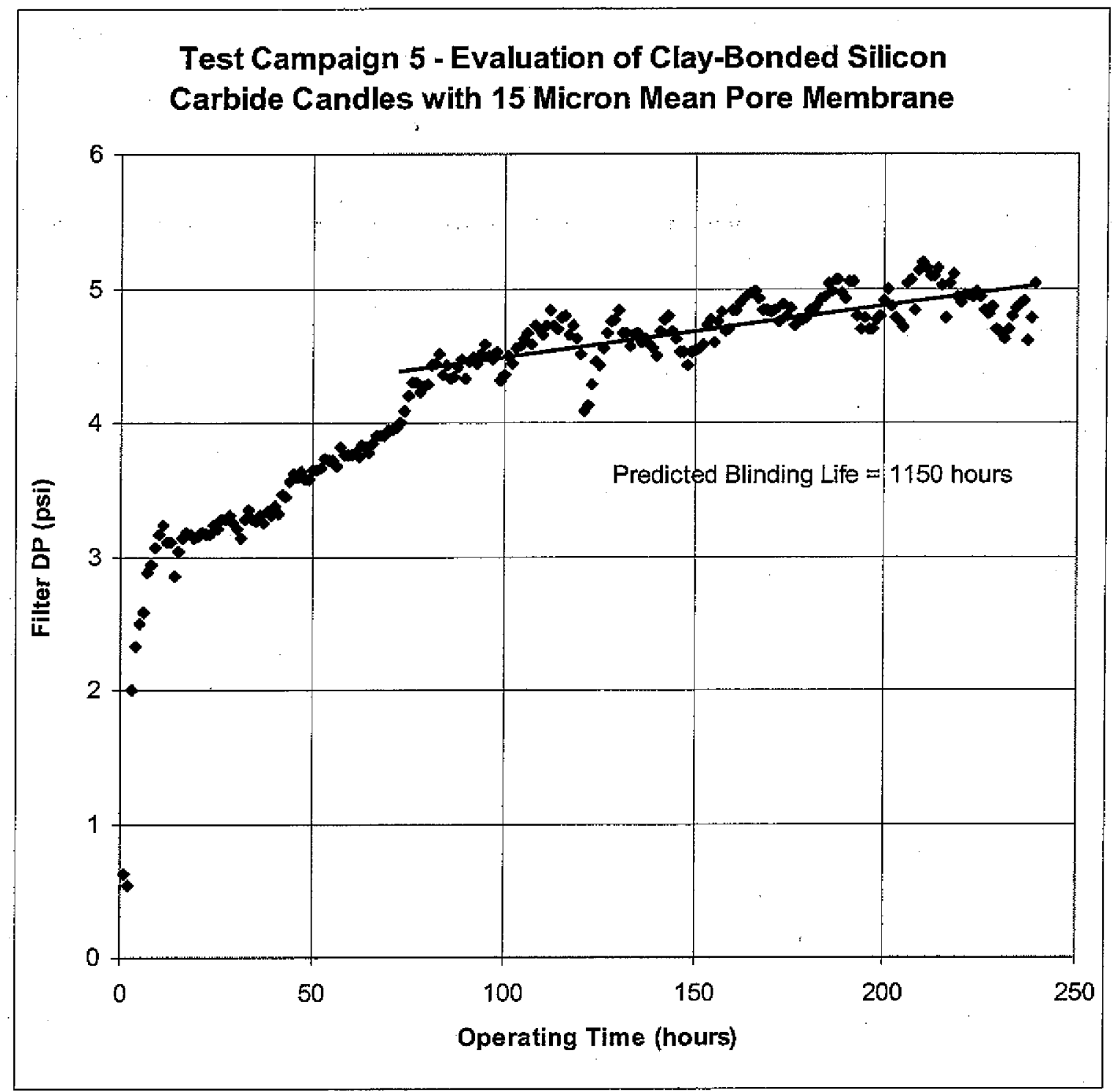

Figure 4.2.6.1: Test Campaign 5: Evaluation of Clay-Bonded Silicon Carbide Candles with 15 Micron Mean Pore Membrane 


\section{RESULTS}

\subsubsection{Test Campaign 6 (8/17 to $10 / 11 / 98)$}

The sixth Slipstream test was structured to support the objectives stated for Task 3 Test No. 7 in the original test matrix plan (see Table I-1 in Appendix I).

In this test, seven (7) 1.5-meter long clay-bonded silicon carbide candles with a 5 micron mean pore membrane were evaluated for blinding behavior and service reliability. The filters involved in this study were procured from the Wabash HGF OEM. The test was planned for 500 hours of syngas operation. The actual test duration was 375 hours. It had to be terminated early due to a major plant outage.

Initial screening of ceramic candles identified this filter as a potential candidate to provide an optimum rate of blinding in the process. The initial investigation took place in both the cold flow unit and the commercial HGF system. A number of clay-bonded silicon carbide candles with membranes ranging from $5-15$ micron mean pores size were tested and in both evaluations the 5 micron membrane showed the lowest increase in resistance. However, the data was limited. The HGF evaluations only provided a starting and final filter resistance. The evaluation was conducted with a mix of filters in the commercial HGF that were known to have a wide variation in permeability. This can have a significant affect on blinding rate. The more permeable filters will have a much higher face velocity immediately after the blowback cycle. The magnitude of this "instantaneous" face velocity has a direct affect on the formation and permeability of the residual char layer. In most barrier type filters the residual char layer is the controlling factor that changes the overall filter resistance. Altering the parameters that go into the formation of this layer can lead to unreliable results. Consequently, it's impossible to establish an accurate rate of blinding when mixing filters in the commercial HGF. Using the Slipstream, a reliable trend is generated that accurately predicts filter behavior in the commercial process.

Figure 4.2.7.1 shows the filter pressure drop as a function of time for test period. The data predicts a filter blinding life of better than 11,400 hours of operation. The conclusion from this

\begin{tabular}{ll}
\hline Slipstream Testing of Particulate Filters at the Wabash River Coal Gasification Project & DOE Award No. DE-FC26-97FT34158 \\
Final Report & June 2003
\end{tabular}




\section{RESULTS}

study is that the candle is fully capable of providing an acceptable period of sustained operation and therefore it would be a viable candidate for the Wabash HGF.

SEM analysis of this filter showed an absence of char penetration into the membrane layer. Both the SEM results and the low rate of blinding demonstrates that this candle exhibits excellent surface filtration characteristics.

The HGF at Wabash originally operated using ceramic candles. In this configuration the candles are fixed in a tubesheet that separates the clean gas plenum from the "dirty" side of the vessel. They were rigidly held in the tubesheet at the head of the candle. Other than the fixed headpiece, they were free hanging and had no means to restrain bottom side-to-side movement. Numerous failures occurred from flow induced movement at the bottom of the candles. In many cases, this was evident by localized areas of spalling at the extreme lower end of the candles.

Consequently, a more robust and reliable ceramic filter restraint system needed to be developed. A key consideration for this system is that it only restricts candle movement. They should not rigidly be held in place. It's extremely important that the filter be able to move to a limited degree with thermal transients in the system. The OEM for the Wabash HGF provided several designs for a new type of filter support mechanism. Both were dimensionally modified for the study. Post-test inspections revealed leakage through one of the candle filter headpiece gaskets. A possible cause for this was that solids may have jammed between the bottom restraint device and filter forcing it upward. In theory, this could relax compression in the filter gasket. The exact root cause is of little consequence since the study showed the other the restraint system to be superior to any previously evaluated at the Wabash facility. The benefits of this system are that it's less costly to fabricate, less time consuming to install and provides only a restriction of side-to-side movement. It has proven to be a highly reliable bottom restraint system that does not promote solids bridging. The next step in the evaluation process was to scale it up for a test in the commercial hot gas filter system.

The backup filter, V-160, had a slow rise in differential pressure over the course of the test period. This likely resulted from the small amount of char that leaked by the filter gasket.

Slipstream Testing of Particulate Filters at the Wabash River Coal Gasification Project Final Report
DOE Award No. DE-FC26-97FT34158

June 2003 


\section{RESULTS}

Neglecting the contribution in resistance from the gasket leak, the overall filter efficiency of the 5-micron mean pore filter appears to be within the acceptable range.

The filters and restraint system used in this study were evaluated in the commercial process later that year. A new fail-safe device was also tested along with them. The restraint system was proven to be equally as reliable in the commercial process. 


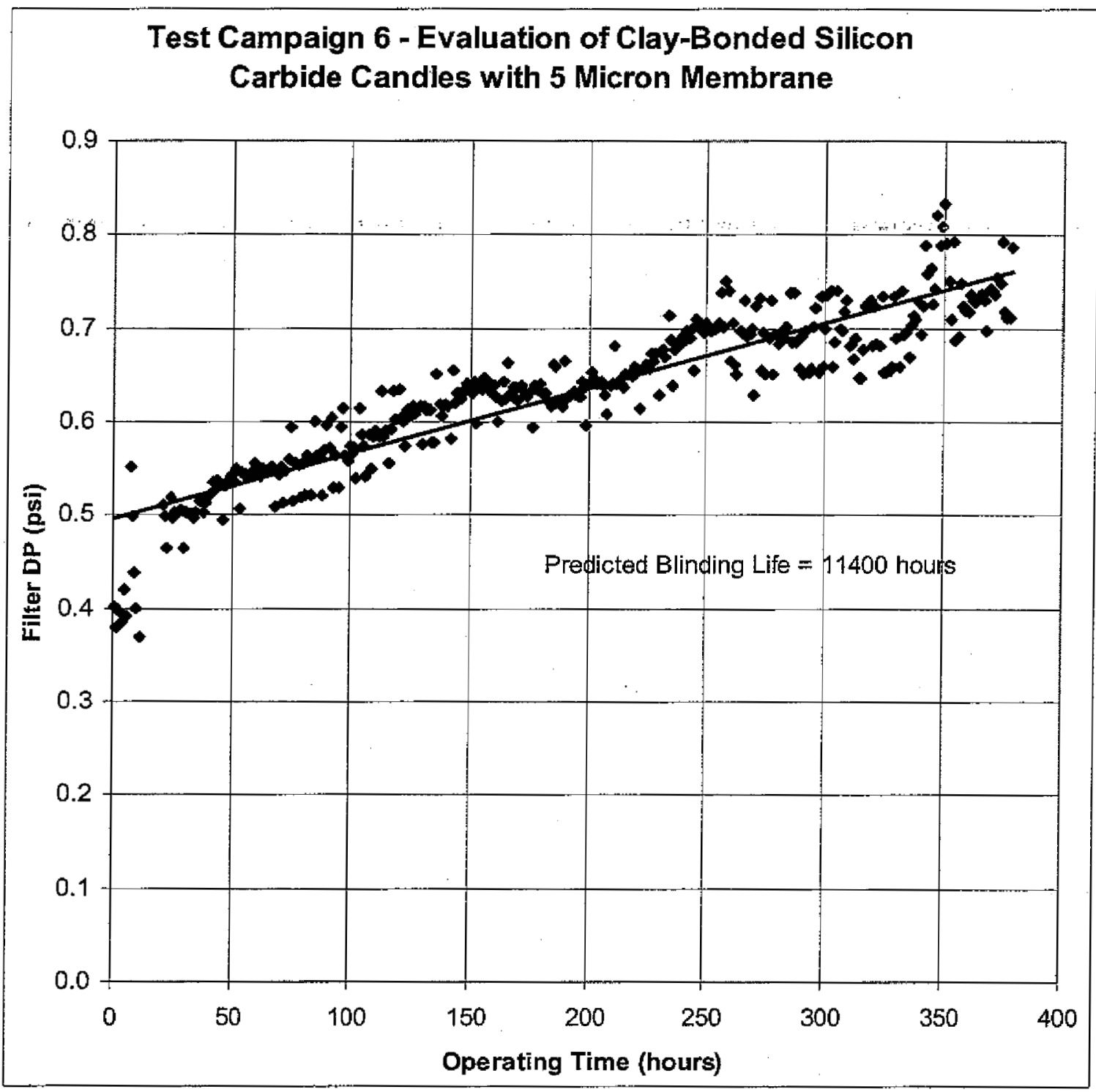

Figure 4.2.7.1: Test Campaign 6 - Evaluation of Clay-Bonded Silicon Carbide Candles with 5 Micron Membrane 


\section{RESULTS}

\subsubsection{Test Campaign $7(10 / 17$ to $11 / 5 / 98)$}

The seventh Slipstream test was structured to support the objectives stated for Test No. 5 in the original test matrix plan (see Table I-1 in Appendix I).

In this test, seven (7) 1.5-meter sintered powder iron aluminide alloy candles were operated in the slipstream unit to study blinding behavior and service reliability. The test was planned for 250 hours of syngas operation. The actual test duration was just over 423 hours.

In certain applications, porous iron-aluminide filters have demonstrated excellent resistance to high-temperature corrosion in $\mathrm{H}_{2} \mathrm{~S}$ rich gas streams similar to the Wabash gasification process. Based on these results, a program was established at the Wabash facility to evaluate ironaluminide materials for hot gas filtration. The evaluation would seek to determine life limitations imposed by both corrosion and blinding in the porous media. The initial screening was conducted in the commercial HGF. In this evaluation, the iron aluminide media showed an acceptable rate of corrosion. However, there was some suspicion that blinding might be a problem. Due to the large number of filters within the commercial vessels, it is impossible to evaluate a small set of test elements and collect meaningful blinding data. This part of the study was better suited for the Slipstream system. A cluster of seven (7) iron-aluminide candles was operated in the slipstream for just over 423 hours. Figure 4.2.8.1 shows the filter pressure drop as a function of time over the operating period. The established blinding trend yields a life prediction of 10,138 hours. The blinding data would indicate these filters are viable candidates for the commercial process. However, long-term corrosion studies in excess of 5000 hours were required to establish a predicted filter corrosion life. This study was conducted in the commercial HGF.

Filters from both the HGF and Slipstream studies were examined by Oak Ridge National Laboratories (ORNL) to investigate both blinding and corrosion. These findings are summarized in a paper prepared by ORNL that is included as Appendix II. To summarize, the general mode of media blinding is caused by a formation of iron sulfide (Fe-S) that grows into and eventually fills the media pores. This process accelerates as exposure time is increased. In addition to this,

Slipstream Testing of Particulate Filters at the Wabash River Coal Gasification Project Final Report
DOE Award No. DE-FC26-97FT34158

June 2003

4-20 
the filters were found to maintain their original strength as long as the Fe-S formation did not occlude more than about $50 \%$ of the pores. Some iron aluminide media samples demonstrated a corrosion life near the acceptable limit. However, a number of samples did not. The study results show that the higher chromium iron aluminide exhibits a better resistance to process induced corrosion. At this point, the media tested here does not reliably demonstrate a corrosion rate that could sufficiently support the required HGF operating times. Subsequent development efforts should focus on evaluating the higher chromium iron aluminide filter media.

Metal powder fail-safes operating in the filters for this study did not see any appreciable increase in resistance over the duration of the campaign. Based on this data, fail-safe blinding when used with iron-aluminide filters is not a concern. One fail-safe did suffer a fracture along the longitudinal weld seam during operation. The vendor determined that this was caused by a problem in the application of the longitudinal weld. As a result, better $\mathrm{QA} / \mathrm{QC}$ processes were implemented to successfully prevent this type of failure in future applications.

There was a slight increase in the backup filter (V-160) resistance over the course of this campaign. However, the inefficiency in these filters was deemed insignificant. 


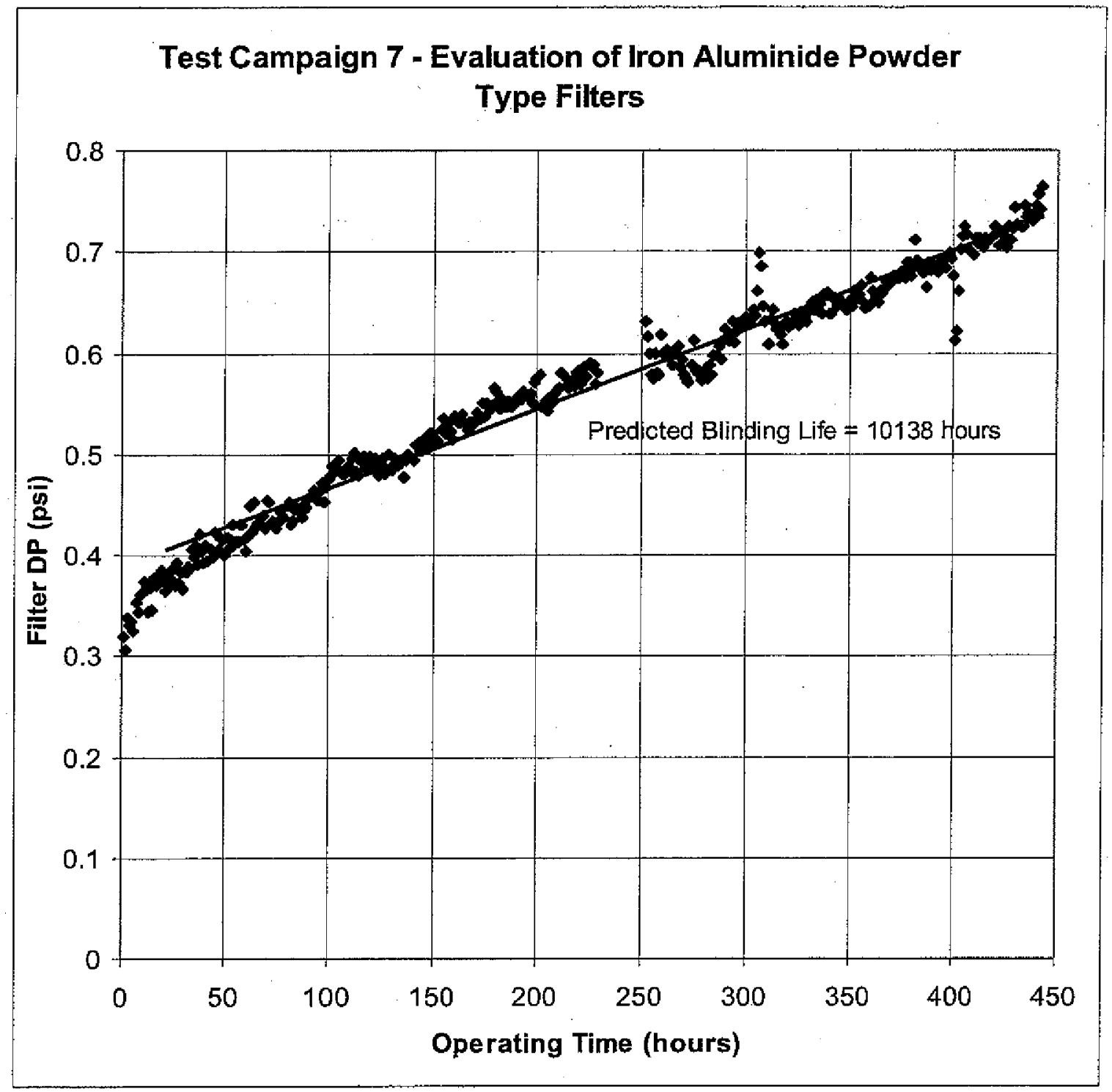

Figure 4.2.8.1: Test Campaign 7 - Evaluation of Iron Aluminide Powder Type Filters 


\section{RESULTS}

\subsubsection{Test Campaign $8(1 / 12$ to $1 / 19 / 99)$}

The eighth Slipstream test was structured to support objectives listed for Test No. 9 in the original test matrix plan (see Table I-1 in Appendix I).

In this test, seven (7) 1.5-meter long candles constructed of metal fiber media were evaluated in the slipstream unit. Corrosion evaluations in both the slipstream and commercial processes had identified a new media alloy as a potential candidate to improve filter life. Results indicate that the media could last two to four times longer than those currently utilized in the commercial system. Due to the difficulty in manufacturing this media, the fiber diameter is slightly larger than the type used in a previous evaluation (see Test Campaign 3). A primary focus in this study was to evaluate blinding in the new media. A second objective was to evaluate a new hardware configuration to fix the filters in the vessel tubesheet. The new design offers several distinct advantages over the existing filter fixing system. A third objective was to qualitatively evaluate the filtering efficiency of the new media.

Up to this point, metal fiber filters provided the best operating life in the commercial HGF. They have been proven to be highly reliable in this system. Corrosion testing of new alloys has shown the media selected for the study to be highly resistant to attack from the process gas. In addition to the alloy material change, a significant difference in this media is the larger fiber diameters used for its construction. The net result is an increase in media porosity and it was this change that made the blinding evaluation a key element of the study. Several prototype medias were constructed from the new alloy fibers specifically for testing in the Slipstream unit to obtain a recipe that yielded optimal rates of blinding.

The first proto-type media study was planned to be 250 hours in duration. However, 3 of the 7 filters failed after 158 hours of operation forcing the study to be terminated early. Fortunately, enough data was generated to establish a blinding trend for these filters. Figure 4.2.9.1 shows the filter differential pressure as a function of time over the operating period. Using a linear regression fit of the data a 2478-hour life is calculated for these filters. This falls short of the

\begin{tabular}{|c|c|}
\hline Slipstream Testing of Particulate Filters at the Wabash River Coal Gasification Project & DOE Award No. DE-FC26-97FT34158 \\
\hline Final Report & June 2003 \\
\hline
\end{tabular}




\section{RESULTS}

required mean time between HGF filter maintenance outages. Based on the study results, it was concluded that this media recipe could not provide an acceptable filter life in the HGF.

During this study, a new hardware configuration to fix the candles within the vessel tubesheet was evaluated. The new design utilized a filter headpiece with parallel machine threads to fasten it into the tubesheet. Redundant gasket seals were incorporated to prevent solids leakage into the clean side of the tubesheet. The parallel threads helped eliminate galling problems experienced in many of the existing fasteners. The current filter fastening hardware configuration requires a significant number of man-hours to replace the candles. One of the major benefits inherent to this design is that it drastically reduces the man-hour requirement for this effort. Study results showed that the redundant gasket seals were quite effective at preventing solids from leaking into the clean side of the system. Candle filter installation and removal processes were significantly improved by utilizing this new system. The study helped to initiate further development work to incorporate an easily removable fail-safe device into the design.

Given the increased porosity of these filters, another objective was to qualitatively evaluate their solids removal efficiency. Due to the new hardware configuration, no fail-safes were used in this evaluation. A faulty instrument caused a number of V-160 resistance measurement problems during the campaign but enough data was collected to evaluate filtration efficiency. The overall trend for V-160 resistance shows that there was minimal char getting through the filters prior to the failures. This data indicates that the new media will provide sufficient filtration efficiency for the process.

Investigation into the filter weld failures identified a problem in the manufacturing process. Implementation of an improved manufacturing procedure has sufficiently resolved this problem. 


\section{RESULTS}

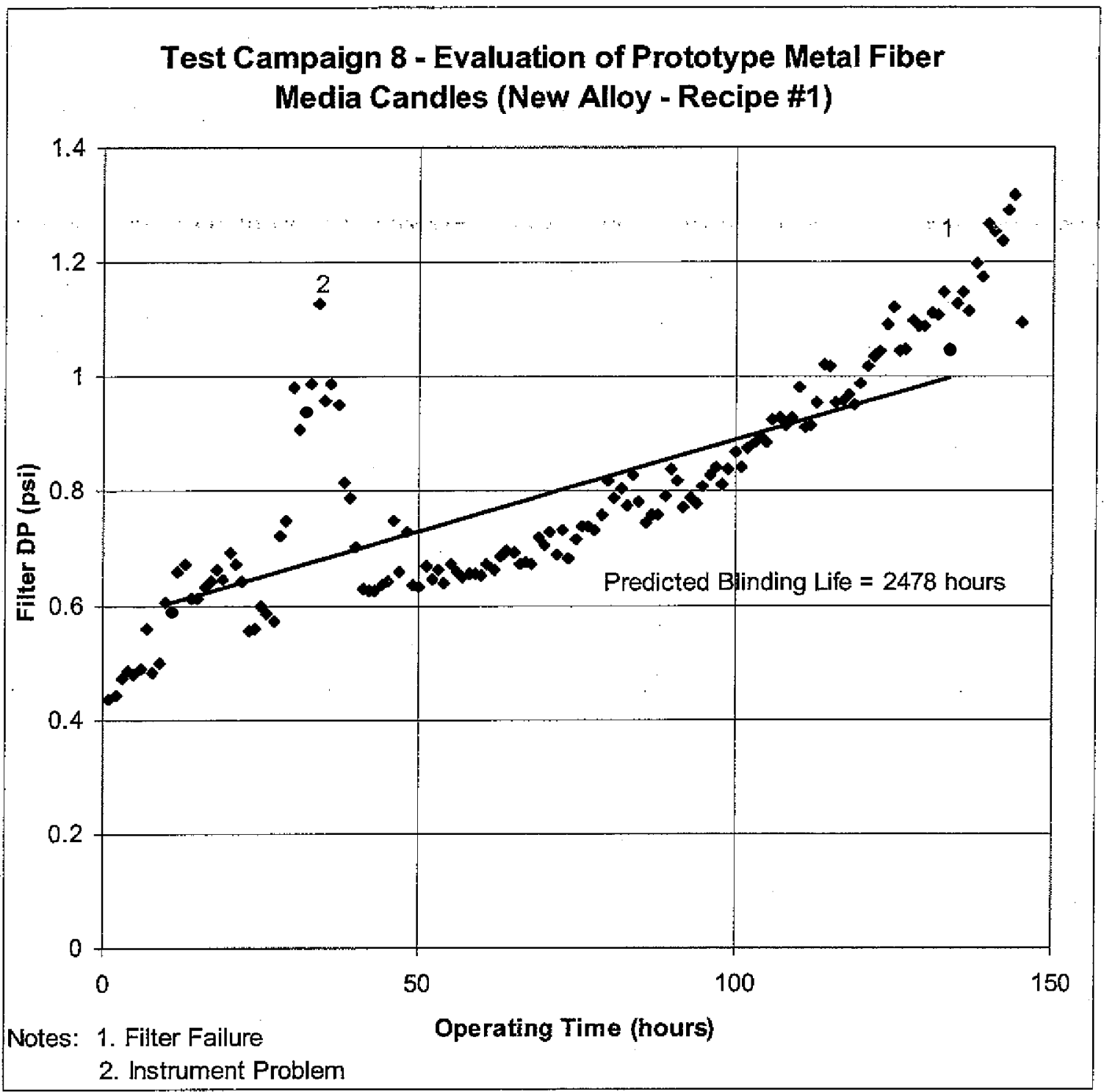

Figure 4.2.9.1: Test Campaign 8 - Evaluation of Prototype Metal Fiber Media Candles (New Alloy - Recipe \#1) 


\section{RESULTS}

\subsubsection{Test Campaign $9(2 / 15$ to $2 / 25 / 99)$}

The ninth Slipstream test was structured to support the objectives stated for Test No. 6 in the original test matrix plan (see Table I-1 in Appendix I).

For this test, seven (7) 1.5-meter long clay-bonded silicon carbide candles constructed using a new proto-type membrane were operated in the slipstream unit to study blinding behavior and evaluate service reliability. These filters were from the same supplier as those evaluated in Test Campaign 5. The only difference was a reduction in the mean pore size of the membrane layer: The test was planned for 250 hours of syngas operation. The actual test duration was just over 235 hours. Early termination was due to a major plant outage.

A similar filter evaluated in Test Campaign 6 had a predicted blinding life of over 11,400 hours. In Test Campaigns 5 and 6 filters were supplied by different manufacturers. They were similar in construction but differed in the pore size of the membrane layer. The mean pore sizes were 15 and 5 microns for Test Campaigns 5 and 6 , respectively. The smaller pore size used in Test Campaign 6 produced a blinding life that was significantly better than the one generated in the previous campaign. Based on these results, this manufacturer developed a new prototype filter that included a reduction in the membrane pore size. The next step in this process was to evaluate the blinding characteristics of the new membrane. The main focus for this effort was to develop a competitive alternative to the OEM ceramic candle.

The primary objective was to develop a predicted blinding life for the new filter membrane. Figure 4.2.10.1 shows the filter differential pressure as a function for the test period. Neglecting the first 50 hours of operation, a linear fit of the data shows a predicted blinding life of 7256 hours. This falls short of the 11,400-hour life predicted for the 5-micron membrane filter in Test Campaign 6. To be considered a competitive alternative, the filters should have more comparable blinding rates. As a result, it's recommended that an additional reduction in membrane pore size be considered for this filter. 


\section{RESULTS}

There was no appreciable gain in V-160 (backup filter) resistance during the study.

Consequently, the overall efficiency of this filter is deemed acceptable for the Wabash process.

Slipstream Testing of Particulate Filters at the Wabash River Coal Gasification Project Final Report
DOE Award No. DE-FC26-97FT34158

June 2003

$4-27$ 


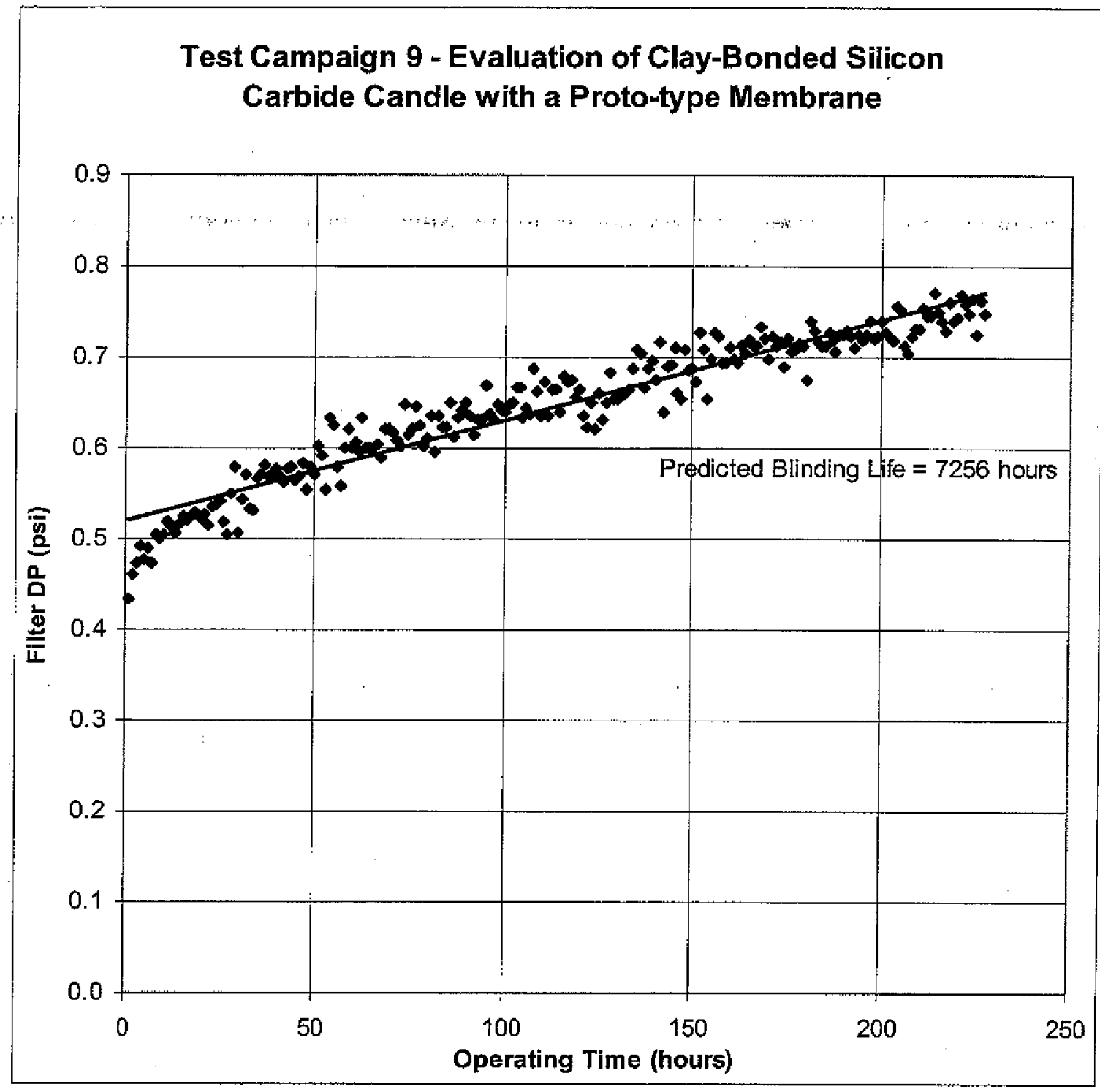

Figure 4.2.10.1: Test Campaign 9 - Evaluation of Clay-Bonded Silicon Carbide Candle with a Proto-type Membrane 


\section{RESULTS}

\subsubsection{Test Campaign $10(6 / 28$ to $7 / 10 / 99)$}

The tenth Slipstream test was structured to support the objectives stated for Test No. 10 in the original test matrix plan (see Table I-1 in Appendix I).

For this test, seven (7) 1.5-meter metal fiber media candles were evaluated in the slipstream unit. It was structured as a follow-up to Test Campaign 8 which had involved the study of a new media alloy and filter construction. The filters for this study used a second recipe for laying down the media fibers. The new design sought to improve the blinding characteristics of this new alloy media. Fabrication improvements were included to address the candle failures from Campaign 8 . The test was planned for 250 hours of syngas operation. The actual test duration was just over 257 hours.

In Test Campaign 8 the predicted blinding life was significantly less than the "standard" fiber media evaluated for Test Campaign 3. The main objective in this study was to establish a blinding rate for the second recipe of new prototype media. Figure 4.2.11.1 shows the filter differential pressure as a function of time over the slipstream test period. The trend predicts a blinding life of over 10,170 hours for this filter. This is a significant improvement over the 2478-hour blinding life predicted in Test Campaign 8 . The trend is more comparable to the one developed in Test Campaign 3. The 10,170-hour life prediction exceeds the minimum filter operating time required for the HGF performance objectives.

In Test Campaign 8 three (3) filters were found to have suffered failures during the study. Improvements were made in the manufacturing process to address the failures. The secondary objective in this study was to evaluate the effectiveness of these changes. There were no failures during the study. Post-examination of the candles showed them to be in excellent condition. It was concluded that the manufacturing improvements had adequately addressed the associated problems.

There was no appreciable gain in V-160 resistance for this study. Therefore, it's assumed that the media provides an acceptable level of filtration efficiency.

Slipstream Testing of Particulate Filters at the Wabash River Coal Gasification Project Final Report
DOE Award No. DE-FC26-97FT34158

June 2003

4-29 


\section{RESULTS}

Based on the favorable results of this study, the filter evaluated here is deemed as an acceptable candidate for the Wabash HGF.

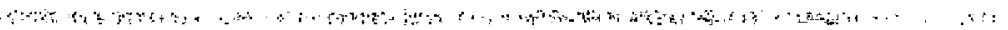

Slipstream Testing of Particulate Filters at the Wabash River Coal Gasification Project Final Report
DOE Award No. DE-FC26-97FT34158 Jupe 2003 


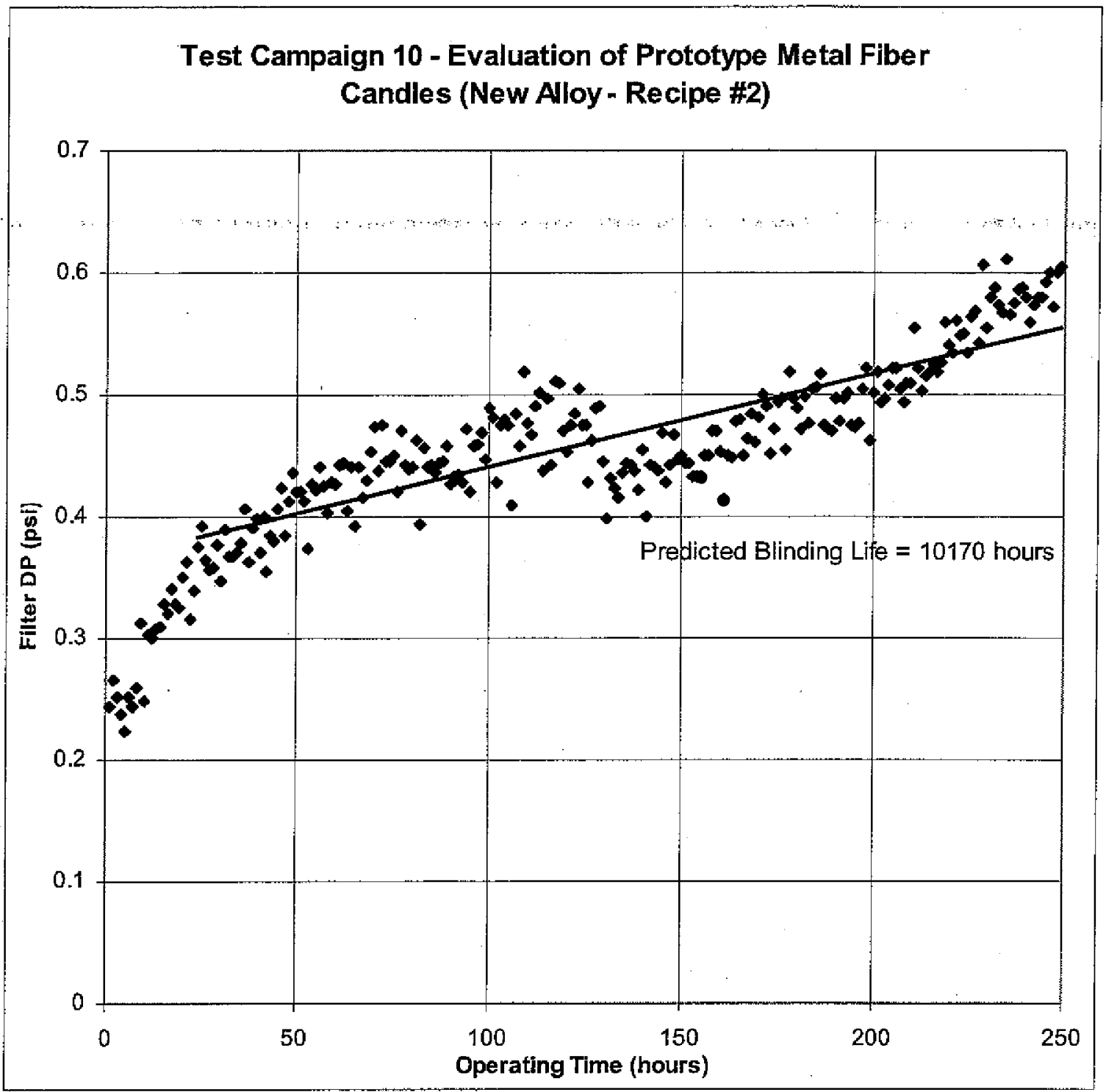

Figure 4.2.11.1: Test Campaign 10 - Evaluation of Prototype Metal Fiber Candles (New Alloy - Recipe \#2) 


\subsubsection{Test Campaign $11(8 / 13$ to $8 / 14 / 99)$}

The eleventh Slipstream test was structured to support the objectives stated for Test No. 16 in the original test matrix plan (see Table I-1 in Appendix I).

For this test, seven (7) 1.5-meter long oxide composite candles were evaluated in the slipstream process. The test was planned for 250 hours of syngas operation. It had to be terminated early due to failures in the candle media.

This was the first evaluation of a ceramic composite type candle in the Wabash gasification process. The primary objectives were to predict blinding life and evaluate the candle's robustness in the process.

The campaign was terminated after 29 hours of operation due to an excessive amount of char leaking through the test fitters. The post-test inspection revealed that several filters had suffered detachment of the outer layer at various locations along each candle. There was also damage in the filter substrate at some of these locations. Attrition of this fibrous structural material was likely caused by high gas flow in these areas following detachment of the filtering layer. This ultimately led to the rapid blinding seen in the backup filter. Due to the short duration of the study, a reliable blinding trend could not be established. Post-test samples were submitted to the supplier for evaluation. They showed the filter permeability to be approximately half of that for a new candle. This was said to be in the normal tange for a candle exposed in similar processes. Filter strength was not evaluated due to the type of failure and short test duration. The vendor's conclusion was that the most likely cause of failure came from forces generated by the high pressure blowback gas. These forces were likely stronger than the bond strength between the filtering layer and the filter substrate. According to the supplier, this was not the first time a failure like this had happened during exposure in a gasification process. The results indicate that an improved method of construction is required to make them stronger and better suited for this and other gasification processes. It is interesting to note that all three monolithic membrane coated ( $\mathrm{SiC}$ ) ceramic candles evaluated in the slipstream system (Campaigns 5, 6 and 9) did not experience this type of problem. Consequently, design improvements for these filters should 


\section{RESULTS}

focus on achieving similar material bond strengths to those used in the clay-bonded SiC candles. Another potential solution might be to perform blowback optimization studies to potentially reduce the forces generated in the filter media. However, the results indicate that stronger more robust candles will need to be constructed to make them suitable for this and other gasification processes.

\subsubsection{Test Campaign $12(8 / 22$ to $9 / 3 / 99)$}

The twelfh Slipstream test was structured to support the objectives stated for Test No: 17 in the original test matrix plan (see Table I-1 in Appendix I).

For this test, seven (7) 1.5-meter long oxide composite candles were evaluated in the slipstream process. This was the second evaluation of an oxide composite candle in the Wabash process. The test was planned for 250 hours of syngas operation. The actual test was 291 hours in duration.

The filters involved in this stady were from a different supplier than the type used in the previous evaluation. However, the objectives were essentially the same as those for Test Campaign 11. According to the supplier, this was the first time a candle of this type had been operated in a gasification process. All previous studies by this manufacturer had been conducted in PFBC type applications. As in the previous slipstream study, the evaluation period was planned for 250 hours. The test period was extended since the end date fell near the weekend. After 290 hours of operation char began to leak through the candle filters.

Figure 4.2.13.1 shows the filter differential pressure as function of time for the campaign. The trend predicts a blinding life of $3,267 \mathrm{hrs}$. The results show these filters are incapable of supporting the required operating time for the commercial $\mathrm{HGF}$. A reduction in the filtering layer pore size would likely be required to improve the blinding characteristics of this filter in the Wabash process. 


\section{RESULTS}

The study had to be terminated due to char breaking through the candle filters and a resultant high V-160 resistance. Three of the seven candles involved in this study had suffered membrane damage in various localized areas. Spalling of the membrane layer resulted in solids leakage through the candle. Another candle was found to have suffered a separation (crack) at the base of the flange area (hemispherical head). Small cracks were present in the flange area as well. It's possible that the force exerted by the spring loaded mechanism used to hold the candles in the tube plate may have been greater than filter material strength. Either a stronger flange (more dense) or a different holding mechanism would be required for this filter to provide acceptable reliability in this process. It's interesting to note that three clay-bonded silicon carbide candles were evaluated using the same type of filter fixing system and had suffered no damage: As in the previous study, spalling of the membrane layer was likely a result of forces generated during the blow back event. It would seem that these forces are higher than the bond strength of the membrane layer to the filter substrate. The manufacturer also commented that a similar phenomenon occurred during testing at another gasification facility. Either a reduction in blowback forces or higher membrane bond strengths will be required to make this filter more reliable in gasification processes.

There was little evidence of char leaking by the candles until shortly before the test was terminated. This was evident in the V-160 backup filter resistance over the campaign. Based on this data, the filter efficiency is deemed sufficient for the process. 


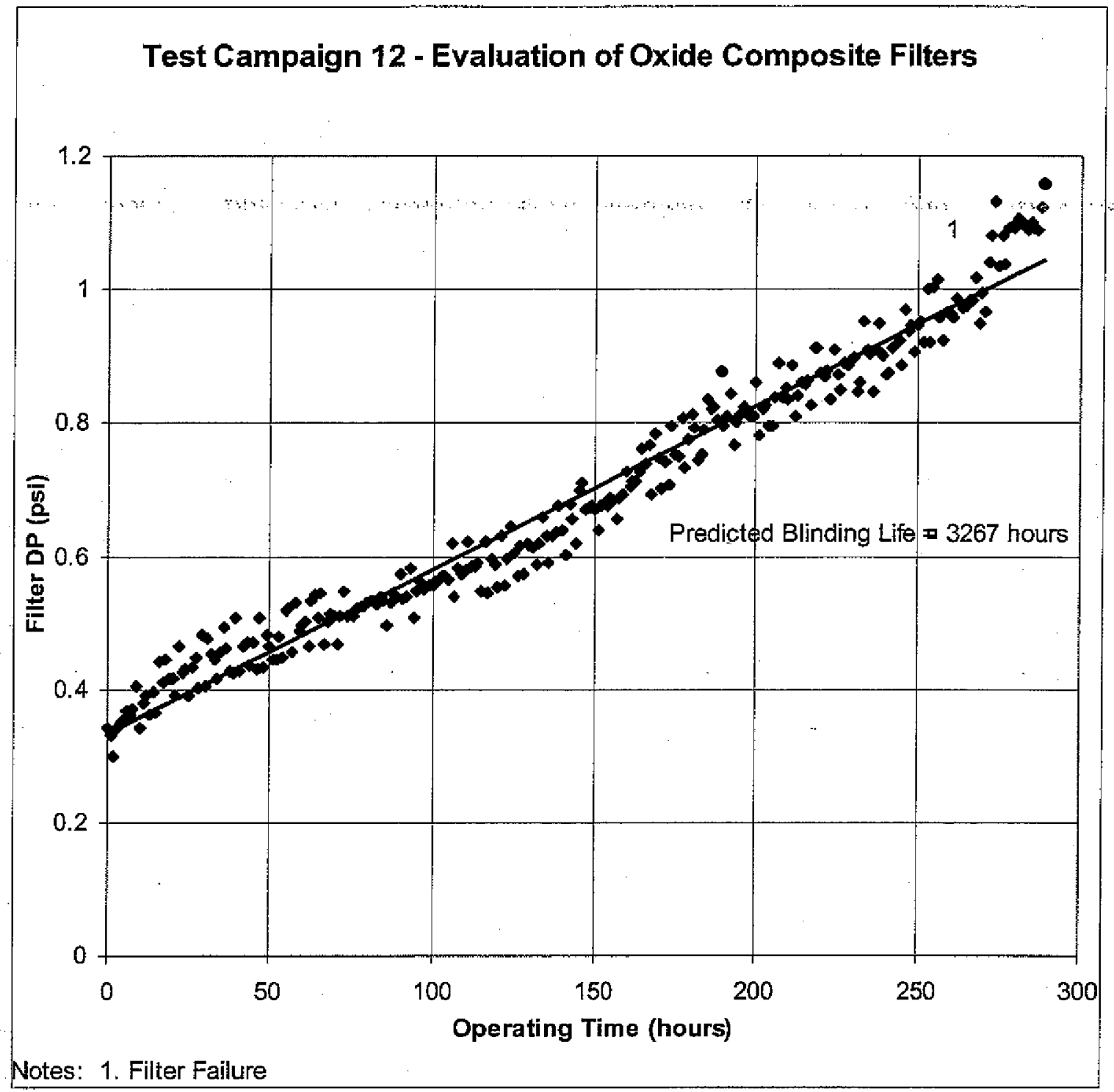

Figure 4.2.13.1: Test Campaign 12 - Evaluation of Oxide Composite Filters 


\section{RESULTS}

\subsubsection{Test Campaign 13 (9/14 to 9/28/99)}

The Thirteenth Slipstream test was structured to support the objectives stated for Test No. 10 in the original test matrix plan (see Table I-1 in Appendix I).

For this test, seven (7) 1.5-meter long candles constructed of metal fiber media were evaluated in the slipstream unit. It was a follow-up to Test Campaigns 8 and 10 where a new media alloy and filter construction were being studied. The only change in these filters was a new recipe for laying down the media fibers. The alteration was made in an attempt to further enhance the blinding characteristics of the filter used in Test Campaign 10. The test was scheduled for 250 hours of syngas operation. It lasted 300 hours in duration.

The filters for this study were constructed with a new media alloy being evaluated for use in the commercial vessels. The primary objective of this study was to evaluate the blinding characteristics for the new media recipe. Figure 4.2.14.1 shows the filter differential pressure as a function of time over the test period. A linear fit of the data predicts a filter blinding life of 7,350 hours. This rate is within the acceptable level required for the WREL HGF. From a blinding standpoint, this filter demonstrates good performance and would be suitable for the WREL process. Also shown on Figure 4.2.14.1 are the three media recipes tested using this new alloy. The data clearly shows that the recipe (\#2) used in Test Campaign 10 offers the best blinding life.

Over the course of the study there was no appreciable gain in backup filter resistance. Consequently, the filtration efficiency for these candles is deemed to be within the acceptable range for the WREL process.

The test concluded a series of studies (also see Test Campaigns 8 and 10) aimed at developing a new alloy filter that would ultimately serve as an upgrade to the "standard" candle filter used at the Wabash facility. When compared to the standard media, the new alloy provides nearly twice the corrosion life and has equally as good or better blinding characteristics. In the early stages of development, problems in fabrication were recognized and corrected. As result the filter has

Slipstrean Testing of Particulate Filters at the Wabash River Coal Gasification Project Final Report
DOE Award No. DE-FC26-97FT34158

June 2003

4-36 
proven to be highly reliable in the commercial process. Along with this effort a new configuration was developed for fixing the filters within the vessel tubesheet. The changes also incorporate an improved system for holding fail-safe devices within the filters. The improvements have significantly increased filter life and greatly reduced the overall maintenance time required for the commercial HGF. 


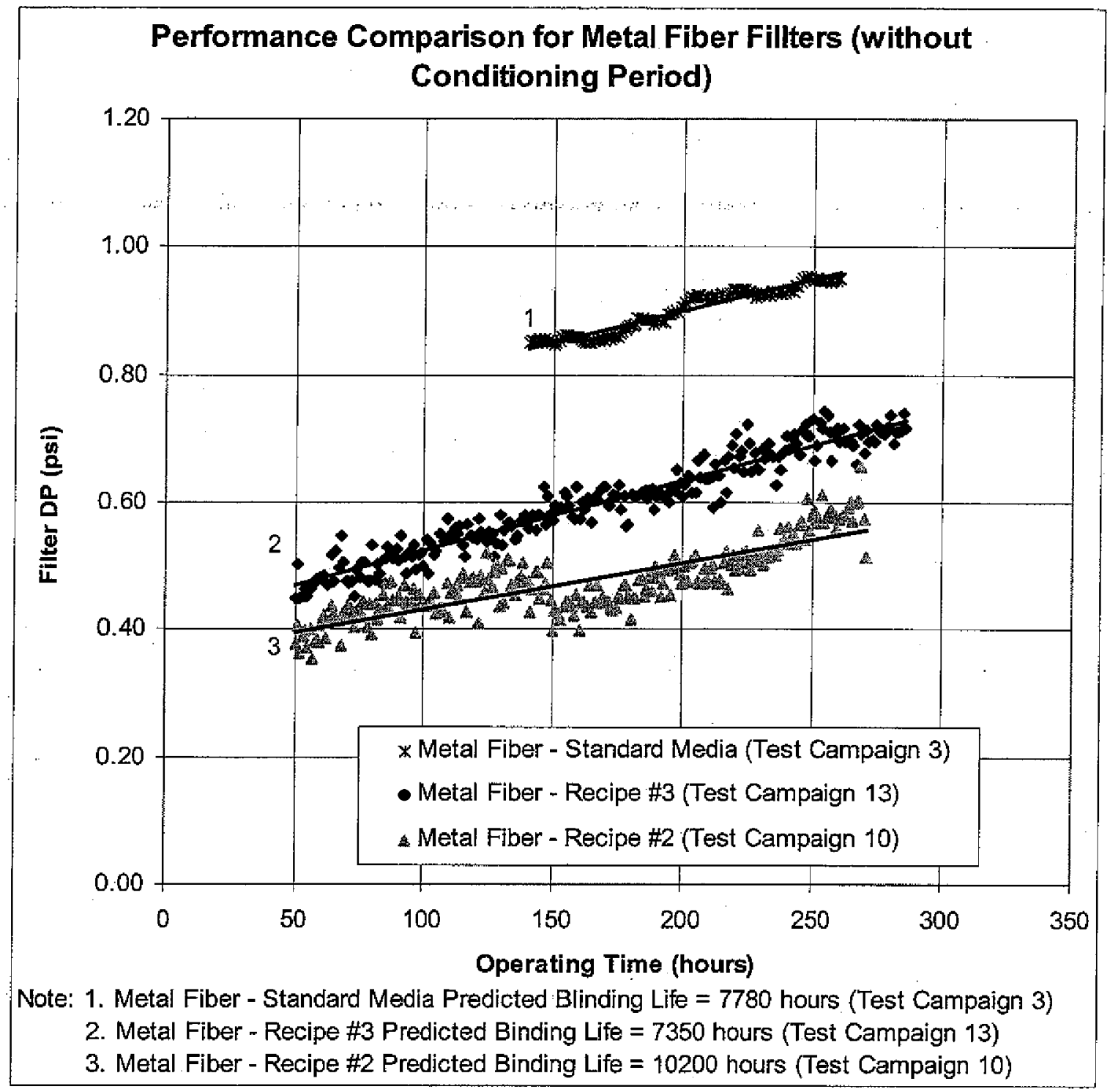

Figure 4.2.14.1: Performance Comparison for Metal Fiber Filters (without Conditioning Period) 


\section{RESULTS}

\subsubsection{Test Campaign $14(9 / 8$ to $9 / 13 / 00)$}

The fourteenth Slipstream test was structured to support the objectives stated for Test No. 4 in the original test matrix plan (see Table $\mathrm{l}-1$ in Appendix I).

In this test, seven (7) 1.5-meter long metal powder candles were evaluated in the slipstream process. The filters evaluated in Test Campaign 4 were made by the same supplier. The major difference in these filters was a slightly reduced media pore size. Also, these filters had no reduction in the surface pores. The test was planned for 250 hours of syngas operation: The actual test was 114 hours in duration.

There is continued interest in this type of filter construction due to a number of favorable attributes. Inherent to its construction is the ability to withstand higher tates of corrosion. This is a distinct advantage over metal fiber type filters. It costs significantly less to fabricate and is quite robust in the process. This type of filter was used early in the commercial HGF when it was converted from ceramic to metal candles. It offered exceptional corrosion resistance but demonstrated an extremely high rate of blinding.

This study differed from earlier evaluations in that the process syngas was now generated from a petroleum coke gasifier feedstock. The Wabash gasification facility transferred to $100 \%$ petroleum coke operation in August of 2000. The main objective in this test was to generate a blinding trend and life prediction for the filter while operating on petroleum coke.

Unfortunately, the study had to be terminated early due to a failure in one of the blowback valves. However, enough data was collected to generate what is believed to be a fairly reliable blinding curve. Figure 4.2.15.1 shows the filter pressure drop as a function of time over the test period. It predicts a blinding life of approximately 236 hours in the process. This is an extremely high rate of blinding when compared to previous trends. This was probably due to increased water loading in the process syngas stream, which is known to cause accelerated rates of filter blinding. However, for reasons not clearly understood, this type of filter is more sensitive to additional water loading in the gas stream. As shown in this study, the blinding rate

Slipstream Testing of Particulate Filters at the Wabash River Coal Gasification Project Final Report
DOE Award No. DE-FC26-97FT34158

June 2003 
becomes extremely high. Samples from previous studies were submitted to the filter supplier to examine them for blinding. As in earlier investigations, trace elements ( $\mathrm{Ge}, \mathrm{Sb}, \mathrm{As}, \mathrm{Pb}$, etc) were again present in the residual layer and in the candle surface pores. It is theorized that a portion of them condensing in the residual layer are contributing to the loss in permeability. At this time, it still remains unclear how an increase in the gas stream moisture causes this extremely high rate of blinding in the residual char layer.

Due to the inability of these filters to perform acceptably during episodes of small increases in process gas moisture, this type of candle is not considered a good candidate for the Wabash process.

Over the course of this study, there was no appreciable gain in resistance for the backup filter, V160. For this reason the filtration efficiency for these candles is deemed acceptable for the Wabash gasification process. 


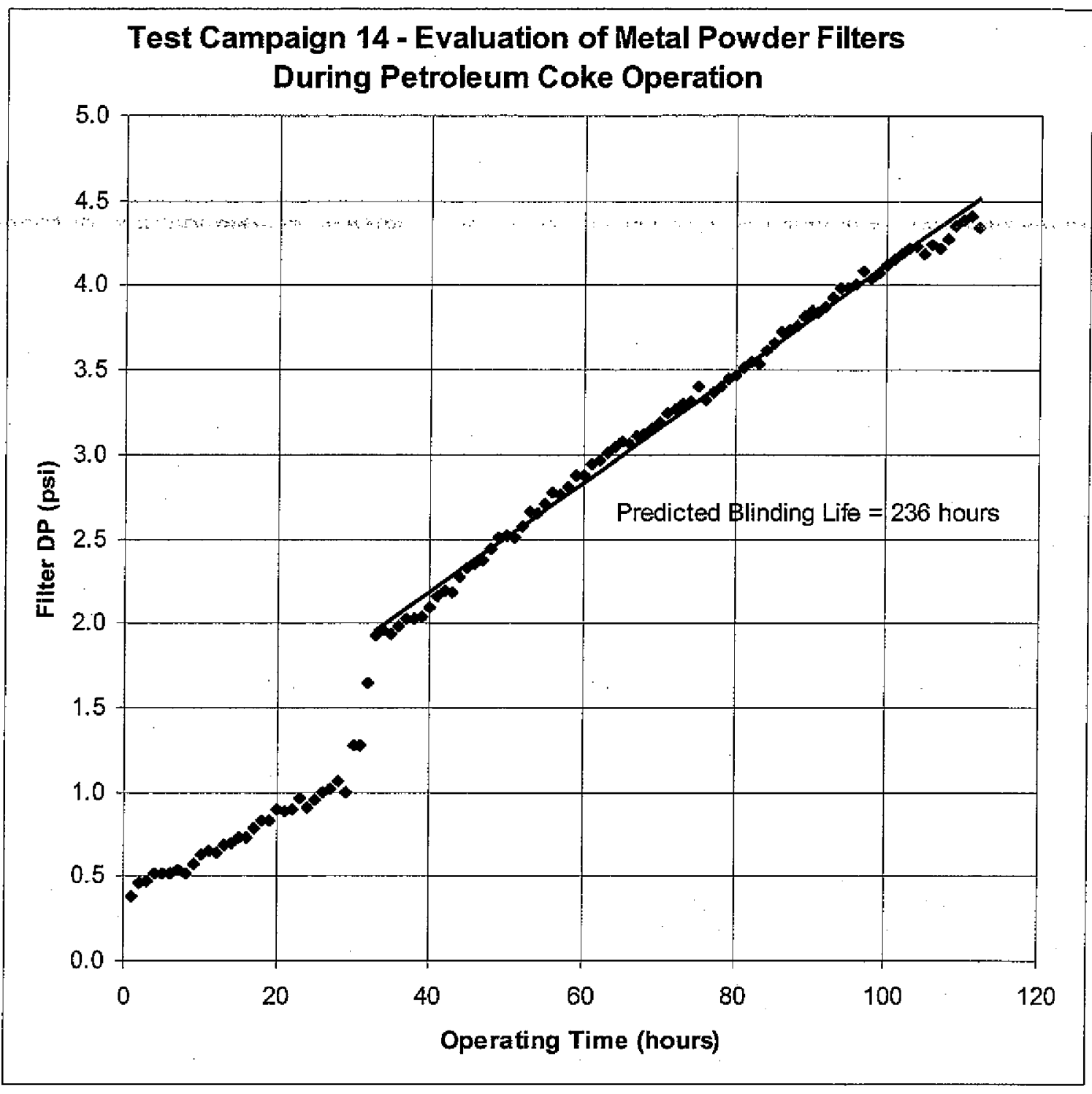

Figure 4.2.15.1: Test Campaign 14 - Evaluation of Metal Powder Filters During Petroleum Coke Operation 


\subsubsection{Test Campaign $15(12 / 11 / 00)$}

The fifteenth operating period for the slipstream unit was similar to the first and second campaigns. In this test the gas stream was again isokinetically sampled to determine solids loading in the commercial filters. This study differed in that the gasifier was now operating on a new type of petroleum coke. As in the first test, the data was used to validate process models. Char characterization data was also generated from this sample.

\subsubsection{Test Campaign $16(3 / 7$ to $4 / 3 / 01)$}

The sixteenth Slipstream test was structured to support the development of metal fiber type filters in the Wabash process (see objectives in Section 2.5.1).

In this study seven (7) 1.5-meter long candles containing metal fiber media were evaluated in the slipstream unit. They were constructed the same as filters operated in Test Campaign 10. The filters for this test had 2,347 hours of previous operation in the commercial process. After removal from the HGF, individual candles were subjected to two different cleaning methods to reduce the overall resistance in them. The candles were then installed in the Slipstream for evaluation. The test was planned for 500 hours of syngas operation. The actual test was 620 hours in duration.

Previous studies with this type of filter focused extensively on both corrosion and blinding (see Test Campaigns 8,10 and 13). Corrosion studies indicate the filters could potentially outlast their blinding life when operated in the commercial process. The life difference becomes even more significant when operating the system with upstream syngas cooler leaks. To address this issue and better optimize filter life, several methods of off-line cleaning were developed to lower process-induced resistance across the filters. Earlier evaluations had shown both methods to be quite effective on other types of candle filters.

The filters for this evaluation had operated in the commercial HGF process and were no longer able to provide another full campaign without reducing their overall resistance. The loss in filter permeability was directly attributable to syngas cooler leaks that developed during this operating 


\section{RESULTS}

time. Consequently, the primary focus was to evaluate filter cleaning efficiency and determine if it would promote corrosion in the filter media. Flow versus pressure drop was measured for the filters before and after cleaning. This data showed a substantial reduction in resistance for both cleaning methods. According to these measurements, the resistance was still $50 \%$ higher than a new filter but the overall reduction was significant. Slipstream resistance data at the onset of the campaign were also in agreement with the air flow measurements. Overall, both cleaning methods were found to be quite effective at recovering lost filter permeability.

Another key objective was to develop a blinding trend for the cleaned filters. Figure 4.2.17.1 shows the filter differential pressure as a function of time over the test period. The trend shows a sharp increase in filter resistance for the first 150 or so hours. At this point, the rate of rise is more gradual for the next 200 hours. Following this is an unexplainable sharp increase in resistance for a short period of time until it finally tapers off again. Assuming the first 150 hours of operation is a conditioning period and excluding this data, the blinding trend predicts a filter life of 5,572 hours. If it's assumed that the sharp increase in resistance between 300 and 400 hours of operation is an anomaly, a linear trend can be applied to the last 220 hours of the campaign. The trend is more linear in nature and it predicts a blinding life of 8,415 hours, which is more characteristic of blinding in a metal fiber filter. This prediction would better support the run hours required for filters used in the commercial process. The results demonstrate that cleaning is a viable option to optimize the life of these filters in the Wabash process.

Both cleaning methods require the filters to be submerged in aqueous type solutions. This was somewhat concerning since the media alloy is known to be highly susceptible to aqueous induced corrosion. Consequently, the study also focused on changes in the rate of corrosion that might occur during subsequent filter operation. After 620 hours of slipstream operation pre- and post-test filter specimens were submitted for analysis. An analysis performed by the filter manufacturer determined that both cleaning methods did induce some aqueous forms of corrosion. In fact, one method had caused a significant degree of attack in the candle media. The other caused only a minor penetration into the surface of the fibers in one localized area. There was no indication of accelerated corrosion induced by the process during post-clean

Slipstream Testing of Particulate Filters at the Wabash River Coal Gasification Project Final Report
DOE Award No. DE-FC26-97FT34158

June 2003

4-43 
operation. The results from this method were encouraging enough to scale up the study to the commercial process.

Over the course of this study, there was no appreciable gain in resistance for the backup filter, V160. Based on this observation, it was concluded that filtration efficiency was not affected by these cleaning methods. 


\section{Test Campaign 16 - Cleaning Method Evaluation for Metal Fiber Candles (New Alloy)}

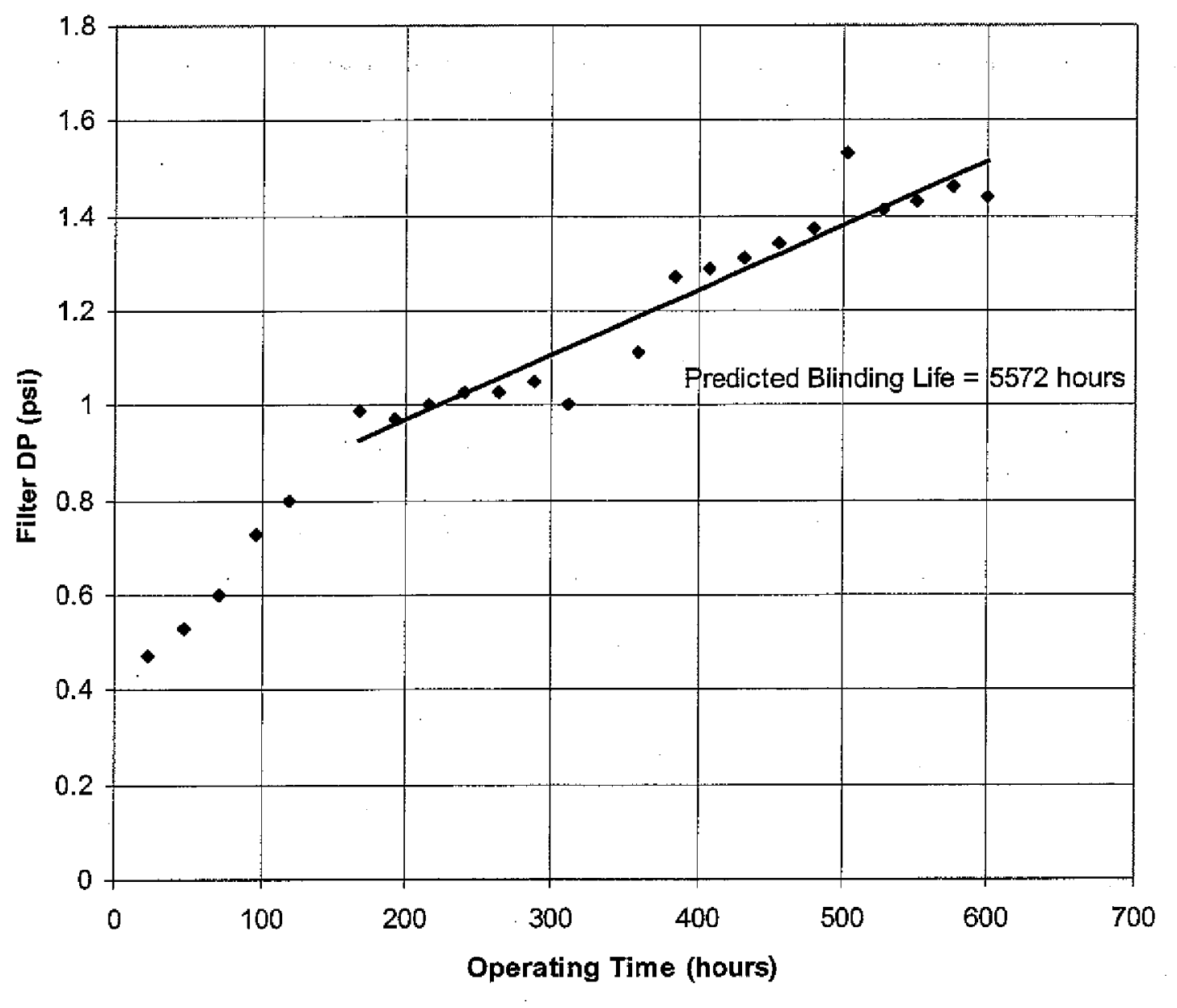

Figure 4.2.17.1: Test Campaign 16 - Cleaning Method Evaluation for Metal Fiber Candles (New Alloy) 


\section{RESULTS}

\subsubsection{Test Campaign 17 (7/14 to $7 / 21 / 01)$}

The seventeenth Slipstream test was structured to support the objectives stated for Test No. 17 in the original test matrix plan (see Table I-1 in Appendix I).

For this test two types of 1.5-meter long oxide composite ceramic filters were evaluated in the slipstream unit. They were obtained from separate manufacturers and both were different from oxide composites evaluated in earlier campaigns. The test was planned for 250 hours of syngas operation. The actual test lasted 188 hours in duration.

In most studies it's undesirable to mix different types of candle filters. Typically, a reliable blinding trend is not established when mixing different types of filters. The major reason for this is the variation in the flow resistance through each filter type. The result is a significant difference in the "instantaneous" face velocity immediately following the blowback cycle. The magnitude of this velocity has a significant affect on the formation and permeability of the residual char layer. This is substantiated by the fact that the permeability of the non-transient layer is directly affected by the blowback event, and more specifically, the force imparted by the high rate of forward flow that occurs immiediately thereafter. The high flow causes a greater compaction force in the residual layer that negatively affects its permeability. This can be dramatic for new filters that have the lowest overall flow resistance.

In this case, one supplier could only provide two candles for evaluation so an alternate test plan was needed. The clean resistance of both filters was calculated using air flow versus pressure drop data. The clean resistance in both filters was similar and for this reason it was deemed acceptable that they be tested together. The only caveat to this was that a general blinding rate could only be established for the filters that made up $75 \%$ of the vessel loading. To provide additional blinding data, the final resistance was measured for each candle during the post-test evaluation. 


\section{RESULTS}

Based on results from previous oxide composite studies, the D-158 supply pressure was reduced to 620 psig in an effort to minimize filter damage that might be caused by the blowback gas. Any further reduction might the blowback ineffective at cleaning the candle filters.

The study had to be concluded early due to char leaking through the primary candles. Damage was found in both candles supplied by the one manufacturer. It consisted of multiple areas in which the filtering layer had spalled off of the candle substrate. As in previous studies, it appears that the damage is a result of forces generated in the blowback gas. At the time of this writing the supplier evaluation of the failures is still pending. The other candles suffered no visible damage.

Figure 4.2.18.1 shows the filter differential pressure as a function of time for the test period. The trend yields a predicted life of 3,280 hours. For the five (5) filters tested, this prediction is likely somewhat low. Post-test air flow measurements showed the failed elements had twice the resistance of the others. This high rate of blinding would have negatively influenced the overall trend for the study. It's also difficult to assess how char leakage may have influenced the rate of blinding in all of the candles. Consequently, a new study utilizing only this type of filter (5) is recommended. The operating period should be sufficient to evaluate their robustness in the process.

There was no appreciable gain in V-160 resistance prior to the first 144 hours of the campaign. Based on this data, the filters should provide adequate filtration efficiencies given that the filtering layer remains intact.

Slipstream Testing of Particulate Filters at the Wabash River Coal Gasification Project Final Report
DOE Award No. DE-FC26-97FT34158

June 2003 


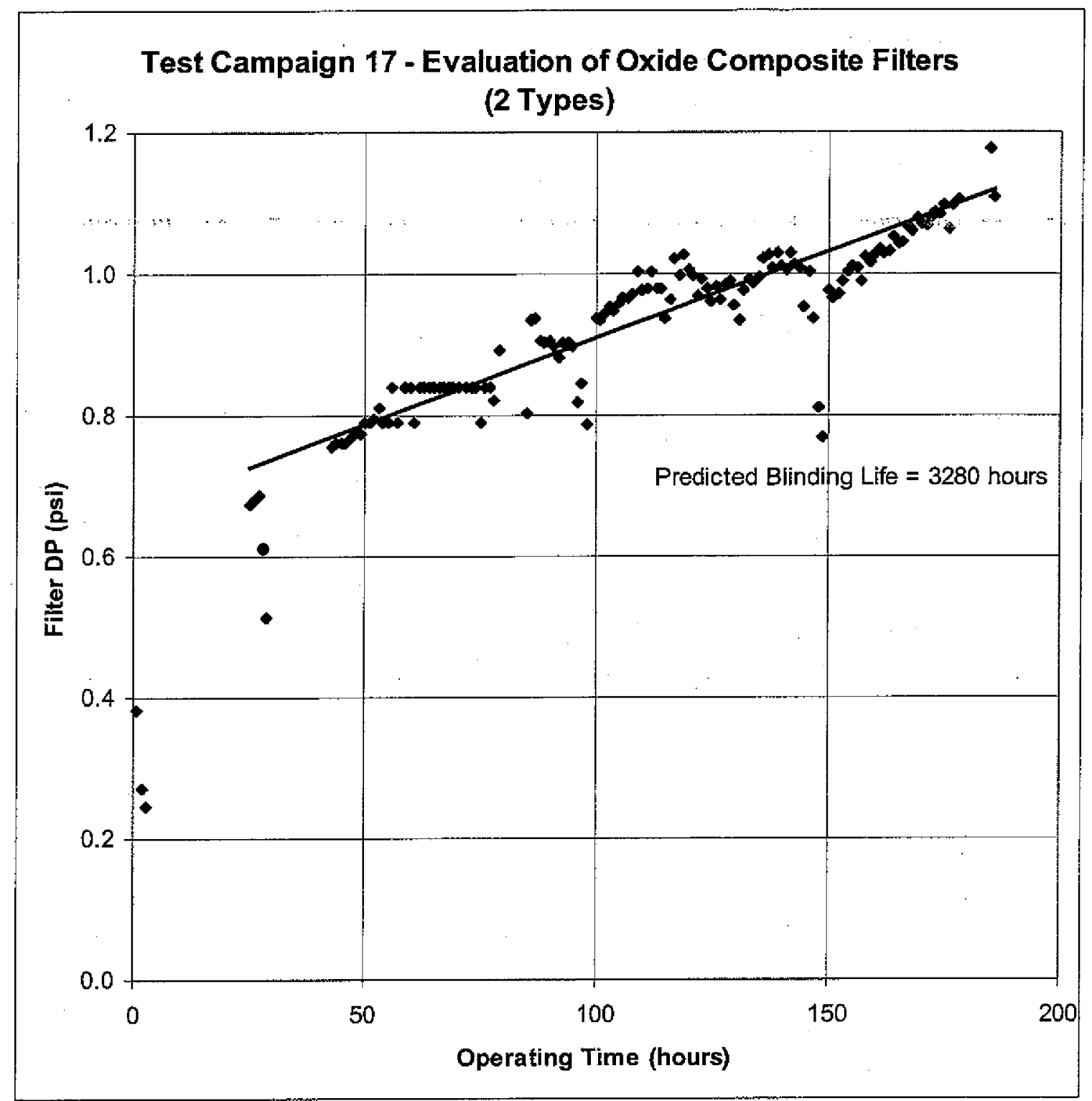

Figure 4.2.18.1: Test Campaign 17 - Evaluation of Oxide Composite Filters (2 Types) 


\subsubsection{Test Campaign $18(3 / 10$ to $3 / 11 / 03)$}

The eighteenth Slipstream test was configured to isokinetically sample the incoming syngas to the commercial HGF. The sample was collected with the gasifier operating on petroleum coke feedstock. The data provides a measurement of gas solids loading to compare with various types of gasifier feedstock and for process model validation. A portion of the char sample was submitted to Southern Research Institute for analysis. The data will be used to design a cyclone unit to be operated upstream of the Slipstream system. The study of a cyclone/hot gas filter particulate removal system is beimg performed under DOE contract DE-PS26-02NT41422-02: Test Campaign 18 was funded by this contract. It has been included in this report as additional slipstream test information. 


\subsection{CONCLUSIONS AND TECHNICAL INSIGHTS}

\subsection{Slipstream Validation}

Slipstream testing is a valuable tool for predicting filter behavior in the commercial process. Studies involving both metallic powder and fiber elements closely follow commercial HGF trends while operating with similar types of filters. The data trends for larger pore sized claybonded silicon carbide filters were similar as well. The agreement in filter behavior between the two systems is validation that the Slipstream is a useful tool to evaluate filters considered for the Wabash HGF process.

\subsection{Fail-safe Development}

A fail-safe system is a better option to contain char leakage in primary HGF. It provides extremely high HGF reliability and is significantly less costly to operate than a backup filtration system. The fail-safe system in use at the Wabash River facility was originally developed with the Slipstream unit. The fail-safe media will effectively plug and terminate gas flow in a leaking primary filter. Many of the concerns with fail-safe robustness, efficiency, resistance and blinding were addressed in slipstream studies. Longer-term evaiuations followed in the commercial process. After operating many fail-safes in excess of 10,000 hours they continue to show little evidence of pore blinding or corrosion. On numerous occasions, the fail-safes have effectively prevented char from leaking into the clean side of the commercial vessels. The devices are so effective that failures are typically concealed until post-filter inspections.

The fail-safe system selected for the Wabash facility has proven highly reliable and is a major reason that the commercial $\mathrm{HGF}$ process continues to operate with $100 \%$ reliability. It provides extremely low operating and maintenance costs and is highly resistant to both blinding and corrosion in the process. 


\subsection{Filter Development}

The Slipstream was used to support two types of filter programs that are in development at the Wabash facility. One involves finding the optimum metallic filter for the Wabash process and the other is focused on developing a reliable ceramic filter system. This section summarizes the conclusions and technical insights developed during the slipstream test program.

\subsubsection{Metallic Filters}

For the Wabash process, metal fiber candles offer the highest reliability and lowest operating costs when compared to metallic powder candles. This is primarily due to the lower rate of blinding that occurs in these filters while operating in process. They are less tolerant of corrosion, but by using newly developed alloys, sufficient process life can be achieved (in excess of $8,500 \mathrm{hrs}$ ). Some filters still in development indicate that corrosion life could far exceed 10,000 hours.

Most metallic filters are sufficiently constructed (robust) to provide high reliability in the process. Consequently, the two major life limiting factors are blinding (gradual loss of permeability over time) and corrosion. Most corrosion testing was conducted in the commercial HGF because it could easily be structured to minimize plant reliability risk, and offered optimum exposure times. Given this, limited corrosion data is included here. In the Wabash process, metal powder media exhibits a higher resistance to corrosion and a better ability to withstand moderate amounts of corrosion when compared to metal fiber media. It offers an exceptional corrosion life in the Wabash process. This is in part due to the sintering bonds of the metal powder being significantly larger than the fiber diameters of the metal fiber media. It also may have something to do with the manufacturing of the two medias. The metal powder media is annealed after construction and many of the fiber types are not. Residual stresses induced in the fibers as they are drawn may render them more susceptible to corrosion attack. The extremely small diameter of the fibers makes them incapable to withstand what would be considered insignificant rates of corrosion for most other equipment in this industry. Viable candidates for metal fiber candles in the Wabash HGF must be alloys that are virtually impervious to corrosion from the process gas. An extensive test program was used to identify a number of alloys as 
potential candidates capable of providing sufficient tesistance to process induced corrosion. Several of the most promising alloys have operated as test filters and have established corrosion rates predicting a filter life in excess of 10,000 hours. Recently, a number of new alloys have been drawn into media fibers and are in the early stages of the evaluation process. The preliminary results from these alloys are quite promising.

These studies indicate that corrosion is a major concern in metal fiber media when operating in the Wabash HGF process. However, due to recently developed media alloys, several types of metal fiber filters have demonstrated the ability to provide sufficiently high corrosion life, even in gas streams with a hydrogen sulfide content as high as $1.8 \%$.

Apart from corrosion, the next life-limiting factor for metallic candles is blinding. As stated earlier, blinding is an increasing resistance to flow across the filters during operation. For most candles, the resistance to flow is primarily in the residual char cake that builds on the candle surface. The cake typically extends into the first or second pore layer of the media. Studies indicate that permeability in the residual layer is reduced by a number of factors such as decreasing particle size and a deposition of trace elements within the layer. These can also be influenced by filter differential pressure and blowback frequency.

As mentioned earlier, metal fiber candles provide a lower blinding rate when compared to metal powder candles. Data trends from both the Slipstream and commercial processes have shown metal fiber candles can provide seven (7) times the blinding life of most metal powder filters. The higher void volume and thinner construction of the metal fiber media provides a less torturous path for the blowback gas to travel. This results in higher reverse flow energy available at the candle surface to more effectively regenerate the residual layer. It is believed that the filter typically operates with a thinner residual layer and that it is periodically removed when its resistance becomes sufficiently high. The construction of metal powder filters yields a lower void volume and thicker media resulting in a much more tortuous flow path through the media. This causes a significant pressure drop in the blowback gas resulting in lower reverse flow energy at the candle surface. This has a two-fold effect on filter blinding. First, the higher forward differential pressure drop increases the density of the char layer on the candle surface 


\section{CONCLUSIONS AND TECHNICAL INSIGHTS}

reducing its permeability. Secondly, the high reverse flow pressure drop renders the blowback energy incapable of "regenerating" any of the non-transient layer. It is believed that this layer becomes thicker and less permeable over time as smaller particles and trace elements migrate into its structure. Data has shown that trace elements strongly adhere to the filter surface and residual char layer as they condense out of the process gas. The combination of char layer densification, increase in thickness, reduction in particle size, and deposition of trace elements all contribute to the high rate of blinding in metal powder media while operating in the Wabash process.

The possible exception to this is the iron aluminide alloy powder candles tested in the slipstream unit. The test data provided a blinding trend comparable to that of most metal fiber candles. However, the iron aluminide candle is incapable of providing an adequate corrosion life in the process. It is interesting to note that the formation of trace element deposits on the outer surface of the iron aluminide filters does not seem to be as significant as in other metal powder media. The trace elements seem to have less of an affinity to form strong bonds to this type of material. In several instances, the residual layer spalled off the outer surface of the filters shortly after removal from the process. This behavior is not totally understood. It was noted that higher cleaning efficiencies (post HGF operation) resulted in the iron aluminide media when compared to filters of similar construction.

Evaluations using SEM/EDS analyses were conducted for metal powder filters previously operated in the Wabash process (coal operation) to determine causes for their high rate of blinding. Results from this study, show a number of trace elements to be deposited on the filter surface and in the residual char layer. The elements found included sodium $(\mathrm{Na})$, magnesium $(\mathrm{Mg})$, aluminum (Al), silicon (Si), sulfur (S), calcium (Ca), iron (Fe), zinc ( $\mathrm{Zn})$, germanium (Ge), cadmium (Cd), antimony ( $\mathrm{Sb}$ ), and titanium (Ti) with germanium being most prevalent. Most of these elements were strongly adhered to the particles in the char layer and on the candie surface.

The efficiency of both the metal powder and metal fiber char filters was found to be acceptable for long-term operation in the Wabash process. There has been no evidence of fail-safe blinding 
or particulate loading in downstream equipment when operating these filter types. Their filtration efficiency was never quantified due to an inability to isokinetically sample the clean gas downstream of the filter system.

\subsubsection{Ceramic Filters}

One of the most important factors in evaluating ceramic filter reliability is the robustness they demonstrate when operating in the process. In general, there were two types of filters evaluated in this study. They were variations of clay-bonded silicon carbide and oxide composites (CFOCcontinuous fiber ceramic composites). Over the course of these studies, the clay-bonded silicon carbide filters demonstrated perfect reliability in the process. In contrast, all but one oxide composite filter failed during operation in the Slipstream system.

The oxide composite filters were stated to have improved toughness in the process due to the continuous fibers used in their construction. For the most part, they demonstrated adequate structural strength during operation. The problem common to all but one oxide composite filter was the low bond strength of the filtering layer. In all filters that suffered damage, there were areas in which the membrane layer looked like it had spalled off during the blowback event. This type of problem persisted even after making significant reductions in the blowback pressure. Based on these results, all but one oxide composite filter was deemed incapable of providing adequate service in the Wabash process. However, the one surviving filter would need to be evaluated for a sustained period of time to determine its ability to resist the same mode of failure. In general, the strength of the filtering layer will need to be improved in these types of candles if they are to provide sufficient robustness in the E-Gas gasification process.

Several types of clay-bonded silicon carbide candles were evaluated in the slipstream unit. Utilizing the proper candle to tubesheet fixing device and bottom restraint system, all filters demonstrated exceptional robustness in the process. The primary focus was then shifted to identifying membranes that offered the best blinding rates. It was generally found that candles with the smallest mean pore size membrane provided the lowest rates of blinding. The vendor specified 5 micron mean pore membrane offered the best overall blinding trend and was found to 


\section{CONCLUSIONS AND TECHNICAL INSIGHTS}

be as good or better than any of the metallic candles evaluated. The reduced membrane pores had little affect on HGF baseline differential pressure. The 5 micron mean pore membrane was the smallest evaluated in this program. In subsequent studies it was discovered that the rate of blinding in these filters rose significantly for periods where the process syngas moisture was increased slightly above normal levels. The exact reason for this is not clearly understood. Analysis performed on the candles showed that the permeability loss was primarily constrained to the residual layer on the outer surface of the filter. The EDAX analysis again showed high concentrations of germanium within the layer. The residual layer was quite hard, compacted and strongly attached to the membrane material. The structure of this layer had an extremely low porosity. It is still not understood why the additional water vapor in the syngas results in this behavior. This phenomenon also has a negative affect on metallic filter blinding as well. Fortunately the negative affect is less dramatic for metal fiber candles.

For the most part, blinding trends could not be established for oxide composite filters. There was sufficient evidence to show that membrane spalling occurred faitly early in most campaigns and would have negatively influenced blinding behavior.

\subsection{Isokinetic Sampling}

The Slipstream proved to be a useful system for collecting an isokinetic gas sample of a highly particulate laden process gas stream. The unit was used to sample the syngas just upstream of the commercial HGF. The data obtained from these samples helped validate plant process models for various types of gasifier feedstock. Characterization of the various types of char will be useful for future plant designs. The char is also used in a number of cold flow studies to evaluate alternate filters and filter/cyclone systems.

\subsection{Filter Hardware Configurations}

One of the more important developments in the ceramic filter studies was a new filter fixing system that held the candle in the tubesheet and restrained its bottom movement. One of the major pitfalls in the original Wabash HGF was that the candles were free hanging. They were fixed at the top within the vessel tubesheet but could swing from side to side at the bottom. Flow

Slipstream Testing of Particulate Filters at the Wabash River Coal Gasification Project Final Report
DOE Award No. DE-FC26-97FT34158

June 2003

5-6 
induced forces caused the candles to swing and impact each other during process operation. On numerous occasions, the impact was sufficient to spall small pieces (chips) off the bottom of the filters and in some cases resulted in total candle failure (circumferential cracks). A new system was developed to restrain this bottom movement. It is not designed to rigidly hold the candle in place, but effectively restrains it so they can no longer impact each other. Also the system provides additional support that enables the filters to better withstand the negative affects of candle bridging. After Slipstream testing, the new design was successfully evaluated in the commercial HGF. The results have shown it should be a vital part of future ceramic HGF systems considered for the E-Gas process.

A new metallic filter fixing system was developed and tested in the slipstream unit. The system utilizes a new and unique method for fixing the filters and fail-safes within the vessel tubesheet. The new system saves significant time and labor for both the filter installation and removal processes. It also minimizes the risk of damaging filters during assembly. The design facilitates more effective cleaning with the candles fixed in the vessel tube sheets. The new system was purchased for the commercial HGF. Its utilization has yielded significant man-hour and plant downtime savings. 


\section{RECOMMENDATIONS}

\subsection{RECOMMENDATIONS}

1. When feasible, slipstream testing should be used to evaluate major process changes. It can accurately predict how changes may affect the process without risking plant production.

2. Slipstream testing at the Wabash facility has been used successfully to improve a number of systems within the process such as hot gas filtration and COS Hydrolysis. When possible, slipstream testing should be used for evaluating all new equipment or major modifications. It provides a low cost way to obtain meaningful data that can accurately predict performance in the process. Slipstream testing can be used to obtain the necessary operating data to ensure high reliability when starting up new equipment.

3. A Slipstream unit is better suited for initial evaluations of materials deemed too risky for testing in the commercial process. However, after the initial evaluation, long-term studies should follow in the commercial process using fail-safes as a filter backup.

4. It's better to conduct filter media corrosion studies in a commercial HGF. It provides the maximum amount of process exposure time, which is often required to obtain meaningful data. Since media corrosion is non-uniform (area specific), and material consumption rates are typically non-linear, it's important to perform these studies over a long period of time (preferably $8,000 \mathrm{hrs}$ or more). Specific procedures defining corrosion analysis methods should be developed and adhered to so that meaningful data comparisons can be made. For coupon testing, the best data is obtained using "flow-through" coupons that are attached to the outer surface of a HGF element.

5. It is recommended that fail-safe devices be used to contain leakage in primary hot gas filters instead of a backup filter system. A properly designed fail-safe system enables the HGF to provide $100 \%$ reliability. It's a low capital cost installation and requires minimal maintenance, especially when compared to a backup or secondary hot gas filter.

Slipstream Testing of Particulate Filters at the Wabash River Coal Gasification Project Final Report
DOE Award No. DE-FC26-97FT34158

June 2003

6-1 


\section{RECOMMENDATIONS}

6. In HGF systems where the potential for blinding is significant, metal fiber or reduced pore membrane SiC ceramic filters should be considered.

7. Filters that develop high resistance during operation can typically be removed from the process and cleaned using a hot aqueous solution. There are numerous methods commercially available. Evaluations should be made to determine cleaning efficiency and negative effects that might be induced by the process.

8. HGF slipstream vessels should be designed with ample clean side plenum space to incorporate testing of various fail-safe devices. The Wabash slipstream vessel had sufficient clean side volume for this testing but it did require some modifications to the blowback system.

9. Include redundant instrumentation for key operating parameters in the original design of a slipstream system. This is necessary to prevent losing critical operating data should an instrument problem develop.

10. Alarms should be incorporated into DCS control code to alert operations in the event of key operating parameter instrumentation failure. This should be considered for each instrument deemed impractical for redundancy. Detailed instructions should be provided to operations personnel that describe corrective actions to be taken when addressing these alarms.

11. Temperature indication should be included downstream of slipstream pressure relief devices. This along with vessel pressure indication can alert the operator of a lifting relief device. PSV relief indications, specifically pressure and temperature (temperature is less costly than flow indication), should be used to transfer the system into a safe shutdown mode. Downstream temperature measurement can also detect if the PSV properly reseats. This prevents erosion damage to the PSV from solids laden gas flowing through the device. Furthermore, critical DCS instrumentation and equipment should be 


\section{RECOMMENDATIONS}

programmed such that it cannot be placed in manual control without using the proper system interlocks.

12. All syngas and solids transport lines should have adequate nitrogen purge capabilities. All lines should be purged of syngas during the shutdown process. This is especially important for the solids transport line to prevent plugging problems that can occur after the system is cooled down.

13. All slipstream piping and equipment should be heat traced with a system designed to maintain normal process operating temperatures. It is important to maintain the slipstream process at commercial operating temperatures to obtain meaningful data.

14. All filter element supplier QA/QC manufacturing programs should be audited thoroughiy, and if necessary, customized by the buyer specifically to ensure they meet plant HGF reliability goals. In setting up a filter element QA/QC program, the supplier should fully understand the performance requirements of the customer's system. This was required several times to address manufacturing defects in filters and fail-safe devices tested at the Wabash facility.

15. Bottom restraint systems should be used to enhance the reliability of HGF systems that use free-hanging ceramic candles. Restraining filter bottom movement not only prevents damage from swinging candles impacting each other, it also helps prevent headpiece gasket attrition that can result from this type of movement. This system also renders candles much more capable of withstanding forces generated by solids bridging.

16. Continue fail-safe development for ceramic filters. Fail-safes are an integral part of a highly reliable ceramic HGF. A number of conceptual fail-safes designed to contain leakage in both the candle and candle gasket have been developed. The new designs should be evaluated for effectiveness in a slipstream process prior to using them in a commercial HGF. 


\section{RECOMMENDATIONS}

17. Additional blinding and corrosion studies should be conducted for higher chromium iron aluminide powder filter media.

18. Conduct additional research to determine why slight increases in syngas moisture can accelerate the rate of filter blinding.

19. Perform additional blinding studies on the newly developed thin-walled metal powder media filters. 


\section{REFERENCES:}

Alvin, M. A., 1996. Westinghouse Electric Corp., Unpublished results from evaluation of Destec Gasifier exposed metal and ceramic filters.

Boxal1, I., Cook, A. P., 1997 - 2001. Fairey Microfiltrex Ltd., Unpublished results from appraisal of filter media samples operated in the WREL gasification process.

June, M.R., 1998. Pall Advanced Separation Systems, Unpublished results from evaluations of metal powder filters operated in the WREL gasification process.

June, M. R., 2000. U. S. Filter, Unpublished results from filter media alloy evaluations in the WREL gasification process.

Seymour, P. T., 1996. Schumacher Filters America, Inc., Unpublished results from SEM analysis of blinding in DIA-SCHUMALITH filters.

Walch, A., 2000. USF Schumacher, Unpublished results from examination of a DIASCHUMALITH candle operated in the WREL gasification process.

McKamey, C. G., Tortorelli, P. F., Lara-Curzio, E., 2001. Oak Ridge National Laboratory, Unpublished results from examination of iron aluminide hot gas filters operated in the WREL gasification process.

Coyle, J., 1995 - 1999. Dynegy Power Corp., Unpublished results from evaluation of various metal filters exposed to the WREL gasification process.

Merrick, D. D., 1995 - 1997. Dow Chemical Co., Unpublished results from cold flow particulate filter evaluations.

Slipstream Testing of Particulate Filters at the Wabash River Coal Gasification Project Final Report
DOE Award No. DE-FC26-97FT34158

June 2003

Ref-1 


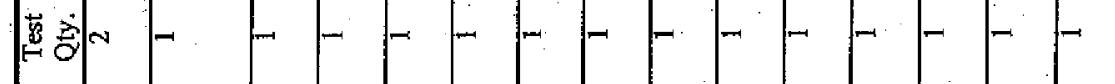

덤

\$뭉

焉

울

菅

따 룰

$\ddot{0}: \stackrel{2}{3}$

क्ष

들

स्

00

है

प

$m$.

幽: 号

E.

켸

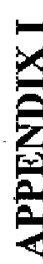

它

을

豆要

क 豆号

壱苨

愛总

票

볼

惑密

舜要

跑焉

홀

跑

$\because \bar{g}$

를

ก

을

$=\infty$

통

焉

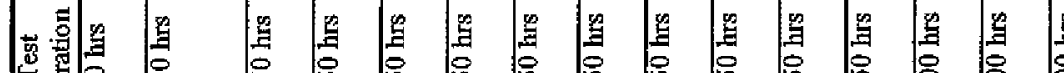

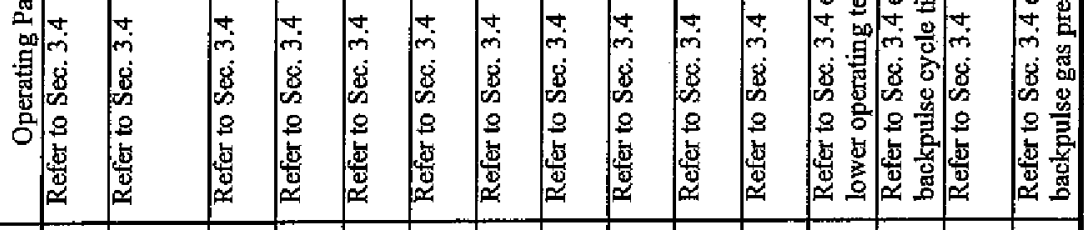

敦

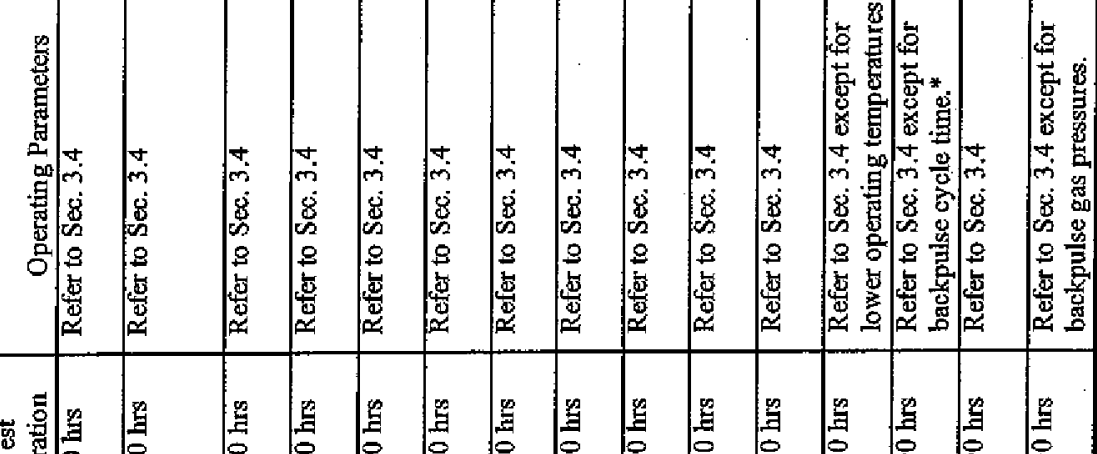

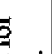

$\underset{3}{\not}$

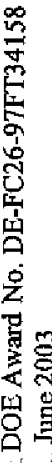

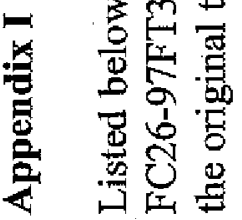

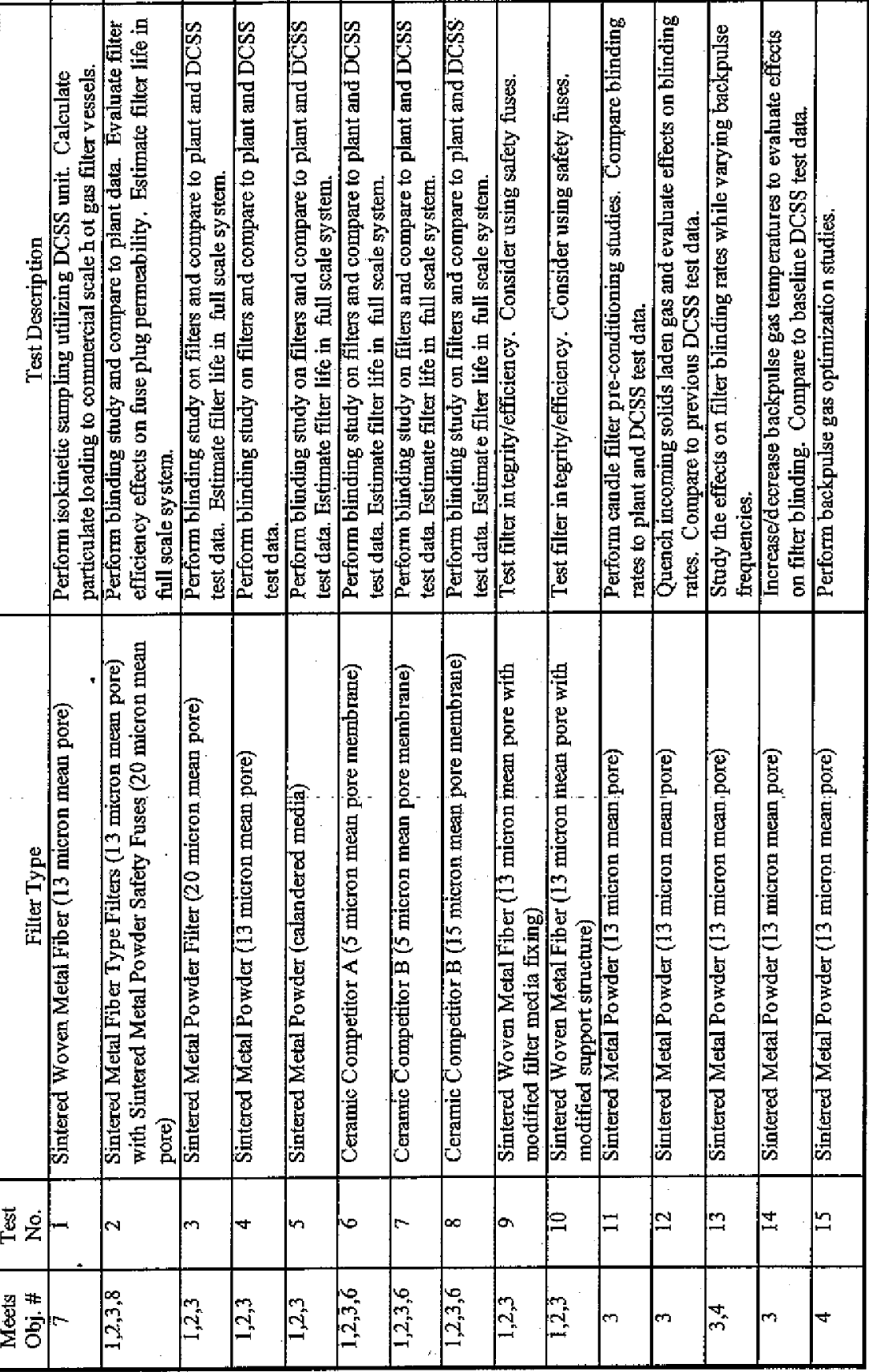

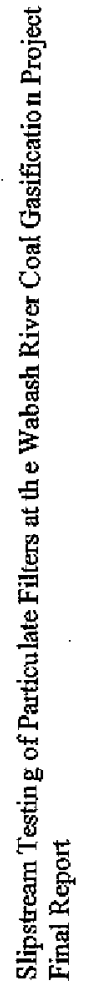





\section{APPENDIX II}

\section{Characterization of Field-Exposed Iron Aluminide Hot Gas Filters}


Claudette G. McKamey

Metals and Ceramics Division

Oak Ridge National Laboratory

P.O. Box 2008, MS-6115

Oak Ridge, TN 37831

Ph. 865-574-6917

Fax 865-574-7659

mckameycg@orn1.gov

Peter F. Tortorelli

Metals and Ceramics Division

Oak Ridge National Laboratory

P.O. Box 2008, MS-6156

Oak Ridge, TN 37831

Ph. 865-574-5119

Fax 865-241-0215

tortorellipf@ornl.gov

Edgar Lara-Curzio

Metals and Ceramics Division

Oak Ridge National Laboratory

P.O. Box 2008, MS-6069

Oak Ridge, TN 37831

Ph. 865-574-1749

Fax 865-574-6098

laracurzioe@oml.gov
David McCleary

Global Energy Inc.

444 West Sanford Ave.

West Terre Haute, IN 47885

Ph. 812-535-6097

Fax 812-535-6100

dpmccleary@GlobalEnergyInc.com

John Sawyer

Pall Process Equipment Development

3669 State Route 281

Cortland, NY 13045

Ph. 607-753-6041

Fax 607-753-8525

John_Sawyer@Pall.com

Roddie R. Judkins

Fossil Energy Program

Oak Ridge National Laboratory

P.O. Box 2008, MS-6084

Oak Ridge, TN 37831

Ph. 865-574-4572

Fax 865-574-4357

judkinstr@ornl.gov

\section{Characterization of Field-Exposed Iron Aluminide Hot Gas Filters}

\section{Keywords: hot gas filters, iron aluminides, microstructural analysis, mechanical strength}

\section{Introduction}

The use of a power turbine fired with coal-derived synthesis gas will require some form of gas cleaning in order to protect turbine and downstream components from degradation by erosion, corrosion, or deposition. Hot-gas filtration is one form of cleaning that offers the ability to remove particles from the gases produced by gasification processes without having to substantially cool and, possibly, reheat them before their introduction into the turbine. T'his technology depends critically on materials durability and reliability, which have been the subject of study for a number of years (see, for example, Alvin 1997, Nieminen et al. 1996, Oakey et al. 1997, Quick and Weber 1995, Tortorelli, et al. 1999).

Materials used in hot-gas filters are required to withstand prolonged exposure to corrosive, hightemperature gaseous environments, as well as to condensable vapors and solid species, some of 
which may have the potential for localized interaction with the filter material after extended times. The gas streams may be purely oxidizing (such as those produced by pressurized fluidized bed combustors, $\mathrm{PFBCs}$ ) or relatively reducing, in which the sulfur species are principally in the form of $\mathrm{H}_{2} \mathrm{~S}$, as in the case of the product gas from integrated gasification combined cycle (IGCC) processes or from carbonizers. Degradation of metallic filter elements has been observed under oxidizing, sulfidizing, and/or carburizing conditions and acts as a driving force for the development of ceramic hot-gas filters, particularly for the higher temperatures associated with advanced gasification and combustion designs. However, iron aluminides can also be considered for such applications because they offer reliability advantages over ceramic filters and typically have good to exceptional high-temperature corrosion resistance in a variety of sulfur-bearing environments relevant to coal-derived energy production systems (DeVan 1989, McKamey et al. 1991, DeVan and Tortorelli 1993, Tortorelli and DeVan 1996, Gesmundo et al. 1994, Natesan and Tortorelli 1997, Blough and Seitz 1997, Saunders et al. 1997a, Bakker 1998).

Metallurgical and mechanical evaluations of porous $\mathrm{Fe}_{3} \mathrm{Al}$-based alloys exposed in test beds that simulate envitonments associated with IGCCs and PFBCs have been conducted (Tortorelli et al. 1998, Tortorelli et al. 1999). Results for as-fabricated porous iron-aluminide filter materials showed good high-temperature corrosion resistance in air, air $+\mathrm{SO}_{2}$, and $\mathrm{H}_{2} \mathrm{~S}$-containing environments. The corrosion resistance was further improved by a preoxidation treatment. The hoop strength of the filters was not significantly affected by the preoxidation treatment or by $100-\mathrm{h}$ exposures in air or air plus $\mathrm{SO}_{2}$ at 800 and $900^{\circ} \mathrm{C}$. The purpose of the current study was to extend such evaluations to iron-aluminide filters that have been exposed in an actual gasification plant. As described below, iron-aluminide filters showed good performance under plant conditions when preoxidation was effective in establishing a thin, protective surface alumina.

\section{Experimental Procedures}

Sintered iron aluminide filter elements have been used for hot-gas cleaning at Global Energy Inc.'s Wabash River (Indiana) gasification plant. These cylindrical ( $\sim 58 \mathrm{~mm}$ outer diameter, $2 \mathrm{~mm}$ wall thickness) elements were fabricated by Pall Corporation (Cortland, NY) from water-atomized alloy powder produced by Ametek Specialty Metals Division (Eighty-Four, PA). The composition of the powder was nominally $\mathrm{Fe}-28$ at. \% Al-2\% $\mathrm{Cr}-0.1 \% \mathrm{Zr}$ (FAS-Zr). Several pieces of FAS-Zr elements were supplied by Global Energy, Inc. to Oak Ridge National Laboratory after use in the Wabash River Plant's clean-up system. In other cases, o-ring specimens (width of approximately $12.7 \mathrm{~mm}$ ) were cut from as-fabricated Pall elements, inserted into the filter system at. Wabash River for various lengths of operating time, and then returned to ORNL for evaluation. (The general exposure conditions are listed in Table I.) The elements from which the specimens were cut were usually fabricated of FAs. Zr, but in a few cases, o-rings of an FAL alloy composition (Fe:28 at.\% $\mathrm{Al}-5 \% \mathrm{Cr}-0.1 \% \mathrm{Zr}$ ) were exposed. During these exposures, the filter materials were exposed to gas produced by combustion of either coal or petroleum coke at temperatures estimated to be in the range of $450-500^{\circ} \mathrm{C}$ (see Table I). Note that, in the case of the o-rings, specimens were either placed directly in the filter vessel (dirty-gas side) or in the plenum that routes the filtered gas from the element bundles (clean-gas side). 
Evaluation of filter materials included mechanical testing of o-rings by internal pressurization to determine tangential (hoop) stress-strain behavior. The o-rings tested in this manner were from the specimens exposed as such (see above) or were cut from the pieces of actual filter elements received from the Wabash River plant. The internal pressurization tests were conducted in ambient air either by subjecting an elastomeric insert (for as-fabricated filter samples) to axial compression at a constant displacement rate of $2 \mathrm{~mm} / \mathrm{min}$ or by use of a positive radial-displacement wedge mechanism (for the field-exposed filter samples) (Lara-Curzio 1999). After mechanical testing, the fracture surfaces were examined using scanning electron microscopy (SEM) and pieces were cut from the o-rings for microstructural analysis using optical and SEM, energy dispersive $\mathrm{x}$-ray spectroscopy (EDS), electron microprobe, and Auger electron spectroscopy.

\section{Results}

\section{As-fabricated Filter Materials}

The as-fabricated filter materials were examined by quantitative image analysis of polished sections. It was determined that they were $40-50 \%$ porous with sintered ligaments that ranged between 1 and $30 \mu \mathrm{m}$ in thickness with a mean value of approximately $9 \mu \mathrm{m}$. There were numerous oxide particles on pore surfaces (Fig. 1) and at the boundaries of agglomerated powder particles (Tortorelli et al. 1998). Qualitative analysis by EDS showed that these particles were most likely alumina and zirconia. These oxides form during the water atomization process and most likely coarsened during subsequent processing. After preoxidation at $800-1000^{\circ} \mathrm{C}$, the original oxide particles were still clearly evident and a thin protective alumina scale had formed on the metal surfaces. (Pall typically preoxidizes the iron-aluminide filter elements.) Depth profiling by Auger electron spectroscopy showed that the alumina scale formed by preoxidation at $800^{\circ} \mathrm{C}$ averaged approximately $2 \mu \mathrm{m}$ in thickness, but could vary between 0.5 and $3 \mu \mathrm{m}$. Filters with oxide layers in this thickness range were gray in color. A filter element with various shades of blue also was used to provide o-ring specimens for exposure at the Wabash River Plant. This coloration would indicate a thinner alumina film was formed during preoxidation and, indeed, Auger analysis determined that the oxide coating on the pore surfaces of the blue filter was approximately $0.2 \mu \mathrm{m}$. An as-fabricated filter without preoxidation was similarly analyzed and was found to have an alumina layer that was no more than several hundredths of a micron thick.

Determination of the room-temperature tangential stress-tangential strain curves using the elastomeric-insert-internal pressurization approach showed that, when allowance is made for the reduced load-bearing area, the measured strengths of the porous iron aluminides appear to be consistent with those for similar dense alloys (McKamey et al. 1991). The average fracture strength for o-rings cut from two as-fabricated filter elements (IA-187, IA-188, three specimens each) was approximately $2 \mathrm{kN}$ (Table I). Microscopy of the ruptured o-rings showed that failure was transgranular through the fully sintered ligaments and the fracture surfaces were free of oxide particles (Fig. 1). As such, the fracture surfaces were typical of the ductile failures observed for fully dense iron aluminide (McKamey et al. 1991). Preoxidation at $800^{\circ} \mathrm{C}$ for $7 \mathrm{~h} \mathrm{had} \mathrm{no} \mathrm{influence} \mathrm{on} \mathrm{the}$ hoop strength of the FAS-Zr filter material (Tortorelli et al. 1998). 
Two different samples of the DC-20 filter, exposed for $574 \mathrm{~h}$ in the filter vessel at the Wabash River plant, were examined (Table I). The porosity in this filter was non-uniform, with the sample in Fig. 2a showing normal porosity, while the sample in Fig. $2 \mathrm{~b}$ had less porosity over the inner half of the filter. A light deposit containing $\mathrm{S}, \mathrm{As}, \mathrm{Ge}, \mathrm{Si}, \mathrm{Cu}, \mathrm{Sb}, \mathrm{C}, \mathrm{Zn}, \mathrm{Ca}, \mathrm{K}, \mathrm{P}$ was observed on the outer surface (that is, the gas inlet side of the filter wall) of both samples. Very little deposit was present on the inner (gas outlet) surface.

The DC-36 filter saw the same exposure conditions as the DC-20 filter, but for a longer time (1565 h). The porosity in this filter was non-uniform, with the inner one-third of the filter having much less porosity than normal (like that shown for DC-20 in Fig. 2b). The outer surface of the filter (at the top in Fig. 2b) contained a light-to-medium deposit consisting of $\mathrm{As}, \mathrm{Ge}, \mathrm{S}, \mathrm{Si}$, and $\mathrm{O}$, while the inner surface had a very light deposit of mostly $S$ and $C$. Pore surfaces in the interior of the filter were covered with an Al-O product approximately $2 \mu \mathrm{m}$ thick. Corrosion due to the exposure was not substantial.

Filter element DC-88 was exposed in the vessel at Wabash River for $2185 \mathrm{~h}$. As shown in Fig. 3 , microstructural examination indicated that many of the pores in approximately the outer $750 \mu \mathrm{m}$ of the filter (top in Fig. 3), as well as approximately $300 \mu \mathrm{m}$ from the inner surface, were almost completely filled. In addition, layers of corrosion products approximately 100 and $50 \mu \mathrm{m}$ thick were observed on the outer and inner surfaces, respectively. These layers appeared to be growing outward from the filter, since the wall thickness after exposure was about $200 \mu \mathrm{m}$ greater than before exposure. The fracture strength of this filter element, along with that of DC-36 above, was less than that of the DC-20 and as-fabricated filters (see Table I).

The microstructure and composition of the DC-88 filter element after exposure was characterized using an electron microprobe. Figure 4 shows that the occluded filter region near the outer surface was composed of basically two phases: an Al/Cr-based oxide (see Figs. 4c,f) and an Fe-based sulfide (see Figs. 4b,e). The layer that formed outward from the surface was Fe-S. No areas of $\mathrm{Fe}_{3} \mathrm{Al}$ were detected in this $750-\mu \mathrm{m}$ region near the outer surface, indicating that the entire original Fe-AI-Cr matrix in this area had been consumed by corrosion. The $\mathrm{Cr}$ in the original filter material appears to have been incorporated predominantly into the oxide phase (see Fig. 4d). Microprobe analysis showed that the Fe-S layer on the surface also contained many other elements and particles filtered from the gas stream, including oxides of $\mathrm{Al}$ and $\mathrm{Si}$, as well as $\mathrm{Ni}, \mathrm{Zn}, \mathrm{Ca}, \mathrm{K}, \mathrm{Ge}, \mathrm{As}$, and $\mathrm{Sb}$. The occluded region of the inner surface (that is, the outlet side of the filter wall) was also composed of $\mathrm{Fe}-\mathrm{S}$ and an A1/Cr-based oxide, with a surface layer of Fe-S. The layer also contained a significant amount of As and some $\mathrm{Ni}$, but few, if any, of the other elements that were observed on the outer surface. In the transition regions of the filter, between the completely occluded regions and the porous original matrix still present toward the center of the filter, some of the Fe-Al-Cr matrix phase was detected along with the Fe-S and oxide phases. Figure 5 shows a micrograph and an $x$-ray scan taken across such a region. The $x$-ray data revealed the light and medium contrast phases to be Fe-Al-Cr and Fe-S, respectively. The composition of the Fe-Al-Cr phase shown in the $\mathrm{X}$-Tay scan is approximately the same as the otiginal filter material, (i.e. Fe-28Al-2Cr), while the composition of the Fe-S phase indicates that it is most likely FeS. A spike in the $\mathrm{Al}$ and $\mathrm{O}$ levels and 
a decrease in the Fe level at the interface between these two phases indicate that an oxide layer is still present on the surface of the Fe-Al-Cr particle; presumably it is the $\mathrm{Al}_{2} \mathrm{O}_{3}$ layer produced by preoxidation. The dark phase is a complex oxide containing $\mathrm{Fe}, \mathrm{Al}, \mathrm{S}$, and $\mathrm{Cr}$. The layered structure of that phase shown in Fig. 5a and the composition shown in Fig. 5b suggest that it may be an intermediate phase between the Fe-Al-Cr matrix and the FeS/oxide structure present nearer the outer and inner surfaces of the filter.

\section{Specimens Exposed as O-rings}

As described in the Experimental Procedures section, o-ring specimens were cut from as-fabricated filter elements and then exposed on the clean- or dirty-gas side of the Wabash River Plant's filtration system. Three o-rings were exposed on the clean-gas side of the filter system without preoxidation: IA-188 for $1628 \mathrm{~h}, \mathrm{IA}-187$ for $2237 \mathrm{~h}$ and another o-ring of IA-187 for $3865 \mathrm{~h}$. Figure 6 compares the microstructures of these three filter o-rings after exposure. All three o-rings appeared to be blocked with reaction products, with only a small percentage of the pores open toward the outer and inner surfaces of the filter exposed for $1628 \mathrm{~h}$. Higher magnification of the center areas of these filters shows the presence of three main phases (the three levels of contrast in Fig. 7), with the lighter contrast phase (the Fe-Al-Cr matrix) gradually disappearing with time. Analysis of these three phases using EDS showed that, with continued exposure, the Fe-A1-Cr matrix was gradually being converted into oxide and $\mathrm{Fe}-\mathrm{S}$ products (the dark and medium contrast phases, respectively, in Fig. 7). Higher magnification SEM (Fig. 8) and EDS showed that heavy elements in the coal gas (e.g., As, Ge, Sb) tend to become trapped in the Fe-S phase. For example, the very bright spots in Fig. 8 are particles of As in the Fe-S phase. The results of internal pressurization tests of o-rings from the IA-187 filter exposed for $2237 \mathrm{~h}$ showed that the strength was reduced by approximately half in comparison to the as-fabticated filters (Table $\mathrm{I}$ ).

O-rings from filter elements that had been preoxidized for $7 \mathrm{~h}$ at $800^{\circ} \mathrm{C}$ were exposed on the cleangas side of the filter system (Table I): DC-207 for $1988 \mathrm{~h}, \mathrm{IA}-191$ for $2237 \mathrm{~h}$, and DC-205 for $4335 \mathrm{~h}$. The o-rings exposed for 2237 and $4335 \mathrm{~h}$ were in very good condition, with no surface deposits, no reduction in strength, and only minor $\mathrm{Fe}-\mathrm{S}$ formation throughout the filter. Their microstructures were similar to that observed for the typical unexposed filter (as in Fig. 2a). However, gas flow in the DC-207 o-ring, which had been exposed for only $1988 \mathrm{~h}$, was completely -blocked by the formation of almost solid-bands of corrosion products on the outside and inside surfaces (see Fig. 9), in addition to corrosion products scattered throughout the interior of the filter (Fig. 10). High magnification SEM (Fig. 9b) and EDS (Fig. 9c) indicated again that the Fe-Al matrix was being converted into Fe-S and oxide products. These results and the results of other analyses discussed above suggest that the iron diffuses outward to fill the pores with $\mathrm{Fe}-\mathrm{S}$, a conclusion that has also been reached by others (Bakker and Stringer 1997). The corrosion products formed throughout the thickness of the filter and Fig. 10 shows the Fe-S growing inside the pores in the center of the DC-207 filter.

As part of the study of preoxidation conditions, two o-rings (from filter IA-141) that were preoxidized at $1000^{\circ} \mathrm{C}$ were exposed for 2237 and $3865 \mathrm{~h}$ on the clean-gas side of the plant's filtration system. The microstructures of the o-rings exposed for 2237 and $3865 \mathrm{~h}$ were similar to those shown in Fig. 6a,b. Both o-rings appeared to be blocked to the flow of gas although the one exposed for 
$2237 \mathrm{~h}$ still had a noticeable number of unblocked pores. Each had layers of Fe-S on both surfaces, the thickness of which approached $100 \mu \mathrm{m}$. High magnification SEM showed an increase in corrosion products and a decrease in the amount of $\mathrm{Fe}$-Al matrix with increasing exposure time, as was shown for the as-fabricated filters in Fig. 7.

As described above, a filter element with a thinner (blue) preformed oxide layer on pore surfaces was used to provide o-ring specimens for exposure at the Wabash River plant. After plant exposure for $1988 \mathrm{~h}$, the o-rings cut from the blue filter (o-rings DC-208 and -211 in Table I) contained only small amounts of corrosion product regardless of location on the clean- or dirty-gas side and their microstructures were similar to that of the as-fabricated filter shown in Fig. 2a. In contrast, o-rings from the gray preoxidized filters exposed at the same time for the same length of time (o-rings DC$209,-210$ in Table I) were almost completely blocked by the formation of Fe-S and oxide products (Fig. 11). The presence of such a large amount of the more brittle corrosion products resulted in significantly reduced fracture strengths for the gray o-ring specimens $(0.9-1.5 \mathrm{kN}$, Table $\mathrm{I})$.

Four FAL (see Experimental Procedures section) o-rings were included in the various exposures at the Wabash River Plant and the results are listed at the end of Table I. All the exposed FAL o-rings, whether exposed for $6212 \mathrm{~h}$ on the clean-gas side or for $4335 \mathrm{~h}$ on the dirty-gas side, exhibited minimal amounts of corrosion products. As expected, the surface deposits on the o-rings exposed on the dirty-gas side were much thicker than on the o-rings exposed on the clean-gas side, but this thicker surface deposit did not affect the appearance; strength (Table I), or filtering capacity of the FAL o-rings.

\section{Strength Measurements}

Examination of the strength data reported in Table I indicates an inverse correlation between the amount of sulfidation observed and the fracture stress of the o-ring during loading by internal pressurization. The hoop-strength data, albeit limited, when combined with the microstructural analyses, qualitatively indicate that the iron-aluminide filters maintain approximately their original strength as long as Fe-S formation has not occluded more than approximately $50 \%$ of the pores.

\section{Discussion}

Evaluation of specimens from plant exposures is complicated by variations in operating conditions from one run to another. Both coal and petroleum coke (higher sulfur content) were used as fuel during the exposure sequences and the temperature was not necessarily the same in each run (probably ranged between 450 and $550^{\circ} \mathrm{C}$ ). In addition, many of the longer exposure times were actually made up of as many as three different campaigns between which the specimens were exposed to unknown lengths of downtime and any possible corrosion associated with such (Bakker 1998, Bakker and Stringer 1997, Saunders et al. 1997b). Nevertheless, this work has yielded some important information about the nature of corrosion of iron aluminides in an operating gasification plant and the effects of composition and preoxidation.

Iron aluminide alloys rely on a thin alumina scale for protection against corrosive environments at high temperatures. For this application, filter elements are normally preoxidized at temperatures 
much higher than the gasification filtration unit to assure that a protective alumina film forms. This scale has been observed on preoxidized elements (see above and Tortorelli et al. 1998). In this work, o-ring specimens cut from filters that were not preoxidized and from an element preoxidized at $1000^{\circ} \mathrm{C}$ were found to be fairly heavily corroded after as little as $1628 \mathrm{~h}$ of exposure (see results for IA-141, -187 and -188 in Table $I$ and Figs. 6-8). In contrast, with one exception (DC-207), the o-rings preoxidized at $800^{\circ} \mathrm{C}$ were still not filled with corrosion products after $4335 \mathrm{~h}$ (see results for IA-191, DC-205, -207 in Table I and Fig. 9). Even in the case of DC-207, corrosion was not as severe as in the absence of preoxidation; its fracture strength (which generally tended to decrease with increasing corrosion - see Table I) was equal to the starting material. These results show the importance of the formation of a continuous alumina layer in assuring corrosion resistance during operation of the gasifier and reinforce the need for appropriate and reproducible preoxidation in this regard. [Presumably, the poorer performance of actual filter elements used in the early phases of this study (e.g., DC-88) may have been due to nonoptimal preoxidation.] Preoxidation at $1000^{\circ} \mathrm{C}$ was not as effective as that done at $800^{\circ} \mathrm{C}$. In another study (Pint 2000 ), the $1000^{\circ} \mathrm{C}$ preoxidation treatment was found to result in an alumina layer on the filter that was locally disrupted by large zirconia particles and not uniformly continuous and thin. Because of this (and Al depletion concerns - see below), it would not be expected to be as protective as the one formed by preoxidation at $800^{\circ} \mathrm{C}$.

Corrosion failure in these filter materials appeared to be associated with the formation of Fe-S inside the pores of the filter. This may mean that sulfidation is kinetically favored under thse exposure conditions. However, as described above, Al-containing oxide products were always observed in conjunction with the sulfides. This observation is consistent with a type of breakaway oxidation (sulfidation) in which aluminum is locally depleted by growth of alumina so that, after some point, if the protective scale is breached, iron sulfides form relatively rapidly. The thinness of the ligaments of the filters (mean diameter of $9 \mu \mathrm{m}$ ) magnifies the importance of aluminum depletion/breakaway as the degradation mode because there is a relatively small volume of this element available to form the protective alumina (Quadakkers and Bongartz 1994). This suggested mechanism can explain the better performance of the blue filter materials vis-à-vis the gray ones; Auger analyses have shown a thinner alumina film on the blue material (see above), thereby indicating a greater starting residual aluminum content in the alloy at the time of exposure. The higher aluminum content will increase the time to sulfidation (breakaway). In the same way, the amount of residual aluminum in the filter material preoxidized at $1000^{\circ} \mathrm{C}$ could be less than what is found in the specimens preoxidized at $800^{\circ} \mathrm{C}$ and may explain the greater corrosion susceptibility of the former.

The comparison of results from the specimens placed on the dity- and clean-gas sides, respectively, of the filtration system at the Wabash River gasification plant provides important supporting information regarding the corrosion failure mechanism. As expected, deposits were heavier for those specimens exposed on the dirty-gas side (Table D). However, the extent of corrosion (formation of Fe-S, see above) did not depend on specimen placement. This observation is consistent with the sulfidation degradation mode described above and indicates that the cortosion mechanism is associated with gaseous sulfur and oxygen species rather than the char per se. 
As described in the Results section, the preoxidized FAL (Fe-28\% Al-5\% Cr-0.1\% Zr) o-rings were not substantially degraded after exposure for up to $6212 \mathrm{~h}$ on the clean-gas side and up to $4335 \mathrm{~h}$ on the dirtyngas side of the filtration system - only a relatively small amount of $\mathrm{Fe}-\mathrm{S}$ was observed. In contrast, after approximately $2000 \mathrm{~h}, \mathrm{Fe}-\mathrm{S}$ was already starting to form in preoxidized filter o-tings made from FAS-Zr powder. Higher chromium concentrations in $\mathrm{Fe}_{3}$ Al-based alloys degrade sulfidation resistance at higher temperatures (DeVan 1989, DeVan and Tortorelli 1993), but may play a beneficial role in this lower temperature gasification plant environment by promoting alumina formation in cases where the oxidized layer is disrupted and/or by improving corrosion resistance at ambient temperatures during downtime (Buchanan et al. 1996). Effects of downtime corrosion can significantly negatively affect subsequent elevated temperature sulfidation (Bakker and Stringer 1997, Saunders et al. 1997b) and may have played a role in the present case for those specimens that saw more than one run cycle during plant exposure. For these reasons, an aluminaforming FeCrAl type of alloy $(20 \% \mathrm{Cr}-5-10 \% \mathrm{Al})$ may offer better overall corrosion resistance at the relatively low operating temperatures of the gasification filter system.

\section{Summary and Conclusions}

Because of their good to excellent high-temperature corrosion resistance in sulfur-bearing environments, iron aluminide alloys are being evaluated as a potential material of construction for metallic filters to be used to clean fossil-fuel-derived gases prior to their introduction into gas turbines. Iron-aluminide filter-element or o-ring specimens have been characterized after exposure at the Wabash River Plant for times of approximately 400 to $6200 \mathrm{~h}$. Several variables appear to be important to the length of service of these filters, including the preoxidation conditions during fabrication of the filter, time and temperature of exposure, and composition of the iron aluminide. The general mode of corrosion failure involves the formation of iron sulfide that grows into and occludes the pores, resulting in blockage of the filter and reduction in mechanical strength. This process appears to be accelerated at longer exposure times, possibly due to the depletion of aluminum from the filter alloy matrix and the resulting breakdown of the protective alumina layer and its inability to reform. However, with appropriate preoxidation treatments (those that produce a thin protective surface alumina), iron-aluminide filters can have extended lifetimes in coal-derived synthesis-gas environments.

A comparison of o-rings exposed on the clean- and dirty-gas side of the unit showed similar corrosion rates and indicated that the heavier surface deposits produced during exposure on the dirty-gas side does not affect the corrosion process to a significant degree. The filter material of iron aluminide with a higher chromium content tended to experience less degradation. One of these showed good resistance to $6212 \mathrm{~h}$. The limited hoop-strength data generated to date have shown that iron-aluminide filters maintain their original strength as long as Fe-S formation has not occluded more than approximately $50 \%$ of the pores.

\section{Acknowledgements}

This work at Oak Ridge National Laboratory was sponsored by the Office of Fossil Energy, Advanced Research Materials Program, U.S. Department of Energy under Contract DE-AC05- 
00OR22725 with UT-Battelle, LLC. The authors thank J. A. Horton and B. A. Pint for comments on the manuscript and D. N. Braski, H. L. Meyer, and L. R. Walker for their Auger and microprobe analyses.

\section{References}

Alvin, M. A., 1997. Performance and Stability of Porous Ceramic Candle Filters During PFBC Operation. Mater at High Temp. 14: 285-94.

Bakker, W. T., 1998. Corrosion of Iron Aluminides in HCl Containing Coal Gasification Environments. Corrosion/98, NACE Intern., Houston, TX: paper number 185.

Bakker, W. T., and Stringer, J., 1997. Mixed Oxidant High Temperature Corrosion in Gasifiers and Power Plants. Mater. High Temp. 14: 35-42.

Blough, J. L., and Seitz, W. W., 1997. Fireside Corrosion Testing of Candidate Superheater Tube Alloys, Coatings, and Claddings - Phase II. Proc. of Eleventh Annual Conference on Fossil Energy Materials, Oak Ridge National Laboratory, Oak Ridge, TN: 357-366.

Buchanan, R. A., Kim, J. G., Ricker, R. E., and Heldt, L. A., 1996. Ambient Temperature Corrosion and Corrosive Sensitive Embrittlement. Oxidation and Corrosion of Intermetallic Alloys, Purdue University, West Lafayette, IN: 351-419.

DeVan, J. H. 1989. Oxidation Behavior of $\mathrm{Fe}_{3} \mathrm{Al}$ and Derivative Alloys. Oxidation of High-Temperature Intermetallics, The Mineral, Materials, and Metals Society, Warrendale, PA: 107115.

DeVan, J. H., and Tortorelli, P. F., 1993. Oxidation/Sulfidation of Iron-Aluminum Alloys. Mater. High Temp. 11:30-35.

Gesmundo, F, et al., 1994. Corrosion of Fe-Al Intermetallics in Coal Gasification Atmospheres. Materials for Advanced Power Engineering, Kluwer Academic Publishers: 1657-67.

Lara-Curzio, E., 1999. Oak Ridge National Laboratory, Oak Ridge, TN, unpublished results.

McKamey, C. G, DeVan, J. H., Tortorelli, P. F., and Sikka, V. K., 1991. A Review of Recent Developments in Iron-Aluminum Alloys. J. Mater. Res. 6: 1779-1805.

Natesan, K., and Tottorelli, P. F., 1997. High-Temperature Corrosion and Applications of Nickel and Iron Aluminides in Coal-Conversion Power Systems. International Symposium on Nickel and Iron Aluminides: Processing, Properties, and Applications, ASM Intern., Materials Park: 265-280.

Nieminen, M., Kangasmaa, K., Kurkela, E., and Ståhlberg, P., 1996. Durability of Metal Filters in Low Sulphur Gasification Gas Conditions. High Temperature Gas Cleaning, Universität Karlsruhe, Karlsruhe, Germany: 120-31.

Oakey, J. E., et al., 1997. Grimethorpe Filter Element Performances -- The Final Analysis. Mater. High Temp. 14: 301-11.

Pint, B. A., 2000. Oak Ridge National Laboratory, Oak Ridge, ' $\Gamma$, unpublished results.

Quadakkers, W. J., and Bongartz, K., 1994. Oxidation Lifetimes. Werkst. Korros. 45: 232-38.

Quick, N. R., and Weber, L. D., 1995. Accelerated-Life Testing of Sintered Filters for High-Temperature Corrosive Environments. Proc. Second International Conf. on Heat Resistant Materials, ASM Intern., Materials Park, OH: 663-71.

Saunders, S.R.J., et al., 1997a. Behavior of Fecralloy and Iron Aluminide Ailoys in Coal Gasification Atmospheres Containing HCl. Mater. Sci. Forum 251-254: 583-89. 
Saunders, S.R.J., Gohil, D. D., and Osgerby, S., 1997b. The Combined Effects of Downtime Corrosion and Sulphidation on the Degradation of Commercial Alloys. Mater. High Temp. 14: 167-73.

Tortorelli, P. F., and DeVan, J. H., 1996. Oxidation and Other Corrosion Phenomena at Intermediate Temperature. Oxidation and Corrosion of Intermetallic Alloys, Purdue University, West Lafayette, IN: 267-331.

Tortorelli, P. F., Lara-Curzio, E., McKamey, C. G., Pint, B. A., Wright, I. G., and Judkins, R. R., 1998. Evaluation of Iron Aluminides for Hot Gas Filter Applications. Proc. Advanced Coal-Based Power and Environmental Systems, U. S. Department of Energy: paper PB7.

Tortorelli, P. F., McKamey, C. G., Lara-Curzio, E., and Judkins, R. R., 1999. Iron-Aluminide Filters for Hot-Gas Cleanup. Proc. International Gas Turbine and Aeroengine Congress \& Exhibition, ASME Intern., New York: paper 99-GT-268. 


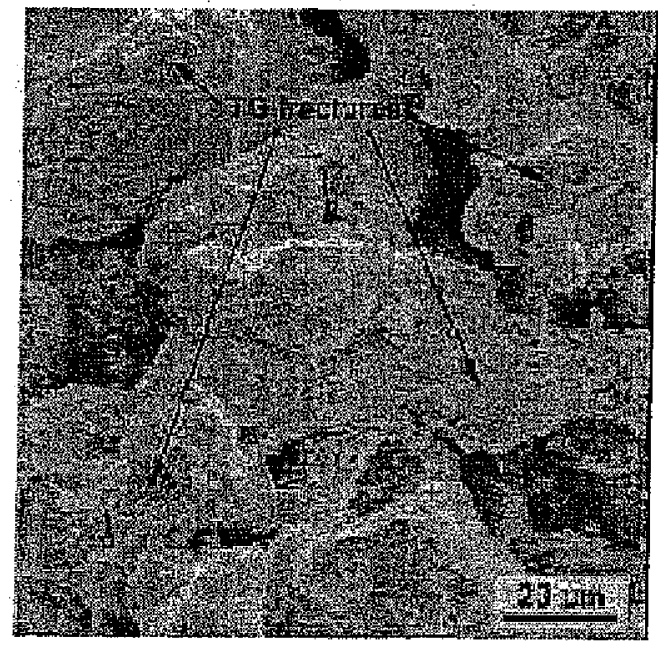

Fig. 1. SEM micrograph of as-fabricated FAS-Zr filter material (IA-187) showing transg ranular failure through fully sintered tnaterial and oxide particles on powder surfaces.

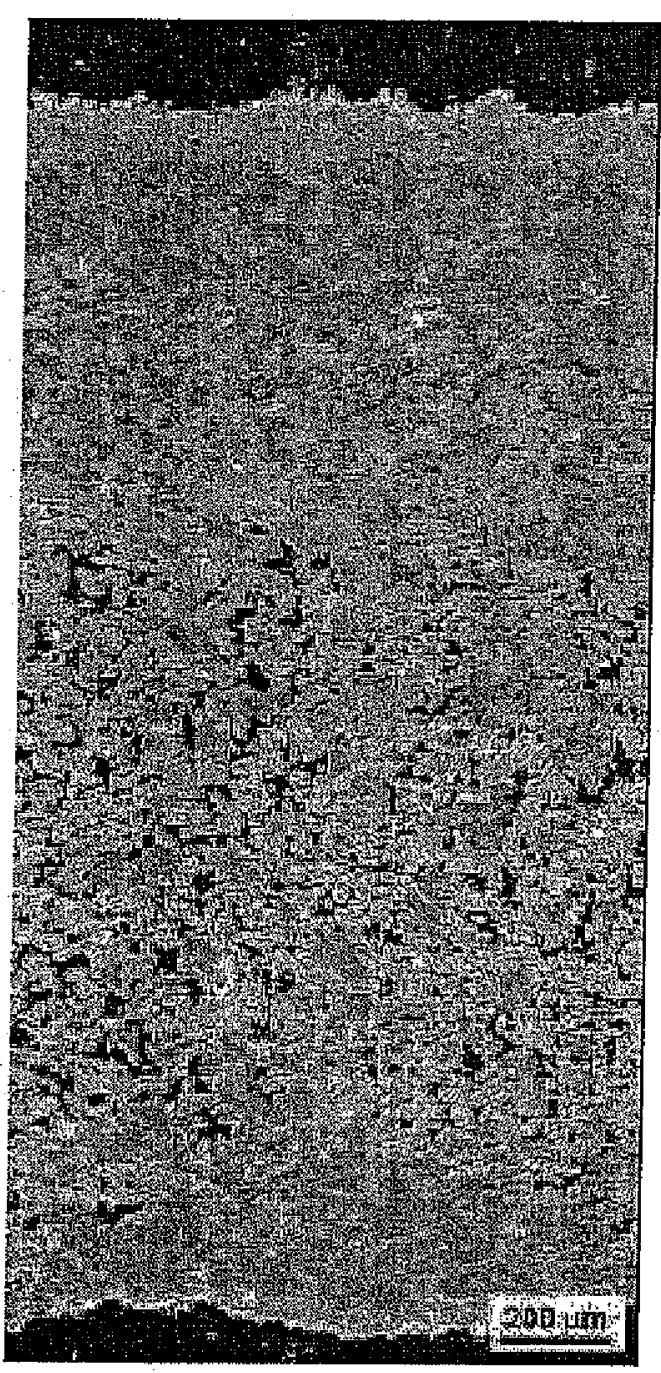

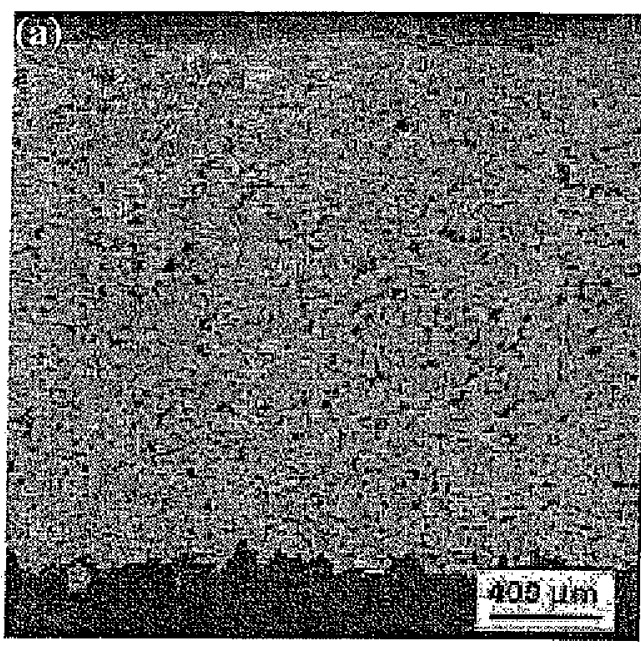

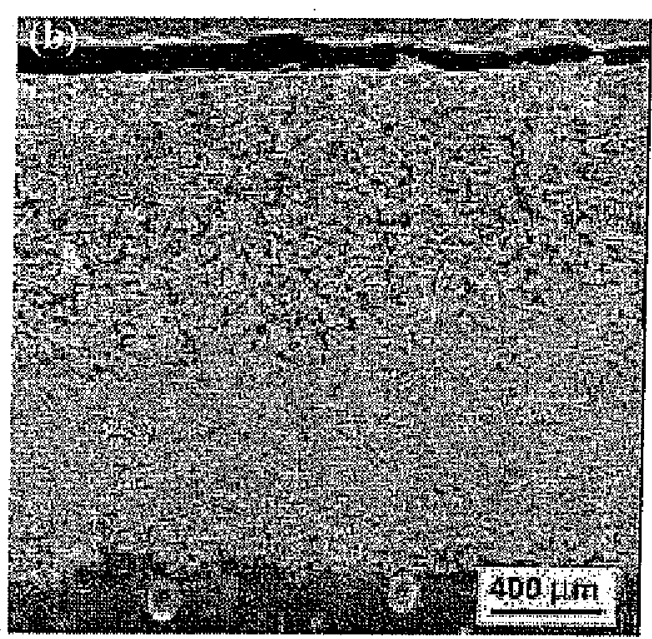

Fig. 2. Microstructures of two different samples of filter DC-20 exposed $1565 \mathrm{~h}$ in the Wabash River Energy Ltd plant; (a) showing normal porosity and (b) showing low inner surface porosity. Outer sutface (gas inlet side) of filter is at top, inner surface (gas ou tlet) at bottom.

Fig. 3. Microstructure of filter DC- 88 exposed for $2185 \mathrm{~h}$ in the Wabash River plant. 


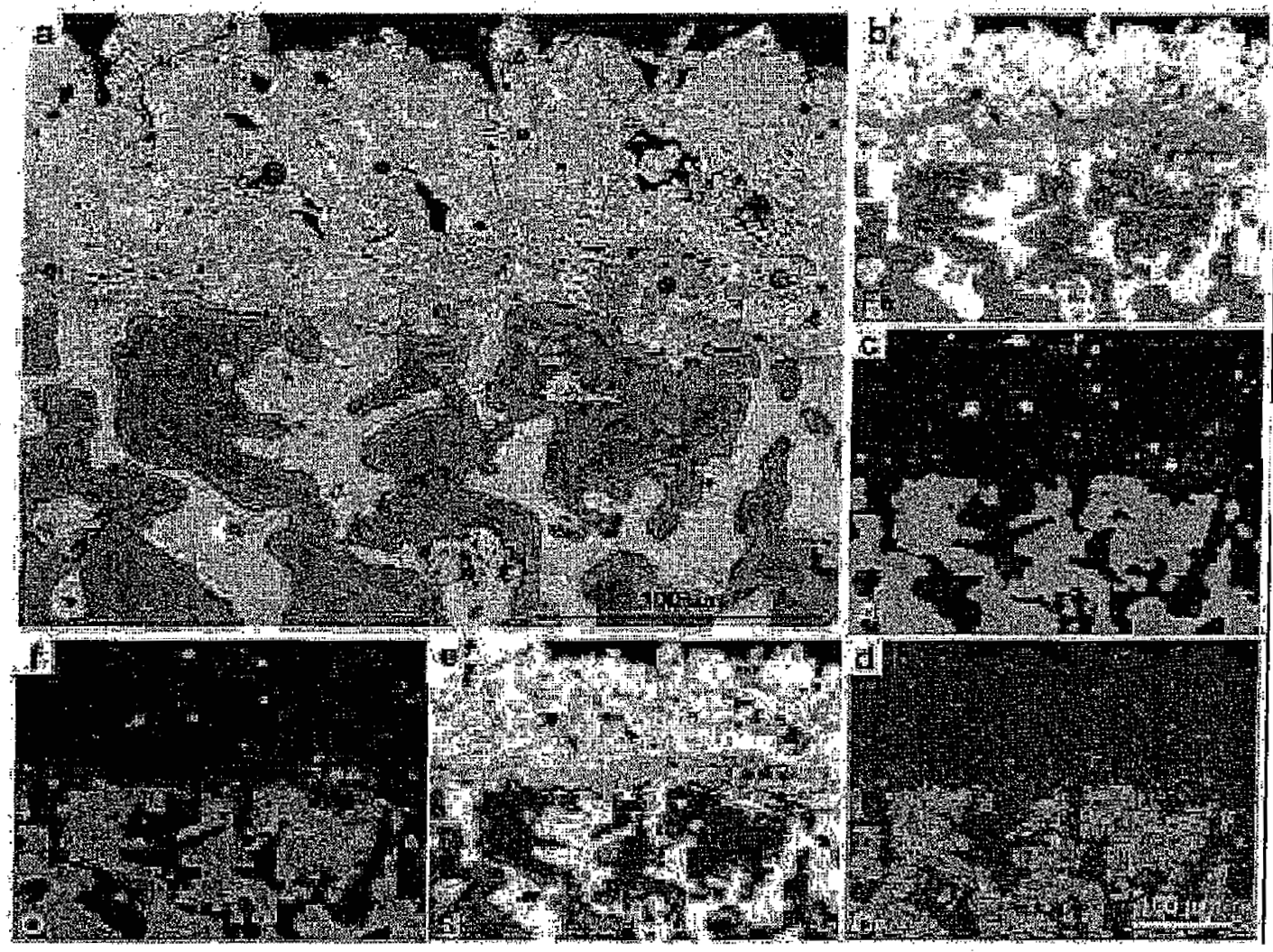

Fig. 4. Backscattered electron image (a) and $\mathrm{x}$-ray mapping for (b) $\mathrm{Fe}$, (c) $\mathrm{Al}$, (d) $\mathrm{Cr}$, (e) $\mathrm{S}$, and (f) $\mathrm{O}$ in the outer region of filter DC-88.
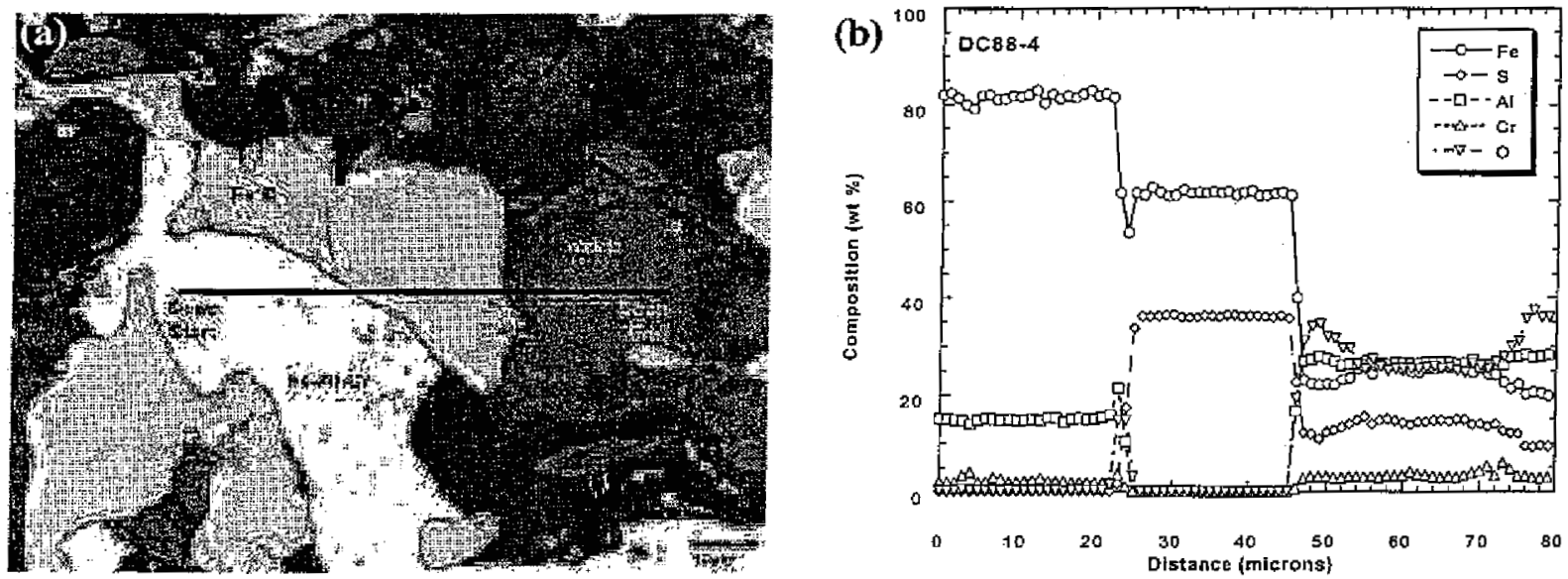

Fig. 5. Backscattered electron micrograph (a) and $\mathrm{x}$-ray scan for $\mathrm{Fe}, \mathrm{S}, \mathrm{Al}, \mathrm{Cr}$, and $\mathrm{O}$ (b) across the three different phases obscrved in filter DC-88 exposed for $2185 \mathrm{~h}$ in the Wabash River plant. 

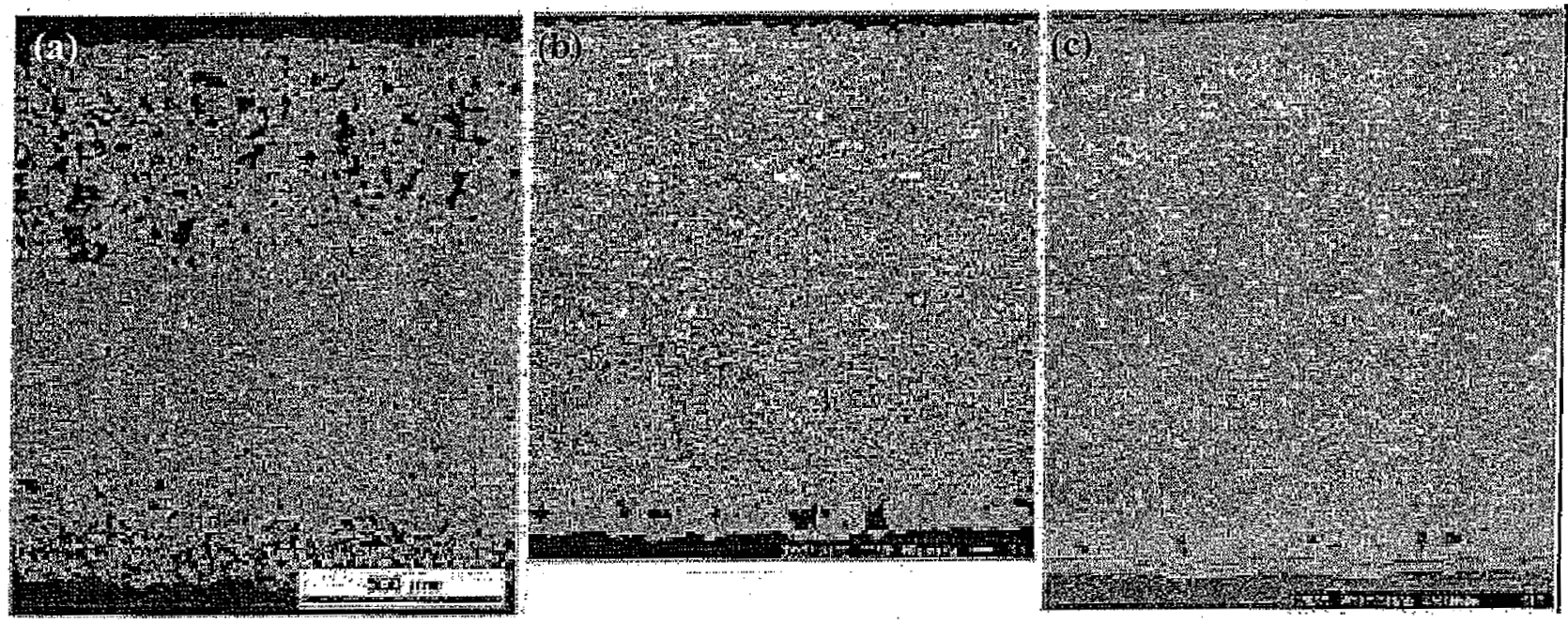

Fig. 6. Opticai micrographs showing the microstructu Ies of as-fabricated Fe-Al filters (a) IA-188 after $1628 \mathrm{~h}$, (b) IA187 after $2237 \mathrm{~b}$, and (c) IA-187 after $3865 \mathrm{~h}$ of exposure on the clean-gas side of the Wabash River Plant. Magnifications of (b) and (c) are the same as (a).
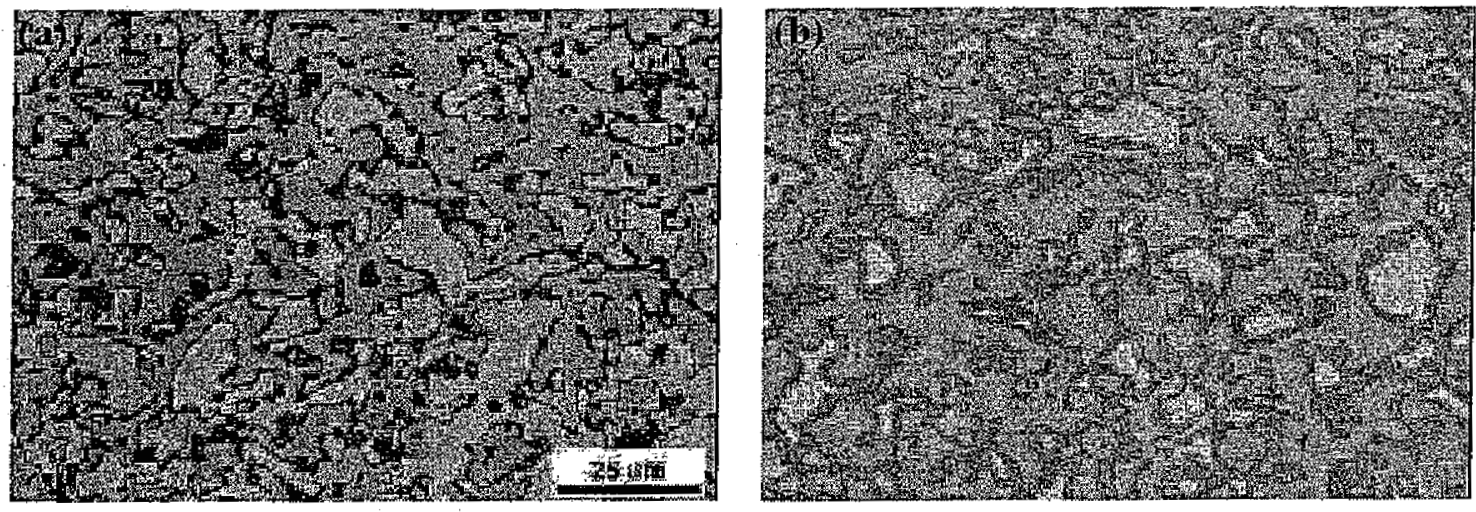

Fig. 7. High magnification optical micrographs showing the microstructures of as-fabricated Fe-Al filters (a) IA-188 after $1628 \mathrm{~h}$ and (b) LA-187 after $3865 \mathrm{~h}$ of exposure on the clean-gas side of the Wabash River Plant. Magnification of (b) is the same as (a).

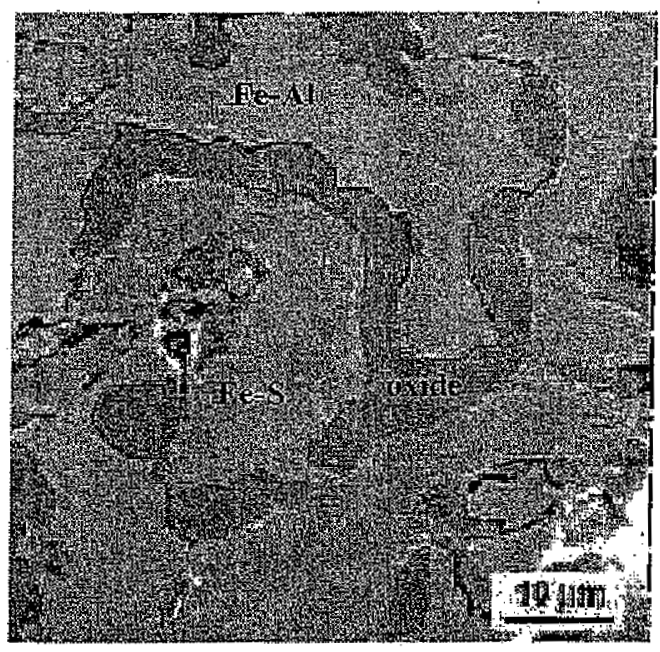

Fig. 8. High magnification optical micrograph showing formation of Fe-S and Al-O phases in as-fabricated Fe-AI filter lA188 exposed for $1628 \mathrm{~h}$ in the Wabash River Plant. White particles in the Fe-S phase are arsenic. 

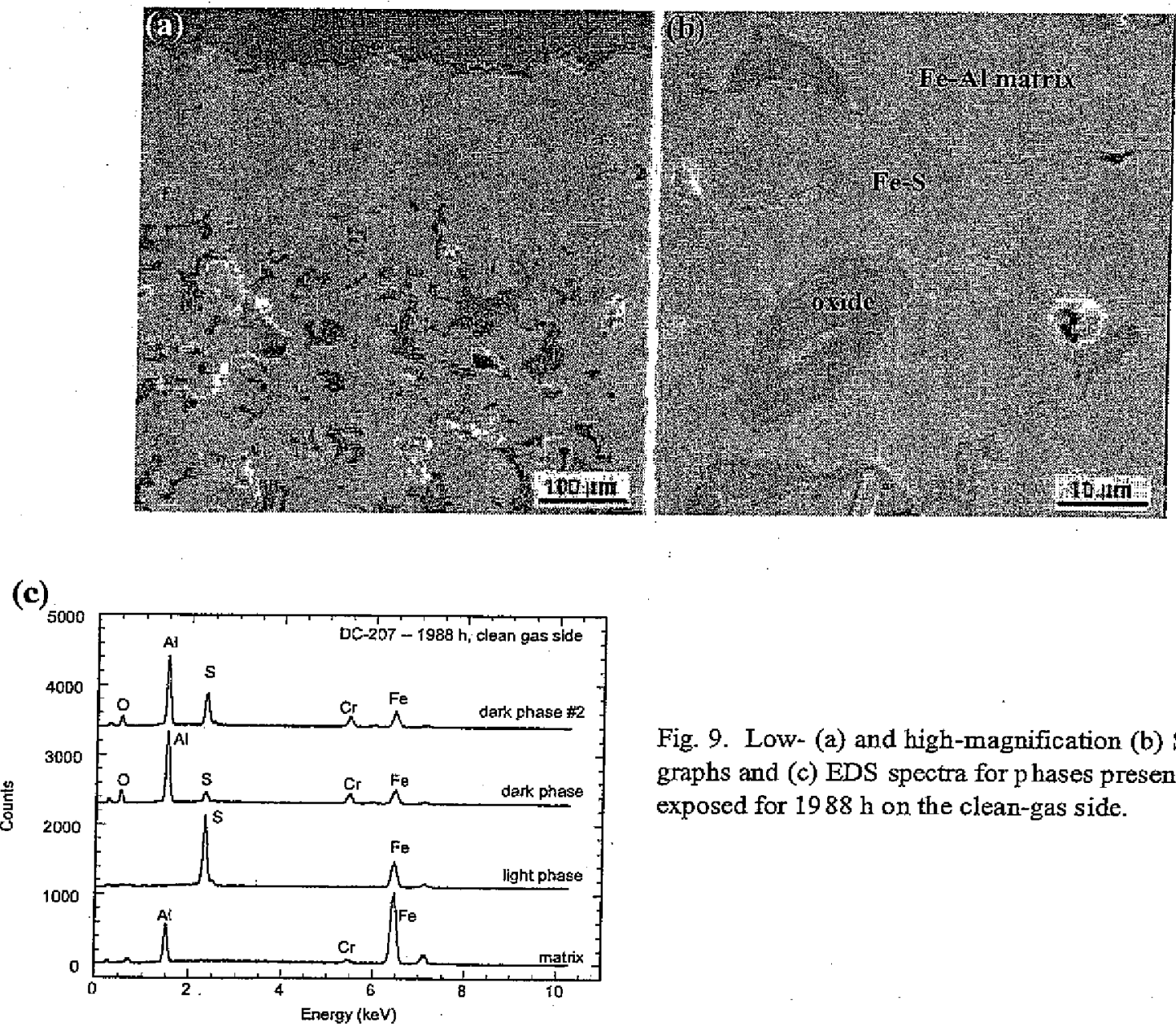

Fig. 9. Low- (a) and high-magnification (b) SEM micrographs and (c) EDS spectra for phases present in DC-207 exposed for $1988 \mathrm{~h}$ on the clean-gas side.

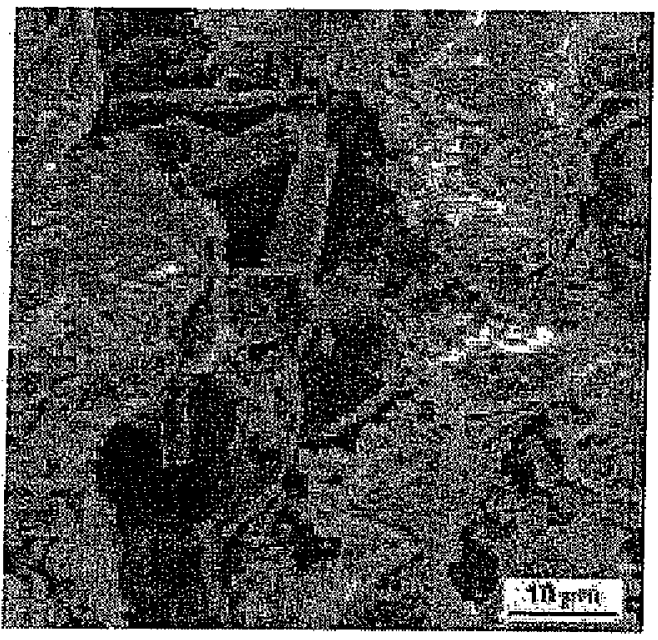

Fig. 10. Iron-sulfur particles forming inside pores in the interior of o-ring DC-207 exposed for $1988 \mathrm{~h}$ on the clean-gas side.

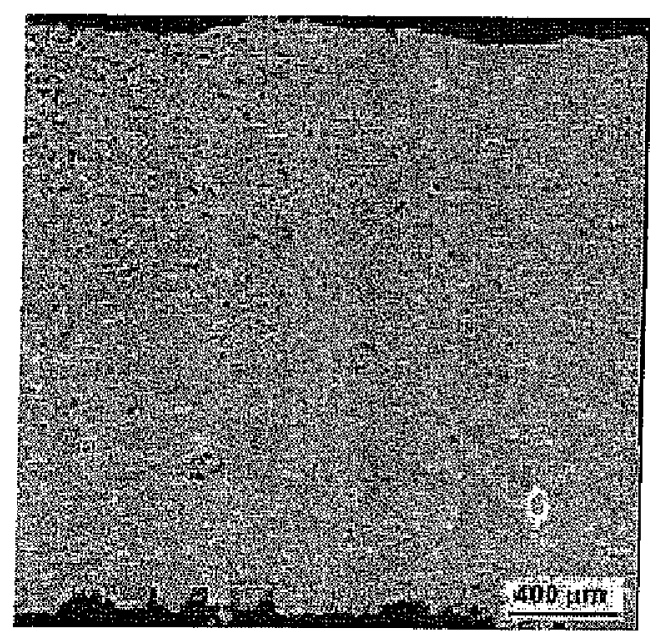

Fig. 11. SEM micrograph showing blocked pores in oring DC-209 (from gray filter) after exposure for 1988 h on the clean-gas side of the Wabash River Plant. 
Table I. Fe-AI Filter Material Exposed at the Wabash River Plant

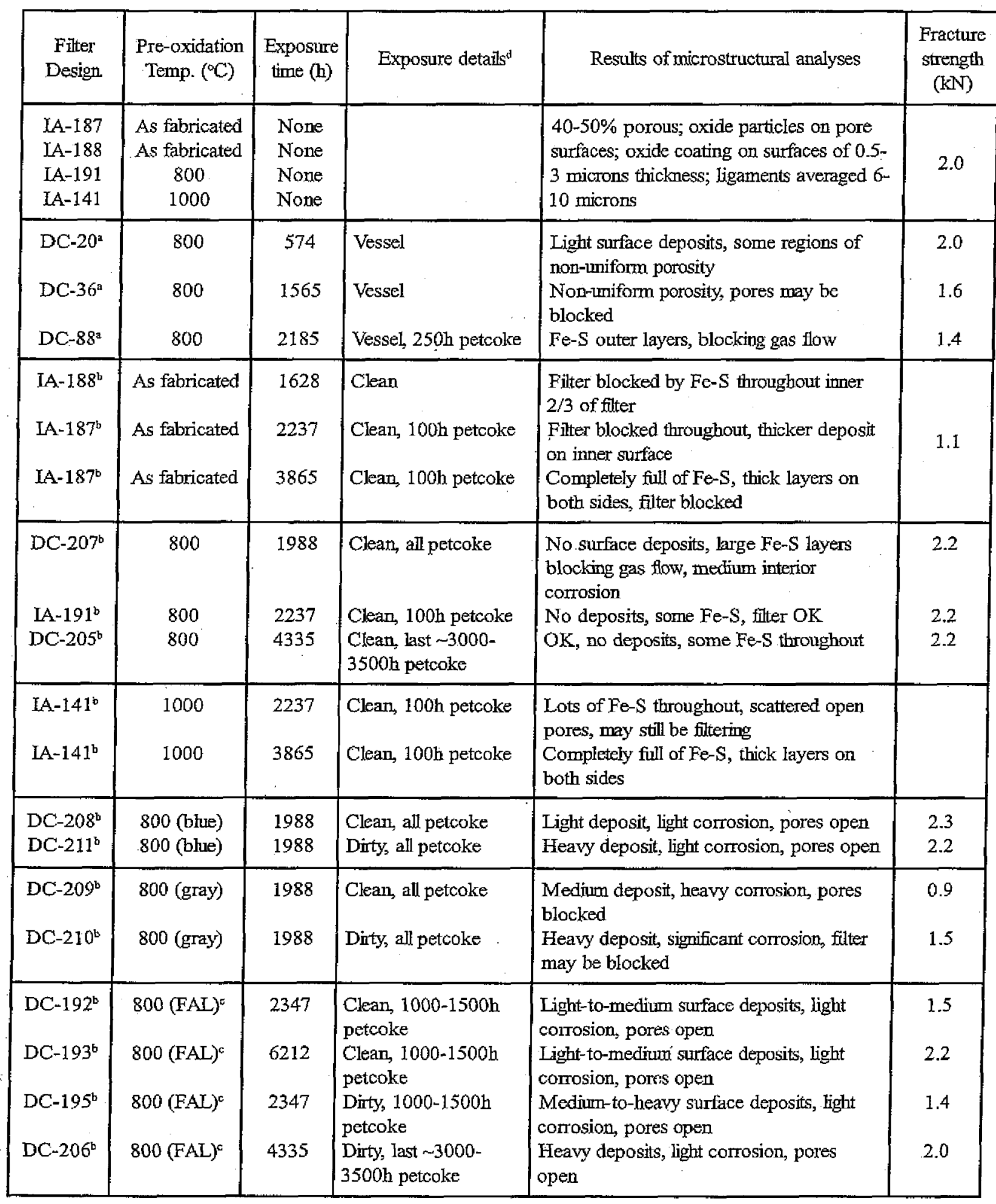

aSpecimen from filter element

Specimen was o-ring cut from filter element

FAL composition $=\mathrm{Fe}-28$ at. $\% \mathrm{Al}-5$ at. $\% \mathrm{Cr}$.

${ }^{\mathrm{d}}$ Clean = clean-gas side; dirty $=$ dirty-gas side. 